\title{
A New Kind of War: \\ Canadian Media Coverage of ISIS
}

by

Mergime Berisha

A thesis submitted to the Faculty of Graduate and Postdoctoral Affairs in partial fulfillment of the requirements for the degree of

\author{
Master of Journalism Studies
}

School of Journalism and Communication

Carleton University

Ottawa, Ontario

\author{
(C) 2017 \\ Mergime Berisha
}




\begin{abstract}
This thesis examines how Canadian journalists are adapting to changing environments in their coverage of terrorism since the rise of ISIS in 2014, the first ever social-media terrorist group. The crux of this analysis focuses on how ISIS has changed the Canadian media's normal journalistic routines and methods of reporting on terrorism and terrorists. Interviews were conducted with seven Canadian journalists to determine how the terrorism narrative has changed as a result of ISIS. In conclusion, although the nature of terrorism has not changed, the way that ISIS promulgates itself through social media proves to be a challenge for journalists.
\end{abstract}


Mom and Dad;

You are the reason for everything I do.

This one's for you. 


\section{Acknowledgements}

To my thesis supervisor, Susan Harada, thank you for your guidance and support. I am grateful to have had the opportunity to learn from you and work with you on this research project. I appreciate you and all that you have done to help me get here. I would also like to thank Chris Dornan who agreed to be my second reader and helped me choose my research topic.

To the seven reporters who I interviewed for this thesis, thank you for taking the time to speak with me about a very relevant topic. Your input and insight is invaluable and helped shape the direction of this thesis.

Roberta Bell and Mimi Golding, thank you for being the nudge to help me move

forward. You both read and re-read my work multiple times and I truly appreciate all your help and encouragement throughout this process.

To my family, especially my two sisters, your love and support mean everything to me. I am so lucky to have you in my life and appreciate all that you do for me. Thank you for always believing in me. 


\section{Table of Contents}

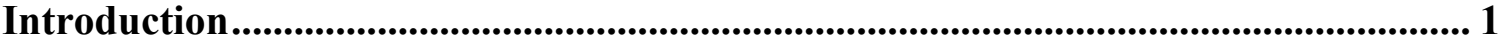

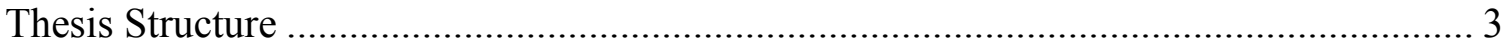

Methodology and Theoretical Framework................................................................. 5

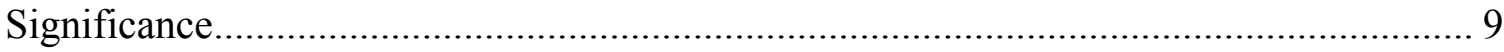

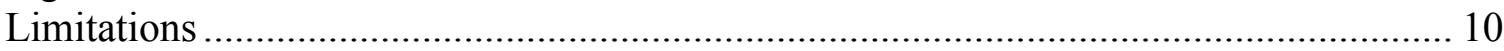

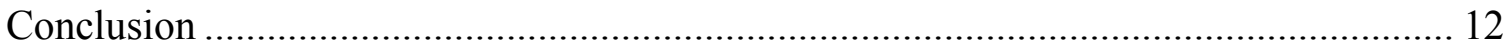

Chapter One: What is Terrorism? ....................................................................... 13

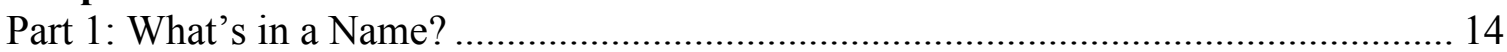

Why is Terrorism so Difficult to Define? .............................................................. 14

Can an Act of Terrorism Ever be Justified?........................................................... 16

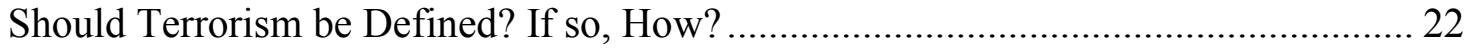

Academic Consensus on Terrorism: Schmid \& Jongman .......................................... 25

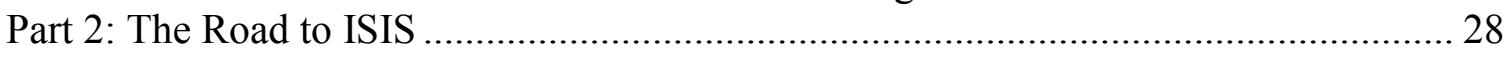

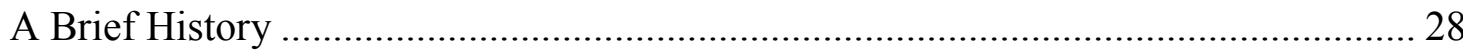

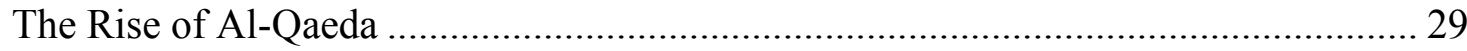

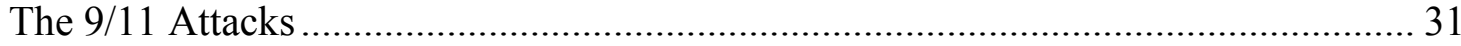

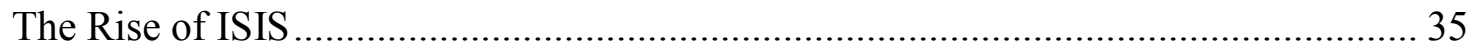

Differences, Similarities, and Present Significance .................................................. 38

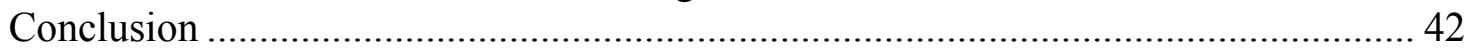

Chapter Two: Terrorism and the Media ..................................................................... 44

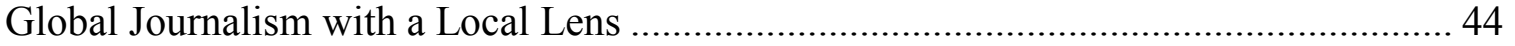

Media Coverage of Terrorism: From Al-Qaeda to ISIS ............................................ 47

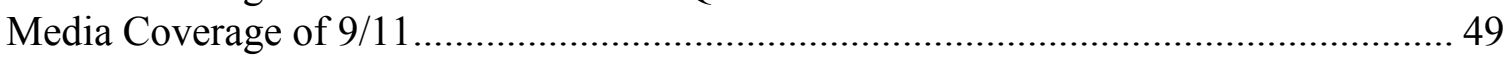

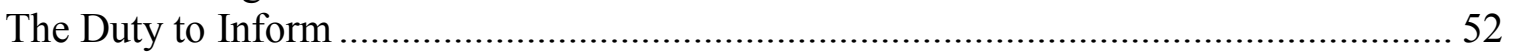

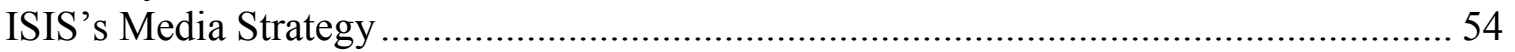

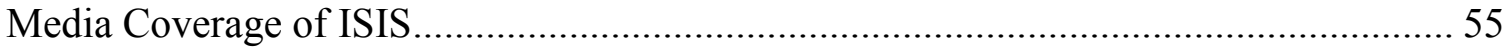

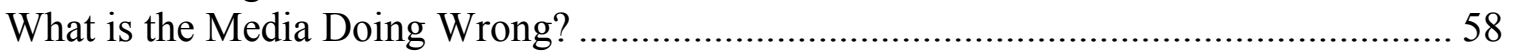

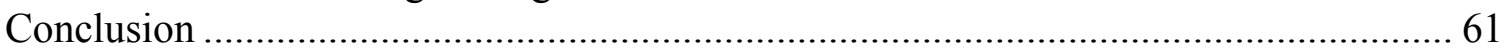

Chapter Three: News Media, Its Democratic Function, Principles that Guide It .... 64

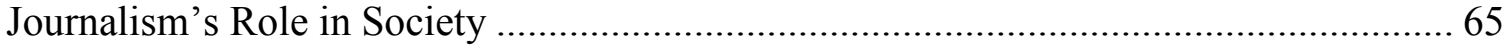

How Journalism Works: The Hierarchy of Influences Model ..................................... 70

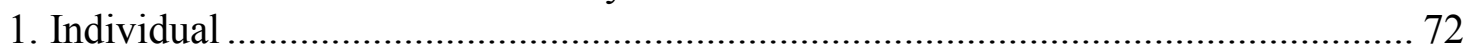

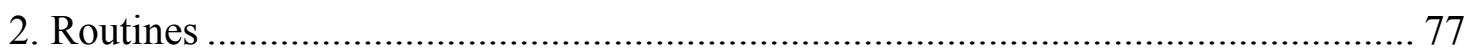

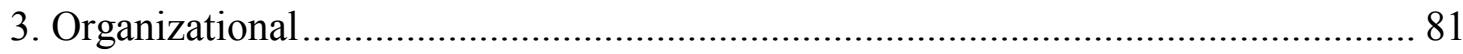

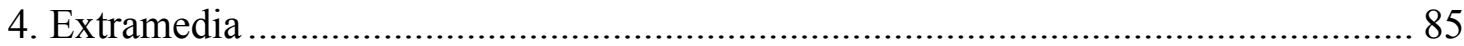

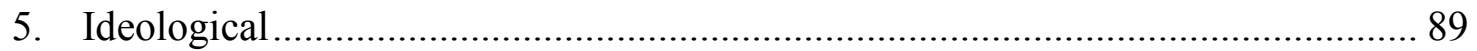

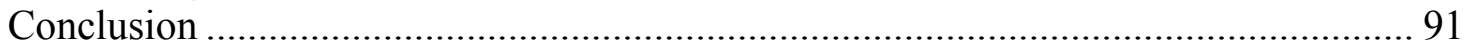

Chapter Four: Canadian Journalists Discuss Media Coverage of ISIS ................... 93

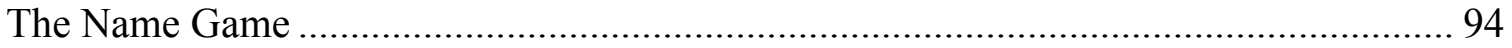

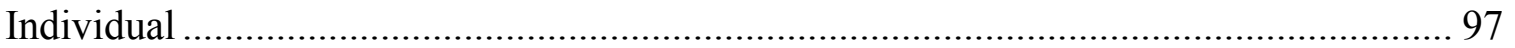

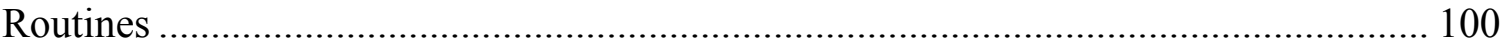

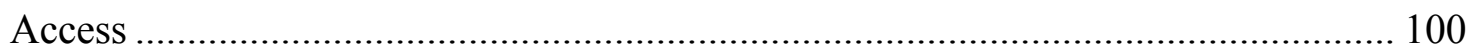

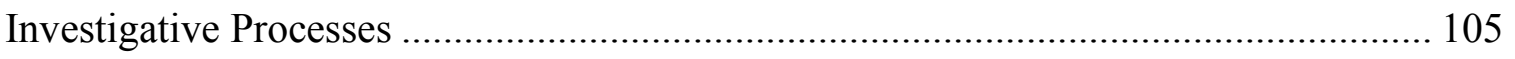




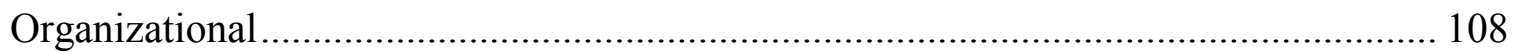

Resources Spent on Foreign Affairs: ............................................................... 109

Organizational Policies and Guiding Principles ……............................................. 110

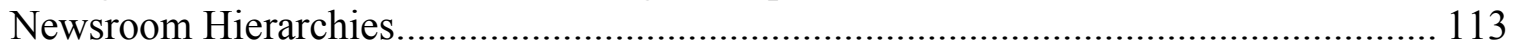

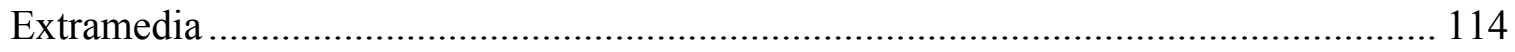

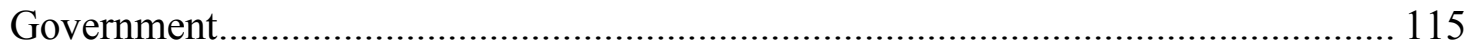

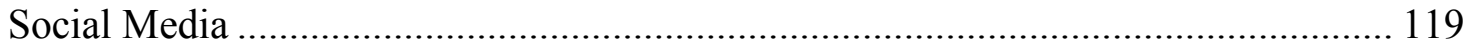

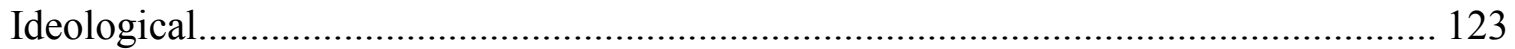

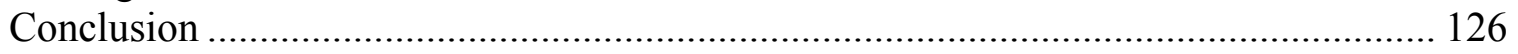

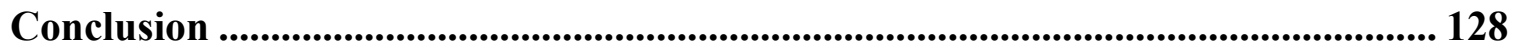

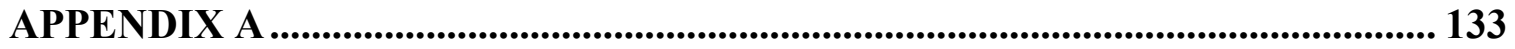

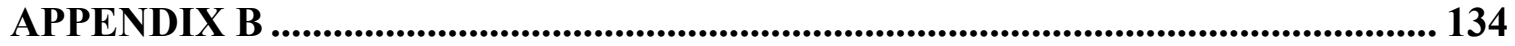

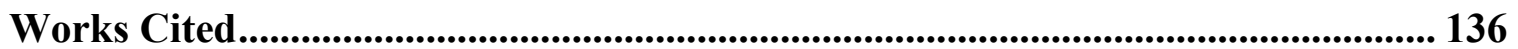




\section{List of Appendices}

Appendix A: Includes short biographies of the seven journalists interviewed

Appendix B: Includes the interview questions used 


\section{Introduction}

The media have historically played a significant role in conveying information to the public. One of the media's central roles within society is its gatekeeping function, its ability to "cull and craft countless bits of information into the limited number of messages that reach people each day" (Shoemaker and Vos 2016: 1). However, this gatekeeping notion has been impacted by technology and the rise of social media, which has created an information overload. The media has a powerful ability to define issues and conflicts by determining "which information is selected (and) what the content and nature of messages will be" (Ibid). The news media plays a vital role in society and helps shape and mould public perceptions. When analyzing conflicts using the journalism lens, it is important to acknowledge that the way a story is covered in the media affects how the public perceives it.

Since the 9/11 attacks in the U.S., which saw the fall of the Twin Towers, terrorism has been a constant topic in the news. This attack engendered the global War on Terrorism, the repercussions of which we are still seeing today. While the U.S.-led coalition managed to destroy the headquarters of Al-Qaeda, the terrorist group based in Afghanistan that perpetrated the attacks, the ideology, mainly of inciting fear and repression, established during this period in history lives on through other clandestine terrorist groups that are waging war against the U.S. and its allies.

Today ISIS is the new face of terrorism. Unlike other terrorist groups before it, ISIS has banked on its ability to self-brand and appeal to a wide array of people living all over the world. Its ability to use technology and social media has taken some of the defining power away from the media, becoming the main "conveyor" of its own truth. 
Furthermore, ISIS directly targets journalists. The group made this apparent when it publicized the beheading of American journalist James Foley on YouTube.

Foley had been missing since November 2012 before he was beheaded in August 2014 by a masked ISIS executioner with a British accent. This event created a widespread media spectacle that established ISIS as the new face of global terrorism. Extreme violence and brutality furthers ISIS's shock value. Its apparent glee in making it known to the world that it is responsible for the horrendous atrocities perpetrated by its members and others who sympathize with them is also alarming.

ISIS directly targets journalists, using Western journalists specifically to further its propaganda by publicizing their murders and expanding its international reach. Reporters Without Borders has called ISIS a "news exterminator," stating "a war without end has turned Syria into the world's deadliest country for journalists" (Reporters Without Borders 2016: 6). In 2016, 19 journalists were killed in Syria, and 21 were held hostage (Reporters Without Borders 2016: 6). Media blackouts in ISIS strongholds such as Mosul in Iraq are heavily enforced. ISIS "imposes a brutal news and information dictatorship in the regions (it) controls... and journalists are closely monitored and often hunted down, kidnapped and killed" (Reporters Without Borders 2014: 5). It has become increasingly dangerous for the news media to gather information about the group on the ground. ISIS strongholds in Iraq and Syria are virtually impossible to access and the Canadian government and military is keeping its operations in these regions confidential, as are most states involved in the fight. This poses a definite problem for the news media tasked with explaining and contextualizing the conflict to their audiences. Without access, journalists are more dependent on packages of information and images that ISIS 
releases on its own and information from official sources. Ultimately, both sources of information present a distinct political agenda or bias. However, the media depends on these sources because it does not have any other option. To create a balanced account of the situation, attempts are made to verify information from these official sources and find new and unique sources. When this is not possible, journalists are left with no other choice but to continue pushing forward with the resources that they have. With covering ISIS, journalists face another challenge; they are being directly targeted by the group.

This thesis examines how journalists are adapting to changing environments in their coverage of terrorism since the rise of ISIS in 2014, the first ever social-media terrorist group. The crux of this analysis focuses on how ISIS has changed the Canadian media's normal journalistic routines and methods of reporting on terrorism and terrorists.

\section{Thesis Structure}

Chapter One is the first part of an extensive literature review that focuses on how ISIS fits in the terrorism narrative that has developed since 9/11. It provides a brief exploration of how academic literature explores the definitional nature of the fraught terms terrorism and terrorist. Ultimately it concludes that although terrorism is difficult to define, terrorist acts have similar elements and the aims of these attacks are clear. The second part of this chapter provides a brief historical background of the rise of ISIS, tracing its roots to Al-Qaeda. It describes the differences and similarities between the two groups and how ISIS has toppled Al-Qaeda as the face of the War on Terrorism. AlQaeda's terrorism was different from ISIS's in one major way: although Al-Qaeda was media savvy, it was not in control of its branding. ISIS, on the other hand, markets its 
own brand and has developed independence unseen by any other terrorist group; it does not rely on the media for publicity, it promotes itself.

Chapter Two discusses the relationship between terrorism and the media to determine how the media has responded to ISIS. Focusing the discussion on the aftermath of 9/11, and later the rise of ISIS in Iraq and Syria, this chapter provides an overview of how terrorism has been covered in mainstream media and whether ISIS has disrupted the normal responses to terrorism by the media. Academic literature is reviewed to explore prevalent criticisms of the media's coverage of terrorism, including the influence of elements such as patriotism, nationalism, and the extensive focus on official sources.

This chapter emphasizes that media coverage of terrorism has changed slightly since 9/11. ISIS fits the terrorism narrative developed by Al-Qaeda, and its interaction with the media is a natural evolution of Al-Qaeda's media strategy. However, interdependency between the media and Al-Qaeda existed, whereas with ISIS it does not. Furthermore, the political and social environment in which ISIS has emerged makes coverage more challenging.

Chapter Three introduces a theoretical framework, the Hierarchy of Influences model established by Pam Shoemaker and Stephen D. Reese, to deconstruct how journalists cover terrorism and the influences that help define the terrorism narrative as it relates to ISIS. It analyzes how the media criticism discussed in chapter two can be explained by looking at how journalism works. Furthermore it helps distinguish the various influences that impact the manner in which journalists cover ISIS today. By focusing on the field of journalism itself, multiple influences emerge that can impact the way conflicts are covered and explained in the media. Exploring these influences 
provides us with an understanding of how journalists go about covering ISIS and the various factors involved. It emphasizes that the perceived bias that seeps into coverage is usually unconscious.

Chapter Four relies on interviews conducted with seven journalists to further analyze how journalism works and the manner in which the terrorism story is told from the perspective of the people doing the telling.

Finally, a discussion on the biggest challenges the media faces when covering ISIS will ensue. The question of whether ISIS and its actions are new forms of terror will be explored. It will also provide a brief synopsis of how journalists are responding to the first social media terrorist group. Moreover, suggestions for further study will be provided in order to build on this thesis and explore how the news media help to define terrorism and the challenges they face to do so responsibly.

\section{Methodology and Theoretical Framework}

In exploring how Canadian news media reports on ISIS and terrorism more broadly and how the terrorism story has changed in the last 15 years, three methodologies were used to provide analysis. Existing literature provided the foundational basis for defining and providing an understanding about terrorism and terrorists. Defining the terms with the caveat that they are fraught helped explore how terrorist actions of AlQaeda and ISIS in particular fit into the "terrorism" mould that has been established throughout the decades. The evolution of ISIS from its Al-Qaeda roots is also explored through a brief historical analysis based on existing literature. Together, this helps us understand how ISIS emerged, how it fits into the pre-determined terrorism narrative, and in what ways it is unique. 
Existing literature discussing the relationship between terrorism and the media, and journalistic practices was also examined to analyze common media criticisms. Moreover, this literature was used to determine the multiple influences that help define the terrorism story as it relates to ISIS.

Furthermore, I used empirical research to provide a first-hand account of how the terrorism story gets covered by relying on interview subjects with many years of honed experience reporting on foreign affairs. I interviewed seven journalists working for Canadian news organizations who provided candid thoughts on their experiences reporting on ISIS, terrorism, and the ever-changing technological environment that has impacted the way they tell stories. There is a large body of literature on the symbiotic relationship between media and terrorism. I will add to this literature by focusing on Canadian media coverage of ISIS. The U.S. drives media coverage on the War on Terror. Canada is its closest ally and offers a different perspective. The way ISIS is covered in Canada is reflective of more of a western world perspective. It has also been noted that Canadian journalism is less "dramatic" and sensationalistic than U.S. media coverage (Novatt 2014). The Canadian government is a member of the Global Coalition against ISIS. Furthermore, its geographic proximity to the United States would lead some to assume that terrorism is covered in a similar fashion in Canada. However, Canadian journalists have used caution when reporting on terrorism. For example, Canadian media received attention worldwide for its coverage of the Ottawa Shooting "in which an armed attacker shot and killed a Canadian Forces member at the National War Memorial" (CBC News 2014, Jonsson and English 2014, Alexander 2014, West 2014). The U.S. chose to cover the attacks using a more sensationalistic approach. This event showed that there are 
differences in reporting of terrorism between the U.S. and Canada and despite the U.S. framing the terrorism narrative worldwide, showing how Canadian media covers ISIS helps deflect the nationalistic, patriot fervour that U.S. coverage of terrorism is known to be criticised for (Waisbord 2011). I chose journalists with years of experience covering foreign affairs and conflict zones. This allowed for comprehensive, authoritative comments on how the terrorism story has evolved and the new challenges that have emerged as a result of the rise of ISIS. Some reporters were chosen specifically for their vast knowledge of foreign affairs reporting and experience covering conflicts throughout the decades. Others were chosen because of their expertise in reporting on domestic terror attacks in the West. Along with the six journalists interviewed who had firsthand experience reporting on terrorism, I also interviewed one editorial manager to give an organizational perspective on ethical dilemmas that have emerged in connection with social media terrorists. All journalists interviewed have experience writing on foreign affairs and have touched the ISIS story.

The journalists work for a variety of media outlets including radio, television, and national newspapers (See Appendix A). I reached out to 34 journalists working for CBC News, CTV News, Postmedia News, The Toronto Star, The Globe and Mail, and Maclean's. I received positive responses from four journalists working for the CBC, two working for The Toronto Star, and one journalist working for The Globe and Mail. Semistructured Interviews were conducted with these journalists. The interview subjects were asked a number of questions concerning their day-to-day routines in the newsroom or in the field covering terrorism (See Appendix B). Articles written by journalists interviewed were also examined, however, this was not a formal analysis. The crux of this thesis is 
developed from themes that arose from the interviews conducted and how they correlate with already existing research. A number of commonalities emerged from the answers that helped explain how journalists perceive the challenges posed by ISIS and how they push forward with their coverage despite these challenges. It is important to note that the empirical research conducted for this project is subjective, and thus the conclusions are broad. However, analyzing information from interviews through the lens of a theoretical framework rooted in existing literature helps to substantiate it.

My research uses two main frameworks to contextualize terrorism and understand how journalism approaches the subject. First, Alex P. Schmid and Albert Jongman's word categories to define terrorism are used to develop an understanding of what the term signifies and who is painted as a terrorist or involved in acts of terrorism. I use Schmid and Jongman's definition to clearly categorize both Al-Qaeda and ISIS as terrorist groups. Their definition is seminal as it provides the first real effort to come up with a working academic definition of terrorism by analyzing more than 109 definitions developed by other scholars. The study identified a list of common defining attributes of terrorism. Although the actual definition developed is rarely used on its own to define terrorism, the list of common elements established through their research provides a useful blueprint to detect the qualities of an act of terrorism.

I use Pamela Shoemaker and Stephen D. Reese's, Hierarchy of Influences model to organize and categorize the various influences that affect the way the media covers terrorism. A number of themes emerged from the interviews once placed against the Hierarchy of Influences model established by Shoemaker and Reese. Organizing my research in this way explains why and how potential biases seep into media coverage of 
contentious issues or conflicts such as terrorism. It helps answer why and how the various criticisms of media coverage of terrorism emerged post-9/11 and why they continue to emerge with the telling of the ISIS story.

\section{Significance}

ISIS has made headlines all over the world the last three years. It has created and intensified an environment of fear globally. The terrorist group is relatively new but developed during a time of technological transformation and change. This change has allowed the terrorist group more control than ever before to define its message and brand. The media traditionally held the role of agenda setter and therefore defined conflicts and issues. However, with the rise of social media, the power the media once had to solely define problems and set the agenda for public discussion is waning (Bro \& Wallberg 2014: 446).

While scholars have been discussing the implications of social media on journalism, little literature exists on how ISIS, using social media, has been able to circumvent traditional means of getting its message across and how this has impacted the way journalists talk about terrorism. The dangers associated with entering ISIS strongholds have limited journalists' access to first-hand information. The only journalistic documentation of ISIS's inner workings was by Medyan Dairieh, a VICE News reporter, who spent three weeks embedded with the group (Dairieh 2014). However, this type of unprecedented access is the exception. After the murders of journalists James Foley and Steven Sotloff, it was clear that getting this close to the group would come at a price. ISIS's direct targeting of journalist is a result of its determination 
to be the messenger of its own story. As such, journalists have to rely more and more on information made available by secondary sources.

This thesis explores how ISIS has affected the way journalists cover stories about terrorism. Media coverage of terrorism has received a lot of criticism. Substantial literature exists on media bias, specifically focusing on terrorism since 9/11. However, focusing on how journalism works results in a better understanding of how media biases emerge. This thesis takes into account criticism of the media in existing literature and juxtaposes it with literature on journalistic practices and interviews with working journalists who have foreign affairs/national security reporting experience. By understanding news gathering processes and the decisions journalists make about coverage on a daily basis, it helps put into perspective some of the criticism about media coverage.

\section{Limitations}

My research focuses on a relatively new terrorist group that gained worldwide attention after publishing the beheading of American journalist James Foley in 2014. The war in Syria and Iraq and the battle against ISIS is still ongoing, and because it is a new conflict, there has been limited research conducted on ISIS's relationship to the news media. Moreover, because the terrorism narrative is defined through multiple lenses including political, legal and social, using journalism to deconstruct ISIS's coverage leaves an array of research out. Although this thesis touches upon political and legal influences on the definitional nature of terrorism, it is beyond the scope of my research to provide thorough analysis of these concepts or conceptualize how they directly influence media perception of terrorism. Furthermore, it is important to remember that this thesis 
considers the viewpoints of working journalists and shares their experiences covering terrorism to identify themes that paint a clearer picture of how the terrorism story gets told. These opinions, though founded in experience, are subjective. However, using the Hierarchy of Influences framework to organize my research and develop themes rooted in existing literature allows me to contextualize the interviews to find trends.

As noted above, this thesis was not able to include voices from all Canadian organizations. Furthermore, the journalists interviewed spoke under the condition that they were speaking for themselves and not the news organization they worked for. Seeing that the terrorism story as it pertains to ISIS is a global phenomenon, narrowing my interview subjects to journalists working for Canadian media is a limitation as it does not include journalistic voices reporting on ISIS and terrorism elsewhere. Furthermore, the journalists interviewed all asserted that the views and opinions they are sharing about their profession are their own and do not reflect the media organization they are working for. This is another limitation as it disallows us to come conclusively link conclusions and themes from this study to the structural or organizational aspect of journalism. In spite of the limitations listed, this research is still useful because it explores how journalists are adapting their work as a result of technological advancements and how they are responding to the first-ever social media terrorist. Canada is a part of the Global Coalition Against ISIS and is also geographically located beside the U.S., the country that signalled the start of the War on Terror. This puts Canadian journalists in an interesting position. American media seeps into the Canadian media landscape, however differences in coverage exist. Interviewing Canadian journalists will provide a unique perspective on 
the terrorism story but is reflective of overall Western coverage due to its proximity and involvement in the war against ISIS.

\section{Conclusion}

With the rise of ISIS, and the hyper social media culture, it appears that news organizations are struggling with how to cover terrorism. It becomes clear from the interviews that ISIS has brought forth a slew of questions for journalists to consider when reporting on terrorism perpetrated by the group. However, as was seen in the aftermath of 9/11, media coverage shapes the way people perceive conflicts (Happer and Philo 2013: 321). When it comes to national security issues, governments depend on the media to relay its message and garner public support to advance its policies (Waisbord 2011: 273). Although the conflict in Syria and Iraq is not over and ISIS continues to be a presence, it is important to analyze how Canadian media is making sense of the issue. Tracking how Canadian media are covering terrorism as a result of ISIS will allow for a better understanding of how the ISIS story might eventually unfold and the direction the story will take. Furthermore, media coverage of important national security events impacts how policy decisions are made. Case in point: the invasion of Afghanistan and Iraq would not have been possible without support from the American public, which was largely garnered through media reporting of the 9/11 attacks (Waisbord 2011: 273). This thesis aims to explore how journalists make decisions about coverage that could affect the way individuals within society feel about their safety and security. 


\section{Chapter One}

\section{What is Terrorism?}

When former U.S. president George W. Bush declared the start of a global war on terror in response to the September 11, 2001 terrorist attacks, he gave the rest of the world an ultimatum: "every nation, in every region, now has a decision to make. Either you are with us, or you are with the terrorists" (Bush 2001: Congress Address). The emotionally charged address was captured in mainstream media coverage throughout the world, marking a pivotal moment in history and a turn for the worse for global national security. Fifteen years later, terrorism continues to be an important issue that has captured the minds of millions globally.

However, despite there being clear dictionary definitions of terrorism, there is no clear agreement on how to label actual events or acts or perpetrators of terrorist acts. Attempts to provide a universal definition of the terms terrorism or terrorist are often met with pushback. The famous saying, “one person's terrorist is another person's freedom fighter" encapsulates the difficulty of determining the true meaning of the word. This chapter examines the concept of terrorism and attempts to provide a useable definition of the term by providing a small, contained history of previously formulated definitions. The goal of this chapter is to examine the various definitions of terrorism and the events that are responsible for shaping our perceptions of the term today.

Part two of this chapter will give a brief historical background on the evolution of terrorism by focusing on terrorist organizations that have emerged in the last fifteen years starting with Al-Qaeda and ending with ISIS. 


\section{Part 1: What's in a Name?}

There have been many incidents categorized as terrorism in the last decade but the exact definitions of the terms terror, terrorism, and terrorists remain vague. A number of academics have attempted to provide a useable definition that truly encapsulated the concept of terrorism but have fallen short. As the discussion, which follows shows, terrorism is a convoluted topic and individuals labelled terrorists are harder to decode or label with any finesse because of the implications of labelling people or events.

It is worth noting that the discussion on what terrorism is and who can be defined, as a terrorist is significant and meaningful. The exercise of examination is to not simply come to a narrow definition of the term, but to understand a complex concept that is as "old as civilization itself" as (Law 2009: 1). Terrorism continues to be a central issue that has become more challenging to understand as the world becomes more interconnected.

\section{Why is Terrorism so Difficult to Define?}

Hundreds of definitions for terrorism exist, from academic, legal, political, media-inspired, to dictionary definitions of the term. There is an overwhelming amount of analysis and interpretation on what terrorism is, however, arriving to a universally agreed upon definition is difficult. The reason for this is that terrorism has various component parts that are complex and difficult to navigate. When attempting to define terrorism it is important to ask the following questions:

a) What is the act or action of violence committed?

b) Who is responsible for the act?

c) Can state-perpetuated violence be considered terrorism?

d) What is the intention when committing the act?

e) What is the purpose of the act? 
Depending on the stance taken when answering these questions, various definitions emerge that touch on these component parts but may not paint a perfect picture. Furthermore, various political implications emerge when these definitions become a label.

It is widely agreed upon by academics, politicians, and legal professionals that a consensus definition of terrorism is unlikely to be reached. Despite terrorism being a resounding problem for the international community as a whole, the United Nations has yet to formulate a universally agreed upon definition of terrorism. The United Nations Convention on International Terrorism, first drafted in 1996, continues to be deadlocked today. The Convention seeks to establish a legal norm by which those who participate in international terrorism can be prosecuted or extradited. More specifically, the Convention seeks to come up with a clear definition of terrorism that can be implemented in each nation's Criminal Law. The ratification of the Convention is at a standstill due to opposition from three major parties: the United States, the Organization of Islamic Countries (OIC), and the Latin American countries. Although all states agree that criminalizing international terrorism must be achieved, negotiations are deadlocked because of disagreements with defining terrorism. Some states do not want to implicate marginalized groups who are fighting for freedom from occupation and they do not want to implicate themselves when carrying out acts of violence within their own borders.

Similarly, in academia, a widely accepted definition of terrorism has yet to be achieved. This leads to the question: how can we understand terrorism if we cannot agree on what it is? In most cases, the general unease with defining terrorism is addressing who 
committed the act of violence in question, and determining the intention or purpose: the question boils down to justifiability.

\section{Can an Act of Terrorism Ever be Justified?}

It is evident that terrorism is a form of political violence. Leading scholars in the field of political violence acknowledge the importance of not dismissing violent acts as “inherently evil” without deeper interpretation of the causes (Fanon 1967, Marcuse 1965, Gambetta 2005, Held 2008, O’Neill 2010, Bargu 2011).

In distinguishing the different forms of political violence, scholars attempt to provide context to violent acts such as terrorism by determining the political motivations. Literature on the topic recognizes the importance of being able to identify terrorism and why in some cases it may be considered justifiable. This section will focus on the justifiability of violent acts by exploring the ideas put forward by scholars Shane O'Neill, Banu Bargu, and Herbert Marcuse. It will then counter these arguments by suggesting that definitions that conflate violent acts and terrorism leave too much room for the justification of reprehensible violence.

O’Neill argues campaigns of violence by oppressed groups can be justified in certain circumstances (O’Neill 2010: 128). In his article Struggles against injustice, O’Neill defines political violence as "actions that involve the exercise of physical force to kill, injure or harm other human beings in pursuit of a political end" (O’Neill 2010: 128). He purports that many scholars do not acknowledge the possibility that political violence can ever be justified, and argues that scholars should look at political violence as justifiable in order to fully understand the experience of injustice oppressed groups face and the reason they may want to take action against their oppressors for political means 
(O’Neill 2010: 129). He recognizes that making a case for justifiability is difficult because of the inherent moral wrong associated with the acts in question. However, he argues, the failure to do so limits the scope of scholarship as scholars are so focused on the concept of "justice" that they ignore the "experience of injustice" (O'Neill 2010: 131).

Building on O'Neill's point, and to take it a step further, Marcuse argues that not only can political violence be legitimate in certain instances, but it should not be censored or prejudiced (Marcuse 1965: 10). In his paper, Repressive Tolerance, Marcuse defines oppression as "state oppression," distinguishing between violence committed against the oppressed and violence committed against the oppressors (Marcuse 1965: 7). He believes that campaigns of violence by the oppressed minority can be justifiable whereas violence committed by the majority or state is not. He states that there is "institutionalized inequality" that places limits on tolerance (Marcuse 1965: 2). He argues, "police, armed forces, guards of all sorts" hold a privileged position within society and make it their job to ensure that there is compliance towards tolerance in order to maintain the status quo (Marcuse 1965: 2). Like O’Neill, Marcuse acknowledges that violence in any shape or form, committed by any party is morally reprehensible, however, because existing ethical standards do not function to suppress violent acts committed by the oppressors, he argues, holding the oppressed to these ethical standards would perpetuate violence towards them because it would weaken their ability to fight against it (Marcuse 1965: 78).

Bargu agrees with O’Neill and Marcuse that political violence can be justified but discusses another dimension of the argument that focuses on the symbolic expression of 
violence. In her article, Forging Life into a Weapon, Bargu argues that not only do oppressed individuals commit political violence against others, they also commit violence against themselves (Bargu 2011). Bargu argues that individuals who perform selfdestructive violence do so in an attempt to combat "conflicts in which they perceive themselves to be facing grave and recurring injustices." She refers to these individuals as "human weapons" and claims that those who "starve themselves, poison themselves, mutilate themselves, immolate themselves, explode and scatter their bodies" are using their bodies, more specifically their lives, to convey a political message (Bargu 2011). Like O'Neill and Marcuse, Bargu believes that critical literature focuses too much on the act of violence and not enough on the people who perform them.

O’Neill, Bargu, and Marcuse make relevant arguments about allowing for the possibility that some violent acts can be justified based on surrounding circumstances. Emphasized in their arguments is the importance of interpreting and contextualizing violent acts. They argue that violence, self-destructive acts, and other forms of rebellious protest can be politically motivated although the acts themselves are not morally justifiable or acceptable. However, these views on political violence are highly controversial. Many scholars (Habermas 1990, Fotion 1981, Bauhn 1989, Corlett 2003, Young 2004, Walzer 2006, Nathanson 2010) have issue accepting that horrendous acts of violence, such as terrorism, could ever be justified.

Michael Walzer, C.A.J Coady, and Saul Smilansky counter the arguments for justifiable terrorism by asserting violence against non-combatants is morally reprehensible. 
For Walzer, terrorism should be categorized separately from other forms of political violence such as state violence, political assassination and guerrilla warfare (Walzer 1977: 197, 203). He defines terrorism as, "the random killing of innocent people, in the hope of creating pervasive fear" (Walzer 2006:3). Walzer argues "randomness and innocence" are crucial when discussing a definition for terrorism (Ibid). Unlike O'Neill, Marcuse, and Bargu, Walzer do not support definitions of terrorism that blend the term to include other forms of violence for the reason that it leads to questions about morality and suggests that the targeting of innocents can be legitimate (Ibid). Walzer argues, "terrorism can never be justified" because "it threatens mass murder even when it does not reach that far" (Walzer 2006: 7).

Terrorists... devalue not only the individuals they kill but also the group to which the individuals belong. They signal a political intention to destroy or remove or radically subordinate these people individually and this 'people' collectively. Hence, while all terrorists are murderers, all murderers are not terrorists. Most murderers intend to kill specific people; terrorists kill at random within a specific group of people (Walzer 2006: 5).

C.A.J. Coady also focuses on the innocence of victims in his analysis of the morality of terrorism in respects to other forms of political violence (Coady 2004: 774). Coady defines terrorism as, "the organized use of violence to attack noncombatants or innocents (in a special sense) or their property for political purposes" (Coady 2004: 774). For Coady, terrorism "is a particular kind of employment of political violence" (Coady 2004: 773). He argues that the targeting of innocents or non-combatants is morally reprehensible. For Coady, major acts of political violence such as terrorism are "morally wrong" and "impermissible" (Coady 2004: 777). Coady acknowledges that exemptions may emerge in "extreme circumstances" (Ibid). However, he argues that making 
exceptions for certain groups to target innocents opens up a Pandora's box of sorts, which will more easily allow exemptions for everyone (Coady 2004: 789).

My own conviction is that we surely do better to condemn the resort to terrorism outright with no leeway for exemptions, be they for states, revolutionaries, or religious and ideological zealots of any persuasion (Coady 2004: 789).

Saul Smilansky sets out a framework to test whether political violence in the form of terrorism can ever be legitimate, in his paper Terrorism, Justification, and Illusion. Similarly to Walzer and Coady, Smilansky defines terrorism as "intentionally targeting noncombatants with lethal or severe violence for political purposes" (Smilansky 2004: 790). He notes that unless there are "overwhelming countervailing reasons, the strict constraint on the intentional targeting of noncombatants should be followed" (Smilansky 2004: 792). Smilansky argues, "major instances of terrorism are not justified" (Smilansky 2004: 193). He goes on to describe the relationship between morality and terrorism as an illusion arguing:

It is not so much substantive moral concerns - with massive danger to life, collective self-determination, personal freedom, basic cultural and religious rights, lack of alternatives, or the like - that lie behind these instances of terrorism, but the ghosts of history, the depths of ill will, and the temptations of power (Smilansky 2004: 799).

Walzer, Coady, and Smilansky's focus on the targeting of innocents as the reason for terrorism's unjustifiability is intriguing. This debate on political violence brings forth an important consideration: can an act of violence, even if its end goal is political emancipation or freedom from an oppressive regime, ever be legitimized if it targets innocent civilians?

Walzer, Coady, and Smilansky would argue that the targeting of innocents ultimately refutes the possibility that terrorism can be justified. O'Neill, Marcuse, and 
Bargu on the other hand would suggest that it could be justified if the individuals participating in the activity are a part of an oppressed group and are fighting against grave injustice.

The two groups of scholars mentioned have differing views that stem from their definitions of political violence and terrorism. Whereas one definition is too broad in scope in that it conflates terrorism with other forms of political violence, the other is too narrow, disallowing the contextualization of violent acts by focusing heavily on the act itself and not enough on what incited the violence. The juxtaposition of opinions highlight the difficulties in defining terrorism. Choosing to define terrorism narrowly per Walzer, Coady, and Smilansky, paints all forms of non-state violence that targets innocents as terrorism and embeds this understanding on moral necessity. To explore this concept, I present the following example: planting a bomb in a government building that targets politicians from an oppressive regime versus planting a bomb on a busy intersection frequented by civilians, would fall under the same umbrella of terrorism. However, a broad definition as used by O’Neill, Marcuse, and Bargu conflates terrorism with other forms of political violence making it difficult to identify. For example, if a government of a country is suppressing the rights of a marginalized group and that marginalized group conducts acts of violence killing a number of civilians, under this definition their actions can be seen as a justified act of political resistance.

What can be extrapolated from this debate is the difficulty in determining what causes should be considered justifiable and what causes are not. The potential that political motivations may paint one group as a terrorist organization and another as freedom fighters depends on that political conditioning. As explored in this document, 
coming to a determination of what should and should not be considered terrorism ventures into murky territory. While defining terrorism is not an easy task, academics, legal scholars, and politicians continue to make attempts to do so every day. The question remains: how important is defining terrorism and is it necessary to do so?

\section{Should Terrorism be Defined? If so, How?}

Academics tend to agree that coming to a consensus about a definition is nearly impossible (Laqueur 2007), though academic definitions have commonalities that are important to acknowledge as they shape and inform understanding of the acts that constitute terrorism as opposed to the concept of terrorism itself.

There are four widely attributed characteristics of terrorism:

1. Terrorism is violence (or its threat) for political effect

2. Terrorism is a 'planned, calculated, and indeed systematic act

3. Terrorists are not bound by established rules of warfare or codes of conduct

4. Terrorism is designed to have far-reaching psychological repercussions beyond the immediate victim or target (Sandler 2005, Hoffman 1988 as cited in Shughart 2006: 10).

Examination of a number of popular academic definitions of terrorism is necessary to distinguish a method that can be used to categorize acts of violence seen today as terrorism. Most definitions of terrorism support the idea that terrorism occurs when certain groups feel they are facing immense injustice (Khan 1987: 945). A definition set forth by Ali Khan in 1987 in his paper, A Theory of International Terrorism states:

Terrorism sprouts from the existence of aggrieved groups. These aggrieved groups share two essential characteristics: they have specific political objectives, and they believe that violence is an inevitable means to achieve their political ends. The political dimension of terrorist violence is the key factor that distinguishes it from other crimes (Khan 1987: 945). 
In his 2006 edition, Khan re-emphasizes his point on aggrieved populations, stating, "aggrieved populations... are located at the center of terrorism. They are the eye of the storm. When international institutions fail to resolve conflicts involving aggrieved populations, this systematic failure spawns violence in forms of terrorism" (Khan 2006: 15). Khan goes on to describe the process by which this happens. Aggrieved populations, he says, are subjected to "occupation, subjugation, and degradation" and their "militant members resort to armed struggle... they attack soft targets, expanding the sphere of vindictive violence" (Khan 2006: 15). Once these militant groups start to form, Khan argues, the aggrieved population is stuck in the middle of the conflict: "between the fight of militants and suppressive entities" (Khan 2006: 15).

Distinguished scholar Walter Laqueur states, "terrorism is violence, but not every form of violence is terrorism" (Laqueur 1999: 8). Laqueur goes on to discuss the question of justifiability when it comes to terrorism:

The trouble with terrorism is not that it has always been indefensible but that it has been chosen more often than not as the prima ratio of self-appointed saviours of freedom and justice, of fanatics and madmen, not as the ultima ratio of rebels against real tyranny (Laqueur 1999: 8, 9).

Laqueur acknowledges the difficulty of defining terrorism. He argues that no widely approved definition of terrorism "will ever be found" for the simple reason that many different types of terrorisms exist. They might have similar components but also differ "in time and space, in motivation, and in manifestation and aims" (Laqueur 2007). Despite acknowledging that a definition for terrorism does not exist, Laqueur maintains "an observer with some experience will know it when he sees it" (Laqueur 2007). 
Some scholars have taken Laqueur's position on defining terrorism. Gilbert Ramsay argues that "terrorism should not be defined because the definitional debate obfuscates rather than clarifies its meaning" (Ramsay 2015: 212). Ramsay argues that enough definitions of terrorism exist and they contain so many commonalities that a consensus on what terrorism looks like exists despite there not being a definitive definition of the term (Ramsay 2015: 213). Others, however, have gone above and beyond in their attempt to define the word. The definitional question, they assert, is an important one because it allows for investigation. Jeremy Waldron argues that the "definitional issues of terrorism" are important to discuss and analyze because they help us "understand the structures of decision, action, and intentionality that it characteristically involves" (Waldron 2004: 7). Furthermore, he argues, because terrorism holds an "emotive" and "descriptive" component, "people have an incentive to ensure that, if possible, it is applied to their dangerous political adversaries" (Waldron 2004: 33). The definitive question he stresses, even if it cannot come to a consensus definition, is important because it allows investigation into these different issues that emerge (Waldron 2004: 7).

As expressed within this document, despite a plethora of information about terrorism available in academia, the debate on whether terrorism should or should not be defined lingers on. For the purposes of this thesis, having a basic understanding of the component parts of terrorism is important to understanding the various ways terrorism has developed throughout the years. 


\section{Academic Consensus on Terrorism: Schmid \& Jongman}

Alex P. Schmid and Albert J. Jongman attempted to come to an academic consensus of terrorism in their 1989 study where they analyzed 109 definitions of terrorism presented by other scholars. They found 22 words that repeated through all definitions. Using these recurring words, they attempted to create a definitive definition (Schmid \& Jongman 2005: 5).

Terrorism is an anxiety-inspiring method of repeated violent action, employed by (semi-) clandestine individual, group, or state actors, for idiosyncratic, criminal, or political reasons, whereby- in contrast to assassination- the direct targets of violence are not the main targets. The immediate human victims of violence are generally chosen randomly (targets of opportunity) or selectively (representative or symbolic targets) from a target population, and serve as message generators. Threat-and violence-based communication processes between terrorist (organization), (imperilled) victims, and main targets are used to manipulate the main target (audience(s), turning it into a target of terror, a target of demands, or a target of attention, depending on whether intimidation, coercion, or propaganda is primarily sought (Schmid \& Jongman 2005: 28).

Schmid explains the criminality of terrorism in his paper, Frameworks for

Conceptualising Terrorism. He argues, "most, if not all activities commonly perpetrated by terrorists, are considered illegal if not always illegitimate by the international community" (Schmid 2004: 197). He acknowledges, that terrorism challenges the "monopoly on violence" held by the state so it always maintains a political component even if the motivation for the violence is "religious, criminal or psychopathological" (Schmid 2004: 200).

Acknowledging the complexity involved in discussing terrorism, understanding terrorism, and defining terrorism, Schmid established "four arenas of discourse on terrorism" in his paper, The response problem as a definition problem (Schmid 1992: 7). The four arenas he discusses are: 
1. Academic discourse on terrorism

2. State discourse on terrorism

3. Public debate (Media)

4. Those who support or perform acts of violence and terrorism (Schmid 1992: 7).

Presented with the challenge that terrorism is difficult to define and many different debates in scholarship have emerged, Schmid and Jongman's method of coming to a useable definition is impressive. Schmid and Jongman combine various definitions established by other scholars to realize a consensus. Although the definition that Schmid and Jongman present as a result of their research does not truly encapsulate or achieve its goal of coming to an academic consensus of the term, the list of words that emerge from the study provide a lens into what the agreed upon traits of terrorism are. The top six elements out of a list of 22 used in 109 academic definitions of terrorism included: violence (force), political, fear (terror) emphasized, psychological effects and anticipated reactions, threat, and victim - target differentiation (Schmid \& Jongman 1988: 5-6). The list of elements provided in Schmid and Jongman's study help provide an understanding of what terrorism looks like despite not providing a clear definition.

For the purposes of this thesis, the concept of terrorism will be examined using Schmid and Jongman's list of elements to determine why Al-Qaeda and later ISIS should be considered terrorist organizations. Furthermore, the way terrorism is understood will examined using the public debate, media angle. The media plays an essential role in informing the public about major issues and events. Examining how the media understands terrorism and the ways in which it defines the concept is important, if not imperative to understanding public knowledge about the issue.

Next, this thesis will outline a brief historical background on Al-Qaeda and ISIS, two terrorist groups that have emerged as a result of the War on Terror. Following 
Schmid's definition of terrorism, the above groups are labelled terrorist groups because they a) have engaged in political violence targeting human victims either randomly or symbolically for political reasons, b) human victims were targeted to serve a message to the wider population, and c) propaganda and intimidation were primarily sought (Schmid \& Jongman 2005: 28). 


\section{Part 2: The Road to ISIS}

\section{A Brief History}

This section provides a brief history of the rise of Al-Qaeda and later Islamic State of Iraq and Syria (ISIS). Al-Qaeda, the terrorist group responsible for the 9/11 attacks in the U.S., became the face of terrorism in the late 20th century. As years went by and terrorist activity throughout the world did not come to a halt as a result of the War on Terror, a framework for understanding terrorism using the Al-Qaeda lens was developed by politicians, the media, and academics alike.

Instead of putting an end to terrorism, the War on Terror did little to subdue the rise of terrorist activity. By discussing how one group developed from another and highlighting the differences and similarities between the two, what becomes clear is that the manner in which various groups perform acts of terrorism has shifted as a result of technological innovation. Despite attempts to control and eradicate terrorism, it continues to exist and transform itself. With the rise of social media and the ability to self-promote, terrorist organizations are more independent than ever before in relaying messages and superseding the need to garner attention using traditional media sources (Weimann 2014: 3).

ISIS, as a terrorist organization and an offshoot of Al-Qaeda, is different simply because it has the ability to control its own image, deliver targeted messages to various audiences, produce media spectacles and disseminate using its own media channels. What this section shows is that the terrorist activities performed by Al-Qaeda and later ISIS are the same in terms of motivation, intention, and outcome, however, the manner in which these activities are publicized has changed. The communication tools used by each 
group to get its message across are essential to understanding how journalists ability to report on terrorism has been affected.

\section{The Rise of Al-Qaeda}

Al-Qaeda was formed on August 18, 1988 in Peshawar, Pakistan (Bergen 2012: 3). At its inception, Al-Qaeda's main goal was to create an Arab army that would participate in the jihad against the Soviets in Pakistan and Afghanistan (Bergen 2012: 7). Osama bin Laden, the face of the organization, was very thorough in his development of Al-Qaeda. He created an advisory council that included a military commander and a religious advisor, established membership requirements, provided information on salary, training, and benefits, and kept detailed financial records of all transactions (Bergen 2012: 3). Before recruiting members, bin Laden ensured that he created a viable plan for his organization to run smoothly. (Bergen 2012: 28). It is important to note that at this point, bin Laden did not intend to make Al-Qaeda "any sort of global terrorist enterprise" (Bergen 2012: 7).

The successful withdrawal of Soviet troops from Afghanistan in February 1989 left the group in high spirits and inspired it to increase its efforts in the Middle East (Bergen 2012: 8). Furthermore, Al-Qaeda leaders also talked about "internationalizing" their efforts during this time (Bergen 2012: 8). Once its mission in Afghanistan was over, the ideology of Al-Qaeda shifted. First, the organization interpreted its jihad as involving "the reclamation of once Muslim lands from non-Muslim rule in places such as Palestine, the then Soviet Union and even Southern Spain" (Bergen 2012: 9). Afterwards, leading figures within Al-Qaeda advocated for "the violent overthrow of governments across the Muslim world they deemed "apostate"” (Bergen 2012: 9). It was 
at this point that the group turned more radical and started to mould into the terrorist organization that gained notoriety around the world. However, Al-Qaeda was still targeting governments in the Middle East and had yet to shift its sights to the United States and more generally the West (Bergen 2012: 9). In fact, bin Laden's main goal and reason for creating Al-Qaeda was said to be "the liberation of South Yemen from communism" (Bergen 2012: 10). However, this plan changed in 1996 when bin Laden began seeing Yemen as a "safe haven for his larger struggle against the United States rather than a front for Jihad" (Bergen 2012: 26). His belief during this time was if the United States, "the head of the snake," could be toppled, then authoritarian, non-Islamic governments in the Middle East would topple as well (Bergen 2012: 27). This shift from waging Jihad on the "near enemy" to the "far enemy" came about after a number of what bin Laden viewed as intrusions by the United States in the Middle East (Rapoport 2008: 2096).

Bin Laden was "deeply angered" by U.S. troops in Saudi Arabia, in 1992, he allegedly stated, "we cannot let the American army stay in the Gulf area and take our oil, take our money. We have to fight them" (as cited in Bergen 2012: 19). This shift occurred largely because of Al-Qaeda's failure to "unify" or "cleanse" Islam in the Middle East as many countries such as Libya, Algeria, Tunisia, Egypt, and Saudi Arabia defended against, and successfully dispelled, the threat of bin Laden and his Al-Qaeda network (Rapoport 2008: 2096). The full transition occurred in 1996 when Al -Qaeda declared war on the United States in an effort to "force the withdrawal of American troops from the Gulf Area particularly Saudi Arabia, the home of Islam's holiest shrines" (Rapoport 2008: 2096). The next five years saw attacks on U.S. troops, bases, and 
embassies situated in the Middle East (Ibid). In effect, Al-Qaeda was fighting the "far enemy" at home. On September 11, 2001 this all changed when bin Laden and Al-Qaeda attacked the world's super power and brought forth a slew of devastation, fear, and anger in the aftermath.

\section{The 9/11 Attacks}

More than a decade has passed since bin Laden and 19 men linked to Al-Qaeda orchestrated four suicide terrorist attacks on the United States (CNN Library 2016). When hijacked planes crashed into the north and south towers of the World Trade Centre, it cost the lives of 2,753 people (CNN Library 2016). The images of destruction and the deaths of thousands sent the world reeling (Haynes 2005: 180). Prior to this assault the United States experienced a sense of security and immunity from external threats (Ibid). It came as a surprise to politicians, journalists, and the public alike that this kind of devastation could happen in America (Ibid). The scale of the 9/11 attacks and the tragedy that ensued changed the way the United States and the international community thought about national security and foreign policy.

Bin Laden made many recorded speeches and released them to media before and after the devastating event. He accepted multiple interviews from Arabic journalists and Western journalists such as Robert Fisk and Peter Arnett (bin Laden transcript, Al Jazeera 2004). His intention was not only to provide justification for the actions of Al-Qaeda but also to demand the withdrawal of U.S. forces and political influence in the Middle East.

However, the attacks did not get the results Bin Laden expected. Instead of retreating, the United States engulfed itself in a global war on terrorism only nine days 
after the attack. Then-U.S. president, George W. Bush invited the international community to join him in the front against terrorism when he stated:

Tonight we are a country awakened to danger and called to defend freedom. Our grief has turned to anger, and anger to resolution. Whether we bring our enemies to justice, or bring justice to our enemies, justice will be done. Our war on terror begins with AlQaeda, but it does not end there. It will not end until every terrorist group of global reach has been found, stopped and defeated (Bush 2001, as transcribed in the Guardian 2001).

On October 2001, the American-led coalition, which was made up of the United Kingdom, Canada, Australia, and Germany, invaded Afghanistan with the main goal of dismantling Al-Qaeda by attacking its headquarters and operations (Haynes 2005: 177). The attack greatly weakened Al-Qaeda (Lee 2015: 37). From early on, bin Laden's plan was to devise an organization that was structurally sound. Al-Qaeda exhibited "significant levels of organization, cohesiveness, and operational capability" (Bergen 2012: 30). Al-Qaeda's visibility was its biggest strength in its forming years; it became its greatest weakness once the United States declared war against it (Rapoport 2008: 2096). The U.S. quickly identified its training centres, its headquarters, and its members (Ibid). It led a fierce attack against Al-Qaeda, attacking its infrastructure, targeting its key members, intercepting its media channels, and cutting its access to funds (Lee 2015: 37). The Coalition experienced a swift victory. Shortly after the invasion, Al-Qaeda's activities were completely disrupted (Rapoport 2008: 2096).

The victory was short-lived as Al-Qaeda's leaders and members managed to disappear into the countryside and mountains of Pakistan (Rapoport 2008: 2097). It was at this point that a once centralized, institution-based terrorist network became a decentralized group (Ibid). The loss of this structure "seriously affected Al-Qaeda's capacities," however the fierce invasion of Afghanistan, and later Iraq in 2003, gave "Al- 
Qaeda a new lease on life" (Rapoport 2008: 2097). Disgruntlement with the U.S. and the purposive invasion of two Middle Eastern Muslim countries encouraged a new batch of supporters for Al-Qaeda (Haynes 2005: 179). bin Laden emerged as victorious in this second phase of the conflict in two ways: he brought worldwide attention to his terrorist organization as the events of $9 / 11$ made the front page of every newspaper in the world. Second, the invasion of both Afghanistan and Iraq, and the later revelations of torture tactics used by U.S. soldiers in Abu-Ghraib, unified a band of disgruntled people who focused "their discontent on the West" and joined bin Laden in his efforts against the United States (Haynes 2005: 179).

In 2004, three years after the 9/11 attacks, bin Laden appeared on Arabic TV claiming responsibility and offering reasons for the incident, stating:

... Security is an indispensable pillar of human life and that free men do not forfeit their security, contrary to Bush's claim that we hate freedom. We fight because we are free men who don't sleep under oppression. We want to restore freedom to our nation. Just as you lay waste to our nation, so shall we lay waste to yours. No one except a dumb thief plays with the security of others and then makes himself believe he will be secure (bin Laden as transcribed in Aljazeera English: 2004).

Furthermore, in the full speech, bin Laden places the blame for the 9/11 attacks on the Bush administration, stating that if Bush accepted his conditions, he could lead "America to the security that it was in before 9/11" (bin Laden as transcribed in Aljazeera English 2004)._The strategic release of this speech, the accusations against the Bush administration, and the reiteration of the reasons behind the attacks was a strategic move on bin Laden's part. With these speeches, Al-Qaeda aimed to "create a global media spectacle, a spectacular advertisement for the organization and its militant ideological goals" (Haynes 2005: 181). In this speech and others, bin Laden was in effect declaring a "call to arms". The most devastating attack in U.S. history brought with it a new 
realization: security is not guaranteed to anyone anywhere and no state, not even America, lives "in an atmosphere of invulnerability from foreign attack" (Haynes 2005: 180).

After the aggressive attack on Al-Qaeda by the U.S.-led coalition, bin Laden had to act fast. Although the group suffered a huge blow as a result of the war on terror, AlQaeda contributed towards the terrorism we know today and the terrorist groups that have emerged since 2001 .

After Al-Qaeda was unable to function in a "centralized manner," it reorganized itself and re-emerged in multiple factions throughout the Middle East (Novenario 2016: 954). This new "affiliate structure" encompassed multiple different regions: Al-Qaeda Iraq, Al-Qaeda in the Islamic Maghreb, Al-Qaeda in the Arabian Peninsula, Al Shabab in Somalia, Jabhat al Nusra in Syria, and Al-Qaeda in the Indian Subcontinent (Novenario 2016: 954). This re-emergence was met with internal friction. Al-Qaeda was unable to maintain full authority over its groups: its internal communications were disrupted, its leader Osama bin Laden was killed on May 2, 2011, and the influence the terrorist group had over its partner groups was beginning to diminish (Novenario 2016: 955). Al-Qaeda in Iraq (AQI) was a very close partner for Al-Qaeda. However, its then leader Abu Musab al-Zarqawi had a much more radical ideology and encouraged more ruthless tactics than bin Laden had supported (Novenario 2016: 955). AQI encouraged violence that would further fuel sectarian divisions (Ibid). Moreover, Al-Qaeda was extremely critical of its Iraq affiliate's use of brutal force against people irrespective of their age and gender (Ibid). Despite its hesitations, Al-Qaeda maintained its ties to the group and supported its initiative to "forge an Islamic State in Iraq" (Novenario 2016: 955). Al- 
Qaeda cut its ties with its Iraq affiliate after the group moved into Syria despite AlQaeda's direct orders and continued to use overzealous brutality in attacks (Novenario 2016: 955).

Al-Qaeda declared that AQI's disregard for human life, its "indiscriminate violence" against Muslims, and insistence on attacking the "peripheral enemy" diverged from its Jihad (Holbrook 2015: 97). Al-Qaeda argued that AQI was using excessive violence, which did not fall in line with its "methods and approaches to jihad" that supposedly "emphasized the preservation of blood" by ensuring that "targets be specific and qualified, and any violence limited" (Holbrook 2015: 97,101). The real issue between Al-Qaeda and AQI, however, was not based on actual ideological differences between the two groups. Al-Qaeda no longer had power over AQI as it continued to advance its goals despite direct opposition from the leaders (Holbrook 2015: 98). It was this insubordination that truly prompted Al-Qaeda to sever ties (Ibid).

\section{The Rise of ISIS}

Prior to 2014, the conflict in Syria was seen as civil strife and the international political community saw any involvement on its part as merely a response to a humanitarian crisis (Friis 2015). There were multiple groups in Syria battling the Assad regime there. This included Al-Qaeda's offshoot AQI that later renamed itself the Islamic State of Iraq and Syria (ISIS), although many different labels have emerged to reference the group (Daesh: Arabic translation, Islamic State (IS), Islamic State of Iraq and the Levant (ISIL)). The group quickly and dramatically positioned itself as the most brutal and powerful terrorist group on the world stage (Sprusanksky 2014: 19). Prior to ISIS, 
terrorism was understood and examined through the lens of 9/11. Al-Qaeda achieved notoriety for the 9/11 attacks; however, in the following years this momentum was lost.

ISIS started making airwaves in the West in 2014 when the terrorist group publicized the beheading of American journalist James Foley through its propaganda media arm, Al Hayat Media Centre. Al Hayat publishes newspapers, magazines, and video releases online in multiple languages; targeting foreign audiences (Greene 2015: 18). Regular updates on ISIS activity in Syria and Iraq are provided in Al Hayat's newspaper Islamic State News and magazine, Islamic State Report (Ibid). Al Hayat's most influential publication is Dabiq, an online magazine with more than 40 pages of content (Greene 2015: 23). The magazine includes high-resolution photos, and recurring sections "with each issue containing photo reports, current events, and informative articles on matters related to the Islamic State" (The Return of Khilafah as cited in Greene 2015: 23). The video of Foley's murder produced and published by the media arm was produced with the intent of reaching Western audiences and fear mongering. In the video, Foley is "kneeling next to a man dressed in black" and is made to say that "his real killer is America" before being beheaded (CNN 2014).

The group used Foley's murder to wage war on the West (Friis 2015: 725). What is notable about the Foley video was not particularly that ISIS was committing a heinous act but the manner in which it delivered its message to the public. Unlike Al-Qaeda, which orchestrated a massive media spectacle, ISIS chose a hostage that was American, and an executioner who spoke English, and staged a beheading with the intention of reaching the Western public directly and inciting fear (James 2015: 138). More importantly, ISIS released the video using social media, allowing for it to be distributed 
organically. Essentially, the message ISIS was trying to emit was that nobody is safe by raising unprecedented fear about "the enemy within" (James 2015: 138). It shaped its own narrative by strategically producing a video that included a Western executioner and a Western journalist, making it clear to members of its target audience that the enemy was closer than they thought.

ISIS's rise to power was a shock to the world, and the beheading of Westerners and its success in winning territory in northern Iraq and Syria compelled Western governments to take immediate action. Since 2014, there have been six beheadings of Westerners: Peter Kassig, American aid worker; Alan Henning and David Haines, British aid workers; Herve Gourdel, French mountain guide; and James Foley and Steven Sotloff, American journalists. All beheadings received extensive coverage in mainstream media. Furthermore, John Cantlie, a British journalist continues to be held hostage and used in ISIS propaganda (McKernan 2016).

Once the murders of Western hostages were publicized by ISIS, Western governments changed their stance on Syria and Iraq, declaring the conflict was a matter of national security that required a military response instead of a humanitarian response as previously noted (Friis 2015: 734). Prior their murders, the terrorist group's advances in the Middle East were framed as "a threat to the region... and a 'humanitarian,' sectarian,' situation requiring containment and humanitarian support" (Friis 2015: 734). After the beheading videos emerged, the situation was "rapidly reframed as a national security issue and ISIS was increasingly described as an imminent threat beyond the Middle East" (Friis 2015: 734). As a result, the West no longer wished to contain members of ISIS, they wanted to "degrade and destroy them" (Friis 2015: 734). 
Recognizing the impact publicizing videos of brutal acts online had, ISIS continued to play on the fears of the Western public (Doward 2015). The violence did not stop with the targeting, kidnapping, and murders of Westerners. The terrorist group took a step further when it declared plans to retaliate against the West directly in the Foley beheading video.

Thus, ISIS created its own media spectacle and utilized social media to garner the same widespread publicity that the $9 / 11$ attacks had garnered before it. ISIS strategy is much different than Al-Qaeda's. Whereas Al-Qaeda strategically planned the 9/11 attacks and focused on creating a large-scale media spectacle, ISIS focused on intermittent terror attacks carried out by sympathizers and released videos of Western hostages being killed in gruesome ways to garner attention and longevity. Central to ISIS's terror was its ability to market the terrorism brand and control its message.

\section{Differences, Similarities, and Present Significance}

What really separate ISIS from Al-Qaeda are its methods of operations (Hashim 2014: 71). Zarqawi, ISIS leader, has been his aggressive approach, "engaging in mass civilian casualties" (Ibid). Zarqawi's insistence on slaughtering Shia Muslims garnered much criticism from Al-Qaeda, which believed the real war was against "the enemy occupier" and attacks on "civilians, churches, and Shia" should be stopped (Ibid). As noted above, Al-Qaeda's leaders urged ISIS to rethink its tactics, arguing that the "slaughter of Shia's" distracts from the fight against Americans, and the "public displays of brutality such as the beheadings of hostages" was not necessary (Hashim 2014: 72). Al-Qaeda stated, "jihadists cannot win without the hearts and minds of the Muslim masses and the scholars" and the brutal tactics used by ISIS would not help garner public 
support (Ibid). When ISIS pressed forward and later made clear its goal and intent to create an "Islamic state," many groups, including Al-Qaeda, criticized this action, considering "the project a deviation from the main task of fighting the American occupiers" (Ibid). The focus of the group veered away from liberating Muslim lands from enemy occupiers to the "creation of an Islamic caliphate" (Hashim 2014: 73). Al-Qaeda argued that the declaration of a caliphate was "inappropriate" and the timing was not right (Hashim 2014: 79). ISIS refused to take any direction given by Al-Qaeda and asserted its legitimacy by referencing its success in controlling territory in Iraq and Syria (Ibid).

Al-Qaeda was focused on internal communications to maintain a cohesive front in the fight against enemy occupiers and rationalizing its terrorist actions to the public. It believed that public support was a necessary component in its jihad and the use of unnecessary violence and force would delegitimize the organization. The main focus of Al-Qaeda was to remove the "enemy occupier" from Muslim lands, not to build an Islamic state. For Al-Qaeda, this step would come much later. ISIS, on the other hand, focused on gaining territory, slaughtering those who do not agree, and using force, violence and extreme brutality to achieve these aims. The war has been a multi-front campaign that targets groups, and all dissenters are fair game. Furthermore, ISIS has not cared to justify or rationalize attacks that result in mass casualties, its number one weapon is violence and fear mongering through propaganda.

This difference is seen today when examining and analyzing recent terror attacks by each terrorist group. ISIS and Al-Qaeda continue to battle each other for power and influence in the Middle East. Both groups encompass the qualities of terrorism as 
outlined in Schmid and Jongman's definition. The 22 word categories repeated throughout the 109 academic definitions analyzed in their study can easily be identified when examining the terror attacks perpetrated by each group. However, it is clear that certain word categories better represent one group over the other. For example, terrorist activities perpetrated by Al-Qaeda usually involve violence, are purposive and planned, highly calculated and strategic, and send a clear political message. Of course, other elements such as fear, publicity, and intimidation exist but the act of terror perpetrated is best exemplified through those word categories.

For example, the 9/11 attacks were highly calculated and strategically planned, targeting the epicentre of the American economy. More recently, Al-Qaeda's offshoot in Yemen took responsibility for the Charlie Hebdo attacks on January 7, 2015. Charlie Hebdo, a satirical French magazine, was targeted for publishing controversial cartoons of Prophet Muhammad. Two armed gunmen killed 12 people. The attacks made news all over the world and shone a spotlight once again on Al-Qaeda motivated terrorism. Media coverage of the incident described the attacks as "sophisticated and calculated" (Toronto Star 2015). Coverage of the attacks noted that "the precision of this operation" was unlike any other terrorist attacks before it. The Charlie Hebdo attacks, like the 9/11 attacks before it, altered people's perception of their own safety and brought a war that seemed far away right to their backyards (Hattem 2015).

However, terror attacks perpetrated by Al-Qaeda have been have been few and far between since 2001. Al-Qaeda is reactive in the way it garners publicity for itself. It plots terror attacks, follows through with them, and awaits media attention in the aftermath. Both $9 / 11$ and the Charlie Hebdo attacks were calculated and planned attacks that 
received widespread media coverage as they happened. Although Al-Qaeda took responsibility for these attacks, it depended on the media for publicity. This is where ISIS diverges from Al-Qaeda. ISIS is proactive in its communications approach. ISIS uses the Internet to promote and recruit, "producing as many as 90,000 posts on Twitter, YouTube, Facebook, and many other social media platforms every single day" (Lieberman 2017: 16). ISIS's success recruiting members and garnering publicity, in large part, can be attributed to their ability to control the message and market its terrorism brand to the world. It is this ability that has shifted the manner in which journalists report on terrorism.

The word categories that best represent the terror activities of ISIS from Schmid and Jongman's definition include: symbolism, fear, publicity, violence, repetitiveness, threat, and victim/target differentiation. ISIS's strength lies in its ability to incite fear through marketing its terror well. It is how they control its message. The repetitiveness of terror attacks perpetuated by ISIS mixed in with the constant releases of videos showing the beheading, torture, and brutal murders of Western hostages provide them longevity in the news cycle. Three haunting videos released by ISIS show the brutal murders of Foley, David Haines, and Steven Sotloff. Foley, discussed above, put ISIS on the media radar.

ISIS releases content with the intent to shock (James 2015: 138). The beheading videos of Haines (September 13, 2014) and Sotloff (September 2, 2014) were shot similarly to the Foley video (August 19, 2014). The execution videos showed all three men, in orange jumpsuits, kneeling in the middle of a desert with a British executioner "holding a knife to (their) throat" (James 2015: 142). ISIS, "through the production of the 
videos, the management of their reception, and their distribution" has developed a method to promote its terror through shock-imagery (Ibid).

ISIS followed through with its promise to bring war to the West when it perpetrated the November 2015 Paris Attacks. Ten attackers "armed with assault rifles and explosives" targeted various locations across Paris, killing 130 people (CNN 2016). The largest number of casualties was at Bataclan concert hall where gunmen killed 89 people (CNN 2016). Three months later, ISIS claimed responsibility for another terror attack in the Belgian capital, Brussels (BBC 2016). Thirty-two people were killed when five attackers bombed the main terminal of Zaventern international airport and the Maelbeek metro station (BBC 2016). According to CNN, ISIS "has conducted or inspired more than 140 terrorist attacks in 29 countries other than Iraq and Syria...(killing) at least 2,043 people" (CNN 2017).

\section{Conclusion}

ISIS has taken full advantage of the Internet to promote and disseminate its propaganda (Lieberman 2017: 1). Terrorism and the media have always had a symbiotic relationship: one feeds the other. In a 2005 letter, Al-Qaeda leader Ayman al-Zawahiri wrote to AQI (now ISIS) leader Abu Musab al-Zarqawi, "we are in a battle, and more than half of this battle is taking place in the battlefield of the media" (Cotte 2015). However, ISIS has changed how it interacts with the media as it now reaches directly to its target audiences "(using) the Internet to fulfill and even surpass the media's function" (Lieberman 2017: 10). ISIS uses the Internet to promote and recruit, "producing as many as 90,000 posts on Twitter, YouTube, Facebook, and many other social media platforms every single day" (Lieberman 2017: 16). It is this ability to control its message and 
market its terrorism brand that has shifted the manner in which journalists report on terrorism. 


\section{Chapter Two}

\section{Terrorism and the Media}

In this chapter, relevant literature will be reviewed to determine how media responses to terrorism are formed. Focusing on the aftermath of $9 / 11$, and later the rise of ISIS in Iraq and Syria, this chapter will provide an overview of how these groups have been covered in the media. It will also provide a concise summation of the differences and similarities in coverage and the challenges Al-Qaeda and ISIS presented to the media. The second part will review literature on the practice of journalism itself, examining how journalists cover stories and methods used to ensure journalistic principles. This section will delve deeper into the inner workings of the media by examining literature on news values, sources, investigative methods, and the influence of external actors.

\section{Global Journalism with a Local Lens}

News has traditionally been categorized into three main categories: local, national, and international. With the rise of globalization and technological innovation, information has been de-territorialized, making room for new categories for labelling news content. Global journalism is a journalistic practice encompassing "the form, structure, and rules of journalistic writing" to show how stories happening around the world are interrelated (Johnson-Cartee 2005: 122, Berglez 2008: 846, 847). The foundation of global journalism is "ongoing relations," the continuous resurgence of issues that affect a variety of people for long periods of time (Ibid). Ultimately, "global journalism transgresses and transcends the traditional domestic-foreign dichotomy" (Berglez 2008: 845). 
The foundation of global journalism is "ongoing relations," the continuous resurgence of issues that affect a variety of people for long periods of time (Ibid). Ultimately, "global journalism transgresses and transcends the traditional domesticforeign dichotomy" (Berglez 2008: 845). With the rise of ISIS, a group that specifically targets the West, a story about a terrorist attack occurring in Paris, Belgium, U.S., or even Turkey has a resounding impact in other countries that are experiencing similar threats. A terrorist attack occurring in a place far from one's own is significant because it is no longer just foreign news, but a reality of the combined threat the West faces. Certain acts of terror, such as the Luxor attack on November 18, 1997 in Egypt that left 62 people mostly tourists - dead, gained international attention (Lancaster 1997). The attacks, carried out by a terrorist group intent on toppling then-President Hosni Mubarak had this sort of global resonance before ISIS and before advances in modes of dissemination (Ibid). However, ISIS has positioned itself as the enemy of the West, making each attack resonate deeply regardless of where the attack occurred geographically.

How does this relate to journalism? With the emergence of disruptive technologies such as radio, film, television, Internet and newer media such as Twitter and Facebook, news transcends borders (Berglez 2008: 847). New media methods enable global coverage of news events as the event is breaking. Technological innovation has created an interconnected world where "the conceptual boundaries of journalism have shifted," creating a global network of news (Hellmueller, Cheema \& Zhang 2016: 2). Known as the "CNN effect" the rapid dissemination of a story, any time, creates a vacuum of consumable news, resulting in little time to reflect, gather facts or explain the context of an event (Livingston 1997: 1). Moreover, the perpetual coverage of certain 
events or issues "affect the conduct of... diplomacy and foreign policy (Ibid). As a result, sensational events get repeated coverage in mainstream media. The information on terrorism that gets produced and released to the public "transcend(s) national frames of references," as it "contextualizes motives, exposes interconnectedness, and explores the scope of problems" by using a variety of international viewpoints and relating them to their domestic audiences (Hellmueller, Cheema \& Zhang 2016: 17). The flow of information is greater than ever, "demolishing barriers of time, space, and national borders" (Jallow 2015: 3). As a result, consumers of news are captured in this whirlwind of activities, which can result in a knee-jerk reaction to an event from the public, policy makers, and politicians alike.

The national narrative that shone through in American media in the aftermath of 9/11 was one of nationalistic pride (Handley \& Rutigliano 2012: 745). Coverage of 9/11 helped then-President George W. Bush and his administration gain the public support they needed to fulfil their policy ventures such as the invasion of Afghanistan and Iraq (Zalman \& Clarke 2009: 101). Moreover, because the American media dominated the global media sphere, the portrayals seen in U.S. media were adapted elsewhere and the U.S. narrative gained dominance in international media (Ibid). Despite counter-narratives produced by smaller media organizations with less significance the terrorism narrative after 9/11 was formed through a U.S. lens (Bennet 2013: 39).

To understand globalization and technological innovation/disruption allows us to understand how the world has become so interconnected, and in turn, how the world's media seems to produce such similar news content when it comes to global conflicts and events such as terrorism. The narrative that succeeds is the one produced by the global 
actor with the most influence, in this case, the United States (Zalman \& Clarke 2009: 101). Having the power to define how terrorism is understood solidifies the 'national narrative' that gets emulated in the global sphere. Although the emergence of social media and sites like WikiLeaks help in constructing a contra narrative, terrorism as it relates to Jihadist terror was first defined by the U.S. The U.S. perspective on the issue transcended borders and was adapted by other media outlets worldwide, with a domestic filter added to stories to help the message resonate with audiences. From George W. Bush's speech that declared a War on Terror and a call to arms to the international community to join the U.S. in this battle, to the thousands of news stories produced in the aftermath, the terrorism story was told using an American-made filter.

\section{Media Coverage of Terrorism: From Al-Qaeda to ISIS}

A defining factor of terrorism is its insatiable vanity. Terrorism feeds on "publicity and propaganda" (Nacos: 2007: 3). Terrorist groups are aware that the use of violence and extreme brutality against perceived enemies provides the most visibility and advertisement potential (Ibid). Osama bin Laden understood that garnering publicity for Al-Qaeda meant utilizing the already existing global media market, which included the Western media (Ibid). As noted previously, bin Laden accepted interviews with Western journalists such as Robert Fisk, focused his attention on media organizations that would transfer his messages to the West such as Al-Jazeera, and even set up his own media bases in Western countries through affiliate members to have a "physical presence in important media markets" (Ibid).

ISIS, however, emerged at a different time, when technological advancements and social media allowed the group to have greater independence to broadcast its message. 
ISIS created its own marketing campaign and established a communications strategy using Facebook, Twitter, YouTube and other social media to publicize its terrorist organization. Its intent was to solidify and further groom its branding as a terrorist organization. The message was simple, ISIS wanted to be recognized for uncontainable strength and political power (Koerner 2016). Despite its impressive media operations, ISIS still garners publicity through mainstream media through their coverage of terrorist attacks by the group occurring on Western land (Williams 2016). It is the way it promulgates an environment of fear abroad as it knows such attacks will receive instant coverage. In areas in which ISIS is in control, the terrorist group attempts to limit outside media coverage. Reporters Without Borders called the group "news exterminators" as "disinformation reign" in ISIS controlled areas and "contact with the outside world is banned or restricted by ISIS, which also controls communications and the Internet" (Reporters Without Borders 2016: 7). ISIS, the first social media terrorist group, is attempting to control its message by controlling the media. While the technological revolution has allowed ISIS to circumvent traditional media, garnering publicity through various media channels remains a central focus in terrorist propaganda (Nacos 2016: 31). Although ISIS is utilizing the Internet and social media to control its message, "the traditional media's frenzied coverage of the group's online postings (are) akin to providing concentrated oxygen or massive blood transfusions to the groups quest for publicity and propaganda" (Nacos 2016: 29,31).

As previously noted in this thesis, the focus of Al-Qaeda's anger was on the far enemy," the United States. Al-Qaeda's target was the U.S. presence in its home countries, targeting and directing attacks toward U.S. representatives in Muslim countries. ISIS, on 
the other hand, targets both the "far" and "near" enemy. While ISIS directs its propaganda towards the West, its main focus is gaining territory, recruiting members, and taking on anyone who opposes its rule whether they are Westerners, opposing groups, or Muslims alike.

Journalism is a profession and a recognized institution responsible for providing citizens with information it needs to be free and self-governing. It has been impacted by the War on Terror as this declaration has shaped the message and the media in times of extreme conflict. With the rise of ISIS and its use of social media and the Internet, it is now being impacted by the terrorist group's crafted messages and approach to publicity as well. Despite directly targeting journalists, ISIS has managed to remain a standing item in media coverage while ensuring the messaging that gets relayed is controlled by the group itself.

\section{Media Coverage of 9/11}

When Al-Qaeda emerged, it presented a different definition for terrorism and introduced new characteristics. The 9/11 terror attacks orchestrated by Al-Qaeda were strategic in their aims. Al-Qaeda wanted to create a media spectacle, one that would give them widespread recognition all around the world (Haynes 2005: 181). The terrorist group also wanted to present a positive image to its target audience by explaining and justifying the violence as a necessary evil. Al-Qaeda communicated its messages using spokespeople, often featuring bin Laden in its videos. To counterbalance this activity, President George W. Bush's government leveraged its relations with the media to unify public support for the government's foreign policy initiatives, including the invasion of Afghanistan later in 2001 and Iraq in 2003. 
In the mid 2000s, literature emerged discussing media coverage of 9/11. Criticism revolved around patriotism and nationalism, and the manipulation of the media by both the government and the terrorist group(s) they were covering (Carey 2011: 88, Waisbord 2011: 274).

Silvio Waisbord examines how media coverage changed as a result of 9/11 in his article, Journalism, Risk, and Patriotism. Prior to 9/11, the American media often focused on local and national events in their reporting (Waisbord 2011: 274). After the attacks, coverage repositioned and news organizations began placing a stronger emphasis on hard-hitting international and foreign news stories (Waisbord 2011: 276). This "colossal shift," Waisbord argues, was due to the new perception of risk that recognized the U.S. was no longer invincible to foreign threats (Waisbord 2011: 273). The terrorist attacks on U.S. soil sent the country into a state of disarray and left its people, its institutions, and its government in a state of shock, ultimately damaging Americans' "self-perception" (Waisbord 2011: 277). This in turn left the political community and the media in search of a new narrative that would help the American people find a sense of security and redefine their identity in hopes that they could put the pieces of American nationhood back together (Waisbord 2011: 264).

The media, Waisbord claims, took on a new function in society, "to provide comfort to a grieving, shocked country and alert it to possible future attacks" (Waisbord 2011: 273). He argues the widely accepted standards of journalism were suspended in this case and journalism became a nation-building organ of the state (Ibid).

To build a sense of self for the people, the media had to clearly differentiate between the nation and the terrorists. This occurred by "articulating the other" and giving 
an identity to the other that "defined them as different and excluded them from the national community" (Waisbord 2011: 277). Waisbord stresses, "the journalism of crisis was a journalism that snubbed the professional requirements of detachment and objectivity and willingly embraced patriotic partisanship" (Waisbord 2011: 278).

Deni Elliott examines the position journalists are placed in when covering a conflict or crisis that directly correlates with their patriotism. Elliot insists that there is a difference between patriotic journalism and nationalistic journalism. Whereas patriotic journalism "keeps in mind what citizens need to know to make educated decisions," nationalistic journalism "echoes what authorities want to say or what citizens want to hear" (Elliott 2004: 30).

Elliot makes an interesting point as it is very difficult for journalists to remain impartial when a terror attack occurs where they live. However, allowing for patriotism or nationalism, although they represent varying degrees of influence, to seep in consciously or unconsciously affects the way the story is ultimately reported. Waisbord's analysis on how patriotism and nationalism affects coverage is insightful as it outlines how journalists' work can be affected by emotions of patriotism and nationalism.

Dan Rather, anchorman for CBS, made a telling comment that showcased the inability of some journalists to ask the government tough questions after the 9/11 attacks:

It starts with a feeling of patriotism within oneself. It carries through with a certain knowledge that the country as a whole - and for all the right reasons - felt and continues to feel this surge of patriotism within themselves. And one finds oneself saying: 'I know the right question, but you know what? This is not exactly the right time to ask it. 'Limiting access, limiting information to cover the backsides of those who are in charge of the war, is extremely dangerous and cannot and should not be accepted. And I am sorry to say that, up to and including the moment of this interview, that overwhelmingly it has been accepted 
by the American people. And the current administration revels in that, they relish that and they take refuge in that (as cited in Engel 2002: 4).

The willing acceptance of the government narrative at the onset of a conflict guides the way the issue is reported once the immediate crisis is over (Reese and Lewis 2009: 778). The Bush Administration's messages on the War on Terror were swiftly internalized and distributed by American media, where it was consumed by the national and international public (Reese and Lewis 2009: 778). Stephen D. Reese and Seth C. Lewis state that journalists "found it difficult to resist being drawn into the national anxiety and general pro-Bush patriotic fervour" (Reese and Lewis 2009: 778).

In her article, Framing Islam: An Analysis of U.S. Media Coverage of Terrorism Since 9/11, Kimberly A. Powell argues that the regurgitation of Bush's messages concerning the War on Terror by the media was "the contemporary beginning of an us versus them or a United States versus Islam that created animosity between East and West" (Powell 2011: 90). For Powell, terrorism, with its sensational and shocking elements, is something that the media is drawn to (Powell 2011: 91). This, in retrospect, was a win for the organizers of the attack as they were able to spread fear, change behaviour, and get attention simply because their actions became so publicized. "From the terrorists' point of view, the attack on America was a perfectly choreographed production aimed at American and international audiences" (Nacos 2007: 45).

Journalism is one of the most powerful institutions in society because it helps shape people's perception of self and others.

\section{The Duty to Inform}

It is important to note that journalists are guided by various principles and values and are aware of their ability to influence perceptions. Principles that guide journalists are 
based on truth and independence. The media has a duty to inform the public on issues and events, thus it is not surprise that public perception of issues correlates with how these stories are told in the media. Maxwell McCombs and Donald Shaw drew a correlation between media coverage and the importance the general public gave to events covered (McCombs 2014: 6). The study found that the more an issue is covered, the more important the public perceives it to be (Ibid). Moreover, the public's understanding of an important issue is shaped by how it is framed in the media (Ibid). Following this stance, the media not only influence people's emotional reaction to certain events by shaping their understanding but also serve "the rhetorical needs of terrorism" (Palmerton 1988: 106). Furthermore, because the media is representative of society as it reflects societal norms, it upholds certain stereotypes and ideas, and perpetuates these ideas further (van Dijk 2003: 94). Starting with coverage on the War on Terror, and continuing with coverage of terror attacks committed by ISIS today, some media has continued to link terrorism with Islam. This point of view has been expressed more broadly the years following $9 / 11$. By listing characteristics belonging to the terrorists and linking them to nationalities, religions, and ethnicities that many other people share, the media advertently, or inadvertently criminalize a number of innocents, perpetuating their othering within society (Powell 2011: 103). Media coverage of attacks shifted the standard of newsworthiness in mainstream media. The War on Terror introduced a global enemy to the political stage: Al-Qaeda. After the attacks on the U.S., Al-Qaeda was viewed as the most dangerous external threat to the West (Sprusanksky 2014: 19). As Waisbord posits, mainstream media took a patriotic, nationalistic approach to covering the news following the $9 / 11$ attacks. Journalists are citizens as well and when a terror 
attack occurs in their homeland it becomes difficult to separate the job and the feelings of patriotism or nationalism. However, it is important that journalists recognize their own biases and tell the story following journalistic guidelines without letting notions of patriotism or nationalism seep in. Patriotic and nationalistic fervour in the U.S. after 9/11 resulted in a media obsession with the possibility of new targets. Furthermore, mainstream media tasked itself with the job of uniting a people after a horrendous event, and attempted to define and resolve the conflict (Waisbord 2011: 273). By offering a nationalistic narrative and providing definitions of what constitutes a terrorist and what constitutes a citizen, mainstream media managed to put forth a new national perception of self (Waisbord 2011: 277).

\section{ISIS's Media Strategy}

Al-Qaeda paved the way for ISIS's media strategy; however, ISIS has had much more success than Al-Qaeda in getting its message across and recruiting members. AlQaeda, like ISIS, had a propaganda media arm called "as-Sahab" where it released a number of videos online (Seib 2008: 74). Moreover, Al-Qaeda focused its efforts in creating documentaries, promotional materials, and publicizing speeches (Greene 2015: 9). Al-Qaeda was not as media-savvy as ISIS however. People still had to find the group online whereas with ISIS, the group makes its presence known on widely popular social media channels. Furthermore, the group is skilled in using social media and produces high quality propaganda that gets disseminated quickly through these channels. "ISIS more effectively gains new recruits by use of social media, takes advantage of newer web platforms, and glorifies extreme violence to a level which arguably is without modern 
precedent (Greene 2015: 12). ISIS creates hard copy propaganda, produces content for YouTube, and is actively engaged online.

Social media is being widely used by terrorists to promote their brand in cyberspace where they cannot be shut down (Weimann 2014: 2). It also provides terrorist groups with more independence and control over its messaging because of the "highly interactive platforms through which individuals and communities share, co-create, discuss, and modify content" (Ibid). Terrorist organizations depend on recruitment and social media allows these groups to enter the mainstream and reach out to target audiences directly (Weimann 2014: 3). ISIS has especially perfected its online marketing campaign. The group has two objectives, "to provoke the U.S. and its allies, and to recruit from outside the Middle East" (Rose 2014). ISIS's Al Hayat Media Arm targets young audiences who are from the Middle East (Ibid). Content produced varies from graphic and gory combat documentaries, to promotional videos that look more like travel advertisements (Ibid). Essentially, ISIS's media strategy includes "distributing diverse materials in several languages, including new videos and subtitles for existing videos, and also articles, news reports, and translated jihadi materials” (Becker 2014).

ISIS use of social media has catapulted it into the position it holds today. Its recruitment efforts have been successful because it is able to disseminate its propaganda to wide audiences. Furthermore, it produces content, releases it on multiple platforms, and ensures that it stays in control of its message.

\section{Media Coverage of ISIS}

As noted previously, ISIS has created a hostile environment for journalists where real danger (torture and death) is no longer a mere possibility; it is a demonstrated reality 
in ISIS controlled areas (Williams 2016). ISIS disseminates its own messages, it is not dependent on the media although the media still helps ISIS bring its content to wider audiences when it is organically picked up by mainstream media. This is quite a shift in the perceived relationship between terrorists' dependence on the media for publicity. The media is no longer able to set the agenda for terrorism coverage; ISIS sets it by deciding when and where to publicize content.

Despite the successful use of social media such as Twitter and Facebook, ISIS still orchestrates violent attacks for the "media's sake" (Steed 2016: 65). ISIS uses extreme violence because it needs to "continually increase the spectacle or it will lose viewers" (Ibid). The videos ISIS produces have high production value, and are carefully crafted to provide the greatest palatability for those seeking excitement of a propaganda snuff film. It is all "staged violence" that is intended to "maximize coverage" (Steed 2016: 66). An important consideration when covering a story is whether it will maintain audience attention (Frampton 2015). ISIS has found a way to maintain audience attendance by leveraging the popular tools adopted by consumers of media such as Twitter, Facebook, YouTube and so on.

A study on media coverage of terrorism conducted by the Lowy Institute in Australia states that ISIS views mainstream media as a tool to serve its objectives (Williams 2016: 2). The terrorist group understands the media cycle and "tailors the production and release of its material to the needs of mainstream media outlets" (Ibid). The inability for journalists to enter war zones in Syria and Iraq and gain firsthand knowledge of the conflict there makes the media more receptive to messages produced by ISIS (Ibid). Although ISIS uses its own communications strategy to control its brand, it 
relies on the media to "amplify its message" (Williams 2016: 7). Information on terrorism and ISIS is highly demanded by audiences and stories about the group are usually the "most read and most viewed news items" (Williams 2016: 8). Thus, mainstream media responds to the demand by expanding their coverage, creating a media landscape saturated with coverage about the group. This in turn, makes the media "unwitting accomplice[s] to ISIS's aims" (Ibid). Journalists interviewed for this thesis stated that a major concern for them is becoming a "propaganda arm for ISIS" and with the overwhelming amount of information and lack of access, journalists are constantly determining the newsworthiness of materials such as beheading videos and other content released by the group (See chapter four for a more fulsome discussion).

Mainstream media does not have direct access to on-the-ground knowledge about ISIS or life under ISIS rule. Due to the direct targeting of journalists, going to Iraq and Syria and reporting from the frontlines has become increasingly dangerous. Verifying videos and other material online is almost impossible. The majority of ISIS-related stories that get covered on the frontlines are terrorist attacks, or foiled terrorist plots occurring in Western countries (Nacos 2016: 329). These attacks get over-reported in mainstream media, fulfilling ISIS's aims of getting publicity worldwide (Ibid).

Another major difference between ISIS and Al-Qaeda is ISIS's targeting of Muslims in the Middle East. As previously noted, Al-Qaeda was hesitant in attacking areas in the Middle East that would result in mass civilian causalities, especially of children (Holbrook 2015: 95). While ISIS has targeted many Western countries, the group has orchestrated many more terrorist attacks in the Middle East (Neofotistos 2016: 2). ISIS is focused on gaining territory and power. Thus, while it focuses on inspiring and 
orchestrating attacks on the "far enemy," it is engaging in combat on the ground as well. Media coverage of terrorist attacks in countries such as Egypt, Tunisia, Afghanistan, Yemen, Lebanon and so on receive very "little media fanfare or world attention" when compared to similar terrorist attacks orchestrated in the West (Neofotistos 2016: 2). Furthermore, when these incidents are covered by mainstream Western media, the focus is not on civilian casualties but on the events being a "normal aspect of everyday life" in countries that are marred with political tension and instability (Ibid).

\section{What is the Media Doing Wrong? Criticism of Western Media's Coverage of Terrorism}

Many academics argue that mainstream media coverage of terrorism fails to accurately depict problems and solutions. Instead of informing the public, scholars argue, the news media creates an environment of fear by creating a sensationalized media spectacle. Thus the media can be used by both political elites and terrorist organizations, presenting biased coverage based on patriotism and nationalism that tends to leave important questions unanswered (Altheide 1997, Kellner 2004, Waisbord 2011).

Extreme violence is a method used by many terrorist organizations because it automatically creates a media spectacle that gains notoriety and fame throughout the world, especially if the act takes place in a Western country. This practice has been used for many years by many different terrorist networks. The more disastrous an event, the more likely it will capture the attention of the media, and thus the public (Kellner 2004: 43). The images of total destruction, the number of casualties, the conflict involved, and the threat of future violence make terrorist attacks an inevitable front-page story. 
The 9/11 attacks were so extravagant, and so novel, they left the public perplexed and the media scrambling to find an explanation (Kellner 2004: 43). The attacks were orchestrated in one of the most famous cities in the world, and the symbol of U.S. economic power: New York City. They set the stage for future acts of terrorism because they made it clear that "the U.S. was vulnerable to terror attack, that terrorists could create great harm, and that anyone at any time could be subject to a deadly terror attack, even in Fortress America" (Kellner 2004: 44). The repeated images of the planes colliding with the iconic buildings and "bursting into flames," the smoke-filled streets of New York, the people jumping out of buildings to escape the fire inside, all played their part in "traumatizing a nation with fear" (Kellner 2004: 44). This left the news media, all around the world, with a puzzle that they had to put together: why did this happen and what will be done about it? It also perpetuated global insecurity.

For a number of scholars, the media's fascination with terrorism produces an environment of fear within society. David Altheide examines the role the news media plays in creating a "public discourse of fear" (Altheide 1997: 647). For Altheide, the connection between how the public perceives their surroundings and their sense of security is directly correlated with how the media defines problems within society (Altheide 1997: 648). The coverage of violent content produced by news media creates a sense of insecurity in the public and exaggerates perceived dangers to society (Ibid). The public's "assumptions about danger, risk, and fear" are then used by governments to achieve political goals (Altheide 2006: 416).

A major criticism of Western media's coverage of terrorism is the reliance on government sources. Decision-makers who are responsible for creating and instituting 
policies during extreme times of conflict are usually "key news sources" who "shape perceptions of mass audiences" and set the stage for public support of such policies (Altheide 2006: 417). An important question that has emerged concerning the media's role in relaying messages to the public is "does media coverage err on the side of governments, due to an overreliance upon the framework of interpretation offered by public officials, security experts, and military commentators" (Norris, Kern \& Just 2003: 3)?

Another important question to ponder is whether media coverage of terrorism benefits terrorists by "lending them legitimacy and credibility" and encouraging future attacks "through a contagion effect" (Norris, Kern \& Just 2003: 3)? Laqueur argues that terrorism is a form of propaganda and the only way this propaganda gets disseminated is through the media (Laqueur 1999: 43). He states, “...journalists are terrorists' best friends, because they are willing to give terrorist operations maximum exposure" (Laqueur 1999: 44). This however, does not mean that journalists are terrorist sympathizers; it simply means that terrorism makes an "exciting story" (Ibid). Laqueur states that the media's focus on terrorism magnifies "the political importance of many terrorist acts out of all proportion" and "in some cases [leads to] the murder of innocents and obstruct[s] complicated rescue missions" (Ibid).

Journalists have been called the "modern tools of terrorists" (Picard 1993: 6). By highly publicizing terrorist attacks, a message gets conveyed to the public, "that the terrorists are effective, that they must be feared, and that they must be taken seriously" (Picard 1989: 12). Furthermore, small terrorist organizations, understanding the power of the media, orchestrate violent attacks to make "themselves heard and known in a very 
short time" (Picard 1989: 13). An example of a terrorist group's quick introduction to the world is ISIS. Prior to Foley video in June 2014, not many people knew about the group. This major event and the attention it received in the media solidified their position as the new face of terror. In the following two years, the group has gained much of its recognition from publicizing heinous violence against Western hostages, carrying out violent attacks in Western countries, and successfully gaining territory in Iraq and Syria; all of which received significant media attention. Some argue that if this avenue for publicity was no more, then terrorists would have no way of entering public consciousness: "no medium, no message; and by extension - no message, no mileage for terrorism" (Jackson 1990: 523). Despite ISIS having a direct line to its audiences and independently disseminating its content to audiences, its widespread publicity in the West still comes from coverage of this content in the media.

\section{Conclusion}

The ISIS story is still developing and the challenge of bearing witness in ISISheld territory places limits on journalists' ability for first hand analysis and interpretation. The media covers ISIS similarly as they did Al-Qaeda, after all ISIS is an offshoot of AlQaeda and terrorism as we know it today has been defined through the lens of Al-Qaeda and 9/11. Jounalists follow the same routines and focus their stories on the same angles such as the victim, national security, perpetrator, future threats, and on-the-ground activity. However, two very important points must be made. Al-Qaeda is distinctively different than ISIS in its tactics and methods of operation. Furthermore, ISIS's highly successful marketing campaign to attract new recruits allows it gain a global presence. ISIS is not merely set up as a terrorist organization, it is also set up as an army 
engaged in war against all dissidents who disagree with its self-imposed mandate. The objectives of the attacks carried out by the two groups vary. While one attempted to uphold legitimacy and rationalize attacks, the other orchestrates one brutal attack after another for publicity while continuing a parade of terror on the home front as well.

Moreover, Al-Qaeda relied on the media and understood its messenger power. In order to relay information to wide audiences, it intentionally orchestrated events that would get picked up and disseminated by news media. It also attempted to rationalize and promote its cause through journalists (see interviews by Fisk 1983, 1997; Arnett 1997, Miller 1998, Yusufzai 1999). This symbolized a rift from the past. ISIS displayed its dislike for journalists and its intent to self-brand; creating a tightly controlled image by ensuring all content was produced and released by the group on its own terms.

By diminishing journalist's ability for newsgathering and ensuring the group itself releases all content, ISIS changed the flow of information, making it one-directional. The demand for ISIS-related news, however, was very high and journalists had to use some information released by the group, such as strategically produced videos, despite it being clear propaganda (Williams 2016). Ultimately, it was ISIS's mastery of social media that garnered it some independence in the way it relays its messages to the world.

Study after study has been conducted focusing in general on poor media coverage, including some of the criticisms examined above. However, many of the studies that are not oriented in the journalism studies field fail to consider the inner workings of the media: its methods of operation such as the steps taken to gather information, what makes a news story newsworthy, attribution, and sourcing. Such journalistic practices are followed and internalized by journalists who use the skills they have learned either 
through education or through practice working in a newsroom to tell what they deem to be the most important stories of the day. Understanding why the media reports on certain issues the way it does means considering the question: how is the practice of journalism applied? Scholars are constantly re-evaluating the role of the news media in democracy. However, most scholars and the general public agree that journalism is necessary for the proper function of democracy (Adam 1993, Carey 2007, Schudson 2008, Kovach \& Rosenstiel 2007). Journalists act as messengers, they relay information but they are not necessarily subject matter experts. They focus on a number of steps to cover the stories they have selected to tell.

The next chapter will focus on the hierarchy of influences framework established by Stephen D. Reese and Pam Shoemaker to examine the number of factors that influence the way journalists tell stories. Analyzing the multiple influencers within the field of journalism will shine a light on some of the important issues discussed in this chapter. It allows for a better understanding of how journalists cover important issues and any possible interference in their storytelling. Once examined, the following chapters will include information gathered from interviews about journalists' personal experience covering terrorism and ISIS. It will provide insight on what challenges journalists face when covering terrorism and how they deal with obstacles that may hinder their ability to fully engage with a story. 


\section{Chapter Three}

\section{News Media, Its Democratic Function and the Principles that Guide It}

Scholars in many fields have long debated the role the news media plays within society. An examination of how journalists tell stories that have longevity in the news cycle has shown there is a case for insisting that media coverage is not always balanced citations. For the purposes of this thesis, balance means, "covering both sides of an issue" fairly (Wahl-Jorgensen et al. 2016: 3). A journalist's personal bias mixed in with societal norms does affect the quality of work produced (Watson 2014: 793-5). It also affects the manner in which it informs the public on major issues such as terrorism (Ibid). Analyzing journalism's role as the messenger of the people means understanding its processes, practices, and surrounding influences. Media plays an important role within society but it is intertwined with other institutions within society such as the political and the legal systems. The journalism it produces is a reflection of this.

This chapter starts with a discussion on journalism's role in society, in particular its relationship to democracy, as explored by Stuart Adam, Bill Kovach and Tom Rosenstiel, Michael Schudson, and James Carey. It will then focus on the inner workings of journalism, paying particular attention to journalistic practices and the various influences that affect coverage. It will use the Hierarchy of Influences Model framework by Stephen D. Reese and Pam Shoemaker to give a brief overview of the different elements that can sway news coverage. By categorizing the various ways the media can be influenced when reporting on terrorism, a better understanding of why stories are told the way they are emerges. 


\section{Journalism's Role in Society}

Journalism, in its most ideal form, allows for the dissemination and analysis of information that helps inform citizens about the world around them and helps society function democratically. On the other hand, journalism is often criticized for being sensationalistic, conflict-driven, focused on mainstream views, and biased (Waisbord 2011, Herman and Chomsky: 1988). Some critics argue that journalism is profitmotivated and represents certain private interests instead of the public interest (McChesney 2004). They argue journalism is a tool used by elites to advance specific agendas (McCombs 2014). The widely believed claim among industry professionals that journalism is by the people for the people is often met with scrutiny from the public because a distrust of the media exists (Ladd 2010: 7, 8). Despite the seemingly systemic issues with the model of journalism at play today, journalism is still viewed as a necessary component of democracy (Schudson 2008: 12).

In his paper "A Short History of Journalism for Journalists”, James W. Carey, for example, argues that journalism and democracy are interchangeable. To make this point, Carey highlights journalism's importance in nation building and community building efforts, arguing that in any developing nation, the public and journalism "emerge in tandem" (Carey 2007: 12). For Carey, the relationship between the public and journalism is most essential. "Without [the public] nothing counts... Journalists justify their actions, defend the craft, plead their case in terms of the public's right to know, their role as the representative of the public, and their capacity to speak both to and for the public" (Carey 2007: 12). 
Moreover, Carey emphasizes that without journalism there would be no democracy and without democracy there would be no journalism. "When democracy falters, journalism falters, and when journalism goes awry, democracy goes awry. The fate of journalism, the nation-state, and the public sphere are intimately intertwined and cannot be easily separated" (Carey 2007: 13). Carey acknowledges this is a controversial assumption in the modern world because it presupposes that journalists are committed to the defence of democracy, which "compromises their valued non-partisanship" (Carey 2007: 13). In response to this, he argues that journalists "are not permitted to be indifferent, nonpartisan, or objective" when it comes to democracy because serving democracy is "their one compulsory passion" (Carey 2007: 13). Taking this "compulsory passion" away would, in his words, reduce journalists to "propagandists or entertainers" (Carey 2007: 13).

Michael Schudson also tackles the relationship between journalism and democracy in his book, Why Democracies Need an Unlovable Press. Unlike Carey, Schudson does not agree that journalism and democracy are one and the same (Schudson 2008: 11). Although he recognizes the important role journalism plays, he states, “journalism exists and has long existed outside democracy" (Schudson 2008: 12). Its importance, he argues, lies in the collection and dissemination of information and facts. Using Hannah Arendt's theory on facts, Schudson makes the case for journalism. He argues that although "democracy does not necessarily produce journalism nor does journalism necessarily produce democracy," journalism is an essential vehicle for democracy to promulgate itself. Schudson sets out six functions that journalism undertakes within a democratic country: information, investigation, analysis, social 
empathy, public forum, and mobilization (Schudson 2008: 12). For Schudson, these functions highlight the importance and value of journalism within society. "Journalism does not produce democracy where democracy does not exist, but it can do more to help democracies thrive if it recognizes the multiple services it affords self-government, encourages the virtues that underwrite those services, and clarifies for journalists and the public the many gifts news contributes to democratic aspirations" (Schudson 2008: 26).

In The Elements of Journalism: What Newspeople Should Know and the Public Should Expect, Bill Kovach and Tom Rosenstiel also attempt to define the role of journalism within society in a world that is becoming distrustful of journalists. They claim that this distrust comes from the inability of journalists to come together on a set of principles and practices that drive the profession. Moreover, Kovach and Rosenstiel argue that "journalism was for building a sense of community that the government could not control; journalism was for citizenship [and] democracy" when discussing its inception alongside an emerging democratic nation (Kovach and Rosenstiel 2007: 15). Today, the purpose of journalism and its raison d'être is a point of contention among the public, scholars, and journalists themselves. Attempting to define journalism in the wake of technological advancements presents another challenge. Kovach and Rosenstiel argue, "technology has created a new economic organization of journalism in which the norms of the profession are being pulled and redefined and sometimes abandoned altogether" (Kovach and Rosenstiel 2007: 16). This, in turn, has broadened the definition "so that anything can be seen as journalism" (Kovach and Rosenstiel 2007: 16). Despite this, the authors argue that the purpose of journalism has remained remarkably "consistent and enduring" irrespective of the changes in practice. The primary purpose of journalism, 
they argue, continues to "to provide citizens with the information they need to be free and self-governing" (Kovach and Rosenstiel 2007: 17). To fulfil this task, they set out a list of 10 principles that "we require of our journalism, principles that citizens have a right to expect":

1. Journalism's first obligation is to the truth

2. Its first loyalty is to citizens

3. Its essence is a discipline of verification

4. Its practitioners must maintain an independence from those they cover

5. It must serve as an independent monitor of power

6. It must provide a forum for public criticism and compromise

7. It must strive to make the significant interesting and relevant

8. It must keep the news comprehensive and in proportion

9. Its practitioners have an obligation to exercise their personal conscience

10. Citizens, too, have rights and responsibilities when it comes to the news (Kovach \& Rosenstiel 2007: 9).

Like Kovach and Rosenstiel, G. Stuart Adam also made the case for journalism and democracy by developing a self-reflective definition in his paper, "Notes Toward a Definition of Journalism." Adam begins his analysis with an assertion that "journalism is a fundamentally democratic art and through it ... a free society engages in conversations with itself' (Adam 1993: 6). Adam's focus when determining a working definition of journalism does not include the institutions of journalism themselves. Unlike the authors listed above, Adam breaks his analysis down to include only those who are actually involved in creating works of journalism: reporters, writers, and critics (Adam 1993: 5). He pursues the task of defining journalism with some specific goals in mind. "To lift the study of journalism in the university out of what (he) regards as a state of limbo. To define journalism in a way that will enable schools to participate more actively in its reform. And to inspire a belief that journalism can be and often is an art form" (Adam 1993: 5). Adam is interested in how journalists frame experience and form consciousness. 
He states, "the transfer of consciousness from one human being to another through a story, any story - from a journalist to an audience, in other words - produces the forms of public consciousness that makes collective existence possible. What is initially private becomes public, and so in journalism society is born and reborn every day" (Adam 1993: 18). For Adam, the emphasis must be placed on the individual act of creating works of journalism. Adam argues that journalists should appreciate that when they create pieces of journalism, they are creating art. When the emphasis is placed on how a story is told instead of what is being told, the process becomes the test. Journalists will feel compelled to stay true to the standards, the techniques, the skills, they learn because they respect the art form. Adam argues that appreciating the practice at an individual level will allow for better journalism. "Journalism is made; it doesn't just happen. So the language we use to see it and teach it must be akin to the language of art. The language of art encourages students to enter the imagination of the artist and meditate on how the artist does what he or she does" (Adam 1993: 1).

What can be inferred from Carey, Schudson, Kovach and Rosenstiel, and Adam is that journalism plays a vital role in democracy, specifically concerning the public's right to know. Kovach and Rosenstiel recognized that public perceptions of and sentiments toward journalism have evolved. Adam recognized that journalism is hard to define and that journalists must look introspectively and find value in how a work of journalism is created to improve its overall quality. Schudson recognized that times were changing and journalism's role in society needed to be re-examined. Carey asserted that democracy and journalism go hand-in-hand. All scholars listed above pursued the topic acknowledging that public dissatisfaction with journalism was growing. Kovach and Rosenstiel argued: 
"We've got to make sure that as the public dissatisfaction grows, it doesn't grow the wrong way, toward censorship that says, 'Stop this. Stop that.' We want a public that is more aware about what quality journalism means to them and their lives and what they've got a right to expect and how to recognize it" (Neiman Reports 2001: 5).

As social media and the Internet challenge journalism's role within society, it is important to understand the essential nature of journalism and its use in informing the public. Despite journalism being an imperfect model, it provides a service to the public as it can facilitate synthesis of information into a concise, easy to understand package. Journalists understand that their obligation is to the truth and their loyalty is to citizens (Kovach and Rosenstiel 2007: 9). Citizens can still hold journalists to account about misinformation being produced because journalists still have a duty to tell the truth. It can be argued that an information overload is being experienced today. Good, credible journalism can help sift through this information and reduce information overload. When covering important issues such as terrorism, journalists must understand that they still can ensure their coverage of the terrorism story is accurate and best represents the truth. They have a duty to their citizens to do so.

\section{How Journalism Works: The Hierarchy of Influences Model}

Journalists, routines and practices are so internalized that it can be difficult for them to define the processes that they use to create a story and to understand its value and significance (Shoemaker and Vos 2009: 60). However, from how stories are written to how events within society become news, there exist sets of processes that guide journalistic coverage. As outlined above, the news media plays a significant role within society and is responsible for shaping perceptions on important issues. Despite the media 
being independent there are both internal and external factors that affect the content that is produced.

Stephen D. Reese and Pam Shoemaker developed the Hierarchy of Influences Model to analyze the factors that "shape media content" (Reese \& Shoemaker 2016: 390). They argue, "this model helps disentangle the relationships among individual-level professionals and their routines, the organizations that house them, the institutions into which they cohere, and the social systems within which they operate and help maintain" (Ibid). Reese and Shoemaker's theory was first published in 1996 but was recently updated to account for technological changes and globalization. The updated version allows for an analysis of how ISIS use of social media affects journalists.

A lot of criticism of the media discussed in the previous chapter pinpoints the media's challenges when it comes to reporting on issues with social implications. This model allows us to delve deeper into the factors that influence media coverage and the reason why we see certain slants or biases in news content on terrorism and other important issues. This thesis uses the Hierarchy of Influences Model because it allows for the "untangling of many of the criticisms of press performance" (Reese 2007: 35). Reese and Shoemaker's model contains five levels of influence: individual, routines, organization, extramedia (institutional), and ideological (socio-cultural) (Reese 2007: 35). Using these categories to flesh out various influences within media organizations will allow for a better understanding of reporting on terrorism, the factors that influence coverage, and why stories get told the way they do. 


\section{Individual}

The first level in Reese and Shoemaker's Hierarchy of Influences Model is the Individual. Examining how journalists perceive their newsroom roles is an important consideration when attempting to analyze news coverage of significant events (Reese and Shoemaker 2016: 398). How journalists perceive their roles is a direct representation of how they perform their jobs (Ibid). Exploring the "personal traits of newsworkers, news values they adhere to (and the) professional roles they take on" provides us with a deeper understanding of the factors that can influence news coverage of important issues (Ibid). The role journalists assume in society and the belief system they adopt is correlated with journalistic tradition that has evolved and developed over time. This section focuses on guiding principles in the field of journalism such as: truth, objectivity, independence, duty owed to the people, and news values. It includes an examination of the process taken to ensure these principles are upheld. What becomes clear is that inherent biases have become interwoven into the processes of creating news content. They still remain, and influence the way journalists tell stories.

\section{The 'Truth' Factor}

Mark Deuze conceptualizes journalism as an ideology (Deuze 2005: 444). This establishes an understanding of journalism by examining "how journalists give meaning to their work" (Ibid). When attempting to analyze coverage on a global issue such as terrorism, examining the values that drive journalism is useful because it provides insight into how these values shape the content produced. In their book, The Elements of Journalism, Bill Kovach and Tom Rosenstiel explored individual role-perception by interviewing hundreds of journalists and concluding that a journalist's first obligation is 
to the truth (Kovach \& Rosenstiel 2007: 4,5). Moreover, journalism gains its legitimacy by being presented "as a truthful discourse about the real world" (McNair 1998: 65). However, what truth means and how it is conceptualized has long been debated. For some scholars, truth is correlated with a journalist's ability to be objective in their reporting (Skovsgaard et al. 2013: 26). Objectivity in journalism means relying on factual information to tell a story and providing balance by ensuring different voices are represented (Ibid). Yet, objectivity is often considered an illusion "since the news is a construction of reality rather than a description of reality" (Skovsgaard et al. 2013: 24). The way journalists perceive truth has transformed over time, as has the way they perceive their function within society.

Journalists' perception of truth gets relayed in the news coverage of everyday events to wide audiences. Although the norm of objectivity, which instils a sense of duty to report content that is fair, balanced, accurate, and factual exists, news is a construct and biases emerge despite a conscious effort by journalists to subdue it. What events make it onto the news? Herbert J. Gans tackles this question in his book, Deciding What's News. Gans sets out a list of enduring news values that journalists use to interpret the newsworthiness of a particular event or issue. For Gans, "enduring values are values which can be found in many different types of news stories over a long period of time (and) often affect what events become news" (Gans 2005: 39). The eight enduring news values Gans introduces are: ethnocentrism, altruistic democracy, responsible capitalism, small-town pastoralism, individualism, moderatism, social order, and national leadership (Gans 2005: 42). For the purposes of this thesis, the news values that are most salient with regards to reporting on terrorism are ethnocentrism, the valuing of one's "nation 
above all"; moderatism, criticism of "groups which exhibit what is seen as extreme behaviour"; and social order, the reporting of "threats to various kinds of order" (Gans 2005: 42,51,52). According to this set of values, terrorism is news because it affects the nation state, it involves extreme behaviour, and it threatens the social order.

\section{Short Term vs. Long-Term News Values}

A number of other elements are considered when determining how to approach a news story about terrorism. Journalists often focus on events and these events paint a broader picture of the issue at hand. For example, the over-reporting of single events of domestic terrorism ultimately shapes global conceptions of terrorism. Thus, short-term news values used to determine newsworthiness of single events overshadow enduring news values. Johan Galtung and Mari Holmboe Ruge explore how short-term news values affect coverage of long-term issues that are constantly developing in their paper, The Structure of Foreign News. Their study includes an analysis of over 1,200 foreign news articles to determine the common value factors that each embraced. This seminal work in journalism studies developed a number of news values that help answer the question: what is news? For an event to be considered news, Galtung and Ruge concluded that it had to have a combination of the following factors (Galtung \& Ruge 1965: 66-84):

- Frequency: When the event occurs and how it fits into the news cycle affects whether the story gets told.

- Amplitude: The impact a story has, whether it affects a large number of people.

- Unambiguity: An event that is not complex, but simple and clear, with a direct story line that is easily understood is more likely to be reported.

- Meaningfulness: If an event is "culturally proximate" or relevant. If people will find meaning in the story and relate to the story.

- Consonance: If a journalist expects an event to happen. If a journalist expects an event to unfold a certain way, the event will most likely be reported.

- Unexpectedness: If an event is new and unforeseen it will make the news. 
- Continuity: If an event has made news before, it will make news again to cement its newsworthiness.

- Compositional Balance: Its relation to other topics covered in the news determines a story's ability to transcend issues and will most likely be reported on.

- Elites: A story about celebrity or powerful countries will most likely make the news.

- Personification: Individualism or a story that tugs at the heartstrings will most likely make the news.

- Negativity: Bad news makes the news. Conflict or negative events occurring within society tend to be reported on.

The list of news values above determines how journalists make decisions about newsworthiness and the types of events that will be reported. Tony Harcup and Deirdre O'Neill updated this list of news values when they revisited Galtung and Ruge's study in 2001. Harcup and O'Neill updated Galtung and Ruge's list to include the following news values; the power elite, celebrity, entertainment, surprise, bad news/good news, magnitude of people, relevance, follow-ups, and newspaper agenda (Harcup and O'Neill 2015: 19).

Clustering the stories surrounding events that focus on a greater issue leads to what this thesis will refer to as an "issue narrative." However, because the stories reported on do not usually focus on the big picture - the grand issue - the "issue narrative" is told through intermittent events. For example, with regards to reporting on terrorism, ISIS came to public consciousness after posting the murder of American journalist James Foley online. This singular event established the group with a strong presence on social media. The terrorism narrative shifted from a 9/11, War on Terror focus to ISIS because of the singular events that emerged from 2014. However, as illustrated in the previous sections, ISIS emerged out of the War on Terror and its rise to public consciousness, when put into perspective, is expected. 
Observing the impact of short-term news values, Galtung and Ruge concluded, "journalists should be better trained to capture and report on long-term development and concentrate less on "events"'(Galtung and Ruge 1965: 84). However, given the 24-hour news cycle and the nature of news itself, journalists do not always have the time or resources to focus on long-term developments. According to Galtung and Ruge, issues that have long-term importance need short-term value factors to make them interesting again to re-enter the news cycle. This affects how an important and developing issue is told and how the public understands it.

\section{Duty Owed to the Public}

Journalists' ability to inform the public and create a democratic forum for information to be shared and discussed adds to their credibility. Kovach and Rosenstiel concluded that, journalists" "first loyalty is to citizens" (Kovach \& Rosenstiel: 52). The purpose of journalism, they argue, is "to provide people with the information they need to be free and self governing" (Kovach \& Rosenstiel: 5). For this to successfully take form, journalism must accept a number of commitments in addition to owing its first loyalty to citizens:

- Journalism's obligation is to the truth

- Its practitioners must maintain an independence from those they cover

- It must serve as an independent monitor of power

- It must provide a forum for public criticism and compromise

- It must strive to make the significant interesting and relevant

- It must keep the news comprehensive and in proportion

- Its practitioners have an obligation to exercise their personal conscience

- Citizens, too, have rights and responsibilities when it comes to the news (Kovach \& Rosenstiel: 5,6)

Journalism, thus, has a duty to the public and makes a number of commitments about the tasks it performs and the information and content that it produces and disseminates. Michael Schudson asserts that journalists "are uninsulated from public 
scrutiny - they have no recondite language, little fancy technology, no mirrors and mysteries to shield them from the public" (Schudson 2001: 165). The public should act as a check on journalism to ensure that journalists' obligation to the truth and loyalty to citizens is being met.

Existing journalistic ethics, values and principles help guide journalists in their everyday functions. However, these norms and principles are not always upheld. The wide array of criticisms discussed in the previous chapter provides examples of how journalists' personal biases emerged in their reporting, how extramedia influences affected the content that was produced, and how the objectivity norms were dislodged when reporting on terrorism after $9 / 11$.

The next section will provide an outline of journalistic routines and the process journalists use to investigate, write, and publish content on a day-to-day basis.

\section{Routines}

Reese and Shoemaker cite routines as the second level in their Hierarchy of Influences Model. Routines, they explain, "are those patterned, routinized, repeated practices and forms that media workers use to do their jobs" (Reese \& Shoemaker 1996: 105). Focusing on the day-to-day routines in the newsroom shines light on how news content is produced and the steps taken to investigate, create, and disseminate this content to the wider audience. This section will explore how day-to-day news work routines get interrupted when sporadic acts of political violence or terrorism occur.

Daily news routines show a correlation between the beat system, which divides news topics, issues, and the geographic areas about which journalists investigate and report. The stories that emerge from these beats are then circulated in the news (Hansen 
et al 1994: 562). Journalists follow a process when investigating a story, which includes determining its news value, finding sources to further interpret the event, aiming for balance by including different voices, and constructing a story based on factual information (Ibid).

Gaye Tuchman explores how routines "control the flow of work" in her paper,

\section{Making News by Doing Work: Routinizing the Unexpected (Tuchman 1973:} 110). Tuchman asserts that journalists "give accounts of a wide variety of disasters unexpected events - on a routine basis" (Tuchman 1973: 111). Journalism counts on unexpected events to occur daily. It is these unexpected events that make for a good news day (Ibid). Journalists must routinize their work to deal with an emerging news story or unexpected event. As Tuchman asserts, routines help journalists do their jobs by providing a method to sort through the vast array of stories that get thrown their way on a daily basis.

According to Tuchman, journalists use five categories when sorting through the news of the day: hard news, soft news, spot news, developing news, and continuing news (Tuchman 1973: 113). When categorizing events into these different types of stories, journalists rely on subject matter (Tuchman 1973: 116). For example, hard news consists of stories that can be interpreted and analyzed. Examples include political events, robberies, and murders. Soft news, on the other hand, consists of human-interest stories and features (Tuchman 1973: 113,114). The categorization of events and the ability for journalists to identify potential news stories in this way is the first step taken in routinizing their work. Events can even become prototypes by this stage and journalists go about reporting on them in a very similar manner. 
Shoemaker and Akiba A. Cohen defined hard news stories as "urgent occurrences that have to be reported right away because they become obsolete very quickly" and soft news stories as "usually non-scheduled events" that do not need to be published immediately and do not need to be timely (Shoemaker \& Cohen 2006 as cited in Reinemann et al. 2011: 4). The other categories presented by Tuchman fall somewhere on the spectrum between hard news and soft news.

Once a story idea falls into the lap of a journalist, the journalist begins to research by digging for background information, conducting interviews with sources, organizing and synthesizing the content gathered and finally, completing the story (McKercher et al. 2011: 40). In effect, most stories that get covered in the news follow this process of investigation. Deadlines that impose time barriers, budgetary restrictions, lack of resources, and wanting to break a story first factor into reporting. Although journalists follow the steps, they may take shortcuts to ensure that they get the story completed on time. That can have an impact on sourcing, an essential part in news work.

Journalists depend on sources to get their stories told and often develop a cache of sources on which they fall back when working on various topics. Exploring the relationship between journalists and sources is important because to whom journalists speak defines the version of news that audiences receive. Angela Phillips explores this relationship in her paper, Old Sources: New Bottles. Phillips argues "the official source (primary definer) holds the power, defines the relationship and ultimately the news agenda, by controlling the flow of and access to, important information" (Phillips 2010: 88). Journalists are constantly sifting through information and material that gets thrown at them. Phillips asserts that journalists tend to "create systems of 'filtration" " in order to 
deal with the vast amount of information they are presented in the day-to-day (Phillips 2010: 100). Thus, journalists “tend to prioritize known, 'safe' sources" when working on stories on tight deadlines (Ibid). Essentially, journalists decide what audiences hear and see, but sources shape the lens. Gans asserts that between journalists and sources, "more often than not, sources do the leading" (Gans 2005: 116).

The sources journalists use often give meaning to the news that is relayed to the public. Moreover, the heavy reliance on sources "provides opportunities for news management and manipulation" (Cheung \& Wong 2016: 1094). When covering developing stories such as terrorism or acts of political violence, official sources play an even greater role (Cheung \& Wong 2016: 1095). When reporting on terrorism, "government, political, and military sources" are depended upon to tell the story (Ibid). The next section will focus on how terrorism changes the routinized process of news gathering and sharing. In doing so, it will delve deeper into an ideological shift that occurs when one's own country is being attacked.

\section{Routines \& The Terrorism Story}

Journalists produce the news content the public consumes every day, but are also consumers themselves. Journalists live "in a cultural duality of journalism and society" where they are the audience of their own storytelling (Nossek \& Berkowitz 2006: 693). When dealing with routine news, such as political events, robberies, murders, and fires, journalists are more in tune with the processes of newsgathering and dissemination because what they are covering is familiar. Therefore, they are more likely to abide by the guiding principles that steer their work, such as objectivity and balance. However, objectivity and balance is a contested concept that some argue does not and cannot exist, 
for example, giving climate change deniers equal time or giving terrorists an equal voice in news coverage. However, when journalists are dealing with a "threatening situation such as terrorism" the issue becomes "culturally proximate" (Ibid). If it occurs in a remote area, journalists attempt to make sense of the incident by creating "links of meaning between actual events and the lived experiences of the audience" (Nossek \& Berkowitz 2006: 694). When a terrorist attack occurs close to home, professional routinized practices become subordinate to "the national identity of the journalist" (Ibid). Thus, "the more national the report is, the less professional it will be" (Ibid).

It is important to note, however, that coverage of terrorism is constantly developing, but initially starts as breaking news. During this time, journalists still follow routinized processes for newsgathering. The question of how journalists cover terrorism will be explored further in the subsequent chapter.

\section{Organizational}

How a newsroom is organized affects the content produced. Shoemaker defines an organization as "the social, formal, usually economic entity that employs the media worker in order to produce media content" (Shoemaker and Reese 1996: 138). Furthermore, it is bureaucratically structured, has clearly defined roles for its members, and is driven by economic goals (Shoemaker and Reese 1996: 147). When exploring news coverage of important issues, it is essential to ask how news structures affect the way that content is produced. Reese and Shoemaker list organizational structure as the third level in their Hierarchy of Influences Model. Journalists work for news organizations that further routinize the task of gathering and disseminating the news. Important questions to consider include: How is the newsroom structured? How is 
power exercised? What are the market and business goals? What are the policies and procedures? How are resources distributed? Exploring these questions will provide insight into how organizational factors influence content production.

\section{Organizational Goals vs. Professional Goals}

As stated above, a motivating factor for news organizations is economic profit. The pressure to meet profit expectations has led news managers to "emphasize achieving business goals over professional or journalistic goals" (Beam 2006: 169). An important aspect of journalism is the belief that it exists for the betterment of society and to inform the public on important decisions. Unfortunately, it exists within a business model and economic factors have an influence on how journalism is promulgated. In effect, the "occupational goals" may sometimes be in direct competition with "organizational goals" (Ibid). An old, but relevant, quote cited in a 1999 article for Neiman Reports describes the relationship between journalistic principles and profit-centric organizational goals:

Greed is wrecking the newspaper business. Budgets are being squeezed to the point that some newspapers no longer adequately report news about their communities. Media conglomerates that increasingly control the press care more about keeping their shareholders content and less about the quality of the news they convey or their responsibilities as special members of larger communities (Ureneck 1999).

While news organizations compete with one another for viewership, revenue, and most importantly, relevance and longevity in an ever-changing society, the competition for revenue affects journalists' ability to stay true to their ideals. Kovach and Rosenstiel, concerned with commercialization, note in The Elements of Journalism that, "news was becoming entertainment, and entertainment news. Journalists' bonuses were increasingly tied to profit margins, not to the quality of their work" (Kovach and Rosenstiel 2014: 4). 
Today's media is owned by a small number of powerful players whose main concern is profit. Media organizations are concerned with increasing their profits at the cost of producing innovative content. David Taras tackles the question of concentrated ownership in his paper, The Ownership Juggernaut. He argues that a real threat to democracy exists because "too much power in too few hands can endanger and distort the flow of ideas and the political process itself" (Taras 2015: 105). Robert McChesney voices similar concern in Corporate Media, Global Capitalism, epitomizing how the media is being used as an instrument to pursue commercial goals by exploiting the media's power of influence (McChesney 2003: 30). Working within this profit-driven framework means news organizations may be more vulnerable to profit incentives.

\section{Hierarchies of Power}

The roles or positions held by various newsroom employees also affect the content that is produced. News directors, producers, assignment editors, senior reporters and corporate management all have a role to play in the functioning of a newsroom. What is interesting is that in journalism, experience really matters and a journalist must prove him or herself and go beyond fulfilling their routinized duties in order to advance and make a name for themselves in the industry. The people who perform the day-to-day tasks in the newsroom also make "key newsroom decisions" (Barber \& Rauhala 2008: 46). Thus, it is important to explore how roles within a newsroom affect the production of news. 


\section{Policies, Procedures, and Guidelines}

Doug Underwood defines newsroom policy as "the means by which journalistic and business principles are implemented in the newsroom" (Underwood \& Stamm 1992: 305). He identified the four areas that newsroom policies must cover:

- Relations between the newspaper and its readers

- Relations between the newspaper and the community,

- Relations between journalists and management

- Relations between management and stockholders (Underwood \& Stamm 1992: 306).

The policies, procedures, and guidelines set by corporate management within a newsroom become blueprints for journalists to follow. As the news business changes these policies shift to accommodate. Ultimately, newsroom morale is affected depending on which aspects of the news business these policies promote: journalism or business (Stamm \& Underwood 1993: 528). News media trends show an ever-increasing move towards "business-oriented policies" that are essentially prioritized over "journalistic policies" such as autonomy (Stamm \& Underwood 1993: 529).

Despite this conflict between business policies and journalistic policies, in general, newsroom policies, guidelines and procedures are useful for journalists covering issues that are sensitive in nature, including terrorism. Furthermore, with social media becoming entwined with news coverage of major events, news organizations have amended their policies to guide journalists on how to use these channels to promote themselves, their organizations, and their stories (Opgenhaffen \& Scheerlinck 2014: 729).

In effect, news policies attempt to get out in front of technological innovation and the overabundance of information that exists online by creating guidelines on how to appropriately use social media and the Internet in a way that benefits the work journalists do without undermining it. Policies and guidelines help with the overall organizational 
structure as they shape newsroom culture by providing information on acceptable forms of conduct that journalists must adhere to.

\section{Extramedia}

This section focuses on three extramedia groups that can influence how certain issues get covered in the news. Journalists depend on official sources to tell important stories (Hall et al. 1978: 57). Although journalists ultimately decide what information to publish, when covering issues such as national security or terrorism, they rely on secondhand information from other institutions within society (Ibid). What this establishes is that room exists for manipulation of the news media. Herman and Chomsky argue that this paves the way for the creation of propaganda by the news media for private interests. They claim, "the powerful are able to fix the premises of discourse, to decide what the general populace is allowed to see, hear and think about, and to manage public opinion by regular propaganda campaigns, the standard view of how the system works is at serious odds with reality" (Herman and Chomsky: xi). Although the claim that the media are actively involved in creating propaganda is contentious, it can be argued that the news media "can sometimes be susceptible to the power of the institutional culture within which they operate" (Bell 2016: 22). With social media becoming a true force in society, the ability for extramedia groups to influence news coverage of major issues is higher than ever. This section focuses on how government, social media, and other groups have interceded in reporting on terrorism.

\section{Government}

Journalists pride themselves on their autonomy (Cook 1954: 7). It is a driving force in the work that they do and they fiercely defend it so they "work hard to maximize 
their autonomy" (Ibid). However, it is no surprise that various groups within society, from public relations professionals to politicians, vie for the media's attention and attempt to influence coverage. Timothy E. Cook explores the relationship between the media and the government, arguing that governments "dictate conditions and rules of access and designate certain events and issues as important by providing an arena for them" (Cook 1954: 12). Journalists "decide whether something is interesting enough to cover, the context in which to place it, and the prominence the story receives" (Ibid).

When reporting with a national security focus, official government sources are especially useful. The media cannot tell the story of terrorism without the help of the government. Since most governments recognize "the importance of convincing their subjects of the appropriateness of key governmental policies," mainstream news media have become an important vehicle, allowing them to use the news to "shape public opinion" (Epstein 1977: 67). Journalists are aware that other institutions within society attempt to spin news in their favour. Despite attempting to maintain legitimacy and credibility journalists have to use information from official sources to inform their audiences on important national security issues. Similarly, journalists also have to rely on official sources when reporting on police or crimes. The main reason for this is the information pertaining to these incidents is confidential and information is not easily accessible elsewhere. Michael Schudson argues that journalists rely on official sources (Schudson 2008: 52). Thus, these sources have a lot of power to define issues and thus set the public agenda.

Official sources wield a lot of power, specifically in terms of "setting the news agenda, defining the parameters of debate and shaping ideology" (Matthews 2013: 
298). Ultimately, the credibility that is awarded to official sources by journalists makes them recurring voices within news stories. These recurring voices are ones that already wield power within society: "governments, police, and large corporations" (Ibid). Therefore, content produced "is dominated by accounts from those in positions of power and authority" (Matthews 2013: 299).

Since government has a direct interest in shaping public opinion in order to pursue its own policies, it is important to discuss just how much leeway government sources have to present their versions of the truth in the media. Furthermore, when journalists must rely on government sources for information on terrorism, an important question to ask is how much their co-operation or choice not to co-operate with the media affects coverage. This question and others like it will be discussed further in the next chapter of this thesis.

\section{Social Media}

The technological era has played a significant role in transforming the way information is gathered, produced, and disseminated. Moreover, the wave of globalization has resulted in an integrated world where the cross-border flow of information has allowed all types of content to infiltrate airwaves. The result has been to become distinct by creating a consistent cultural identity.

Social media directly affects the way that journalists do their job. On the most basic level, social media impacts the sheer amount of information available, the interconnectivity between journalists and their audiences, and the ability for journalists to collect and gather information from all parts of the world. Social media has created an environment where groups and individuals can set their own agendas, brand themselves, 
and promote their messages without having to go through the news to do so. This wide reach has affected journalistic processes by "challenging editorial decisions about what to select and reject as news stories" (Bro and Wallberg 2014: 447). Peter Bro and Filip Wallberg discuss the transition from the news media's traditional role as gatekeeper of information with respect to the rise of the Internet. They argue that the digital age has introduced a "new generation of gatekeepers" (Bro and Wallberg 2014: 449).

Edson C. Tandoc Jr. and Tim P. Vos follow this line of thinking in their paper, The Journalist is Marketing the News. They assert that the growing number of people using social media such as Twitter, Facebook, and YouTube has prompted news organizations to adjust their structures and procedures in order to appeal to wide audiences (Tandoc Jr. \& Vos 2016: 950). The sheer volume of information disseminated through these channels threatens the media's role as gatekeeper of information (Ibid). In order to adapt to these technological changes, the news media have "embraced new forms of audience feedback and new platforms for information dissemination, heeding audience preferences and habits to keep them from migrating to other sources" (Tandoc Jr. \& Vos 2016: 950). In effect, audiences have much more power in determining what they see in the news today than they did prior to the emergence of the Internet (Ibid). Although there is a clear benefit to having a two-way conversation, it becomes troubling when some important stories are covered less because priority is given to stories that would attract larger audiences.

Furthermore, various groups using social media to brand themselves have “become key players in disseminating content” (Tandoc Jr. \& Vos 2016: 952). Terrorist groups have also benefited from social media as they are now able to circumvent 
traditional messaging channels and are no longer exclusively reliant on news media. ISIS, for example, has etched its footprint as the first social media terrorist group. Laura Huey discusses this phenomenon in her paper, This is Not Your Mother's Terrorism. Huey asserts that social media has allowed terrorists to rebrand and reach out to potential recruits by using "social media, rap videos, counterculture magazines, clothing and other forms of propaganda aimed at disaffected youth" (Huey 2015: 1). Today, ISIS members can be found on all social media platforms. Ultimately, the lens through which the group is seen and the available information about the group corresponds to an image crafted by its membership and shared with the public.

Furthermore, there is a danger associated with on-the-ground reporting of ISIS. In areas where the group has control, journalists are prevented from getting hands-on access. Some of the content relied on by journalists, thus, may be clear ISIS propaganda

Thus, journalists at times are relying on content that is produced by the terrorist group for clear propaganda purposes. For example, many news outlets around the world report heavily on beheadings videos of hostages, specifically when they are Western hostages. Journalists interviewed for this thesis stated that ultimately news judgment is used to determine the newsworthiness of these videos.

This brings forth a slew of other considerations journalists must make when reporting on the terrorism story.

\section{Ideological}

Mainstream media and the messages that get produced and disseminated on the day-to-day are largely “dominated by Western culture, particularly the U.S.” (Turan et al. 2009: 55). It is important to take note of the social system within society in order to 
understand how messages delivered through news content have been impacted by the cultural values of the country where they originated (Ibid). Edward Said discusses the power of imparting Western perceptions on other societies through his orientalism theory. For Said, "orientalism can be discussed and analyzed as the corporate institution for dealing with the Orient - dealing with it by making statements about it, authorizing views of it, describing it, by teaching it, settling it, ruling over it: in short, Orientalism as a Western style for dominating, restricting, and having authority over the Orient" (Said 1978: 3). Furthermore, Said argues that with time, the Orient starts personifying the traits, which have been attributed to it by the West, leading to a merger between "imaginary" and "real" depictions of itself (1978: 5).

Today bookstores in the U.S. are filled with shabby screeds bearing screaming headlines about Islam and terror, Islam exposed the Arab threat and the Muslim menace, all of them written by political polemicists pretending to knowledge imparted to them and others by experts who have supposedly penetrated to the heart of these strange oriental peoples. Accompanying such warmongering expertise have been $\mathrm{CNN}$ and Fox, plus myriad evangelical and right wing radio hosts, innumerable tabloids and even middle-brow journals, all of them recycling the same unverifiable fictions and vast generalizations so as to stir up America against the foreign devil (Said as cited in Al-Zo'by 2015: 222, 223).

What has emerged alongside terrorism has been the idea of an ideological war between the East and the West - between Islam and Western values - a Clash of Civilization of sorts. The Clash of Civilization theory developed by Samuel Huntington in 1993 argues, "nation states will remain the most powerful actors in world affairs, but the principal conflicts of global politics will occur between nations and groups of different civilizations. The clash of civilizations will dominate global politics. The fault lines between civilizations will be the battle lines of the future" (Huntington 1993: 22). 
Examining $9 / 11$ and the emergence of ISIS, Huntington's theory has largely been mirrored in news coverage. Despite the fact that terrorist groups do not constitute a civilization, and do not represent the entire religion of Islam, media coverage of terrorist attacks have purported to address and debate the ideological differences between Islam and Western culture. Although this aspect of the Hierarchy of Influences Model will not be given extensive attention in this thesis, it is important to mention that media coverage of terrorism has ideological implications and is rooted in perceptions of Western culture.

\section{Conclusion}

As can be seen from the literature presented above, many different factors influence the way journalists tell stories. Criticism of media coverage of terrorism is extensive. However, breaking down how the media covers major stories provides insight into how news works and the influences that shape the way stories are told. Scholarly studies show journalists will strongly disagree with the notion that they intentionally produce propagandized content that favours government, organizational or private interests. Autonomy is the number one goal for journalists and their aim is to produce content that will inform audiences. Journalism touches on all aspects of society, it is a benchmark of democracy, and it functions multilaterally; relying on information from all segments of society to tell the most important issues that affect the largest number of people.

By using the framework developed by Reese and Shoemaker, this thesis strives to pinpoint how news coverage can be influenced. The following section will provide details on how journalists deal with some of these influences in their day-to-day 
operations. Furthermore, it will give an overview of how journalists are responding to the challenges of covering terrorism, specifically related to ISIS. 


\section{Chapter Four}

\section{Canadian Journalists Discuss Media Coverage of ISIS}

Academic literature on media coverage of terrorism since $9 / 11$ has mainly focused on journalism's shortcomings in presenting unbiased objective analysis. Criticism of the media's coverage of the events that unfolded post-9/11, including the invasions of Afghanistan and Iraq by the U.S. is case in point. However, as described in Chapter Three, a real understanding of how journalism works is necessary when exploring how issues are covered. Understanding the process of journalism can deflect some of this criticism. Moreover, to understand why stories are told they way they are, it is essential to discuss the many factors that influence the newsgathering process. ISIS is the newest terrorism threat facing the West. Journalists grapple with how to cover it on a regular basis, from what to call it, to how to discuss it, to simply understanding the complex environment in which it emerged. David Common (2016), host of the CBC's World Report, highlights this difficulty for journalists:

It is not a two-sided conflict in Syria, nor in Iraq. It is not ISIS versus everybody else. It is not ISIS versus the Assad regime. It is not even ISIS versus the Free Syrian Army. There are so many factions in there that it is an extremely complex tale. I wont pretend to fully understand it. I think and I hope that I understand it a bit better than most people, but it is a very convoluted thing to try to explain. People understand things much easier when it is not jagged with as much nuance.

This chapter is built around interviews conducted with seven Canadian journalists who describe their experience covering the complex tale that is ISIS. It will examine articles published by these journalists since January 1, 2016. It is important to note that this is not a formal analysis although correlations between the answers provided from interviews and the content produced by these journalists will be sought and examined. To 
find these articles I used Google News and searched the journalists names with the key words terrorism, and ISIS. This chapter will present information using Reese and Shoemaker's Hierarchy of Influences framework discussed in the previous chapter. By categorizing interview content, the various influencers shaping the ISIS story will emerge.

In addition to Common, from the $\mathrm{CBC}$, I interviewed: Susan Ormiston, a foreign correspondent with more than 35 years of experience; Jack Nagler, the Director of Journalistic Public Accountability and Engagement; and Derek Stoffel, the Middle East correspondent. From the Globe and Mail, I spoke with Paul Koring, the Washingtonbased International Affairs and Security correspondent. From the Toronto Star, I interviewed Foreign Affairs reporters Olivia Ward and Marco Chown Oved. These journalists were chosen because they work for media organizations with significant saturation: The Globe and Mail is the most read newspaper in Canada with a readership of 3.5 million (Globe and Mail 2017). CBC News is the largest news broadcaster, and The Toronto Star is the largest daily newspaper in the country (Toronto Star 2017, CBC News 2017). Moreover, the journalists interviewed have covered terrorism throughout their careers, have reported the ISIS story, and are equipped to discuss the evolution of the terrorism narrative. Together, these journalists have more than 180 years of experience. Their knowledge, expertise, and insight into how the terrorism story has evolved provide a perspective that is grounded in experience.

\section{The Name Game}

The first challenge with covering ISIS is deciding what to call it. There are multiple names used by politicians, journalists, and the public to refer to ISIS including 
Islamic State of Iraq and the Levant (ISIL), Islamic State, and Daesh, the Arabic equivalent of the acronym ISIS. Names are important. How a group is defined and labelled correlates to how its story plays out in the media. A number of media organizations have had a difficult time deciding on what to call the group. The $\mathrm{CBC}$ continues to use ISIS. Nagler (2016), the CBC's Director of Journalistic Public Accountability and Engagement, says:

I will say right up front that it is always an open and ongoing conversation. I mean we have stuck with ISIS, but there is no ideological determination that it should be ISIS and that it can't be something else. Every time there is a reason to reconsider it we reconsider it.

By and large, each option presented above has its positives and its negatives. For the CBC, Nagler asserts, using the term ISIS "provided the best balance of being an accurate description of what the organization is and most importantly it is the term that we think offers the most clarity to our audience. When we use ISIS, everybody knows who we mean." Koring (2016), who works for The Globe and Mail, but is speaking on behalf of himself and not the organization, agrees:

I generally think that organizations have the right to call themselves what they want. And for news organizations to adopt other terms that reflect the views pejorative or otherwise of other people of an organization is a mistake. So if the Islamic State wants to call itself the Islamic State, and prior to that ISIL, and prior to that ISIS... whatever the lexicon is, I'm not sure that it's a good idea to refer to them by some other term, particularly a term that's regarded in the Arab world as derogatory.

The Toronto Star is the only Canadian news organization that has chosen to stop using ISIS and switch over to using Daesh instead. The term Daesh is the Arabic translation of the acronym ISIS, however it bears close resemblance to Arabic term Daes, an insulting word that "means to tread underfoot or crush" (Ibid). Oved (2016) 
says that the decision is sound because of the inherent conflation of a whole religion with a violent terrorist organization.

If you're going to be referring to this radical, niche violent group all the time in the paper why would you use the term that includes the word Islamic in it? It's a way of removing the reference to the religion every single time you talk about the terrorist group. I think that is not an unimportant consideration considering how many people - all you have to do is read the comments or look on Twitter - automatically conflate terrorism with Islam.

The discussion about what to call ISIS is not a challenge for journalists alone. Politicians are also grappling with what name to use, resulting in a shift towards using the term Daesh to refer to the group. The French government, for example, has been referring to the group as Daesh since September 2014 and encouraged its journalists to do the same (Stone 2015). The British government has followed suit, switching from ISIL to Daesh in December 2015 (Osborne 2015). The United States government is officially using the term ISIS to refer to the terror group (Tomlinson 2017). A memorandum released by the Pentagon outlining the change from ISIL to ISIS stated, "We view ISIS, ISIL and Daesh as interchangeable terms for the same thing. ISIS is the term most known and understood by the American public, and it is what our leadership uses. This memo simply aligns our terminology" (Ibid). The Canadian government stopped referring to the terror group as ISIL or ISIS and opted for Daesh instead in August 2016 (Canadian Press 2016). Ralph Goodale, Public Safety Minister, stated that the reason for the change was because "ISIL is neither Islamic nor a state" (Ibid).

Names have political and social implications that affect the way that audiences understand the issue. Identifying the best term remains in dispute. For the purposes of this thesis the decision to use ISIS was cemented in the journalistic tradition that Koring outlined in his quote: organizations are called what they want to be called. How using 
ISIS to reference the group can affect the framing of terrorism is yet to be seen; the story remains so new. However, it is important to note that journalists and media organizations have put consideration, thought, and debate into naming the group. That being said, it is unclear if the names they use have impacted the way the journalists perceive or tell stories about the terror group. Depending on how the ISIS story is resolved, the implications of using one term over the other will most likely be researched and analyzed in the years to come.

\section{Individual}

How journalists perceive their roles and the guiding principles that establish their professional values impact the way they tell stories; the aim to be truthful and fair in their reporting makes the ISIS story especially difficult to navigate. As Common expressed, the ISIS story is complex. Journalists see themselves as messengers, as purveyors of truth, but it is very difficult to report what is happening in Syria and Iraq because ISIS has targeted and killed journalists. Furthermore, governments are keeping on-the-ground operations in Syria and Iraq confidential for the most part. The government publishes news releases about on-the-ground fighting at times, however, these releases are not in depth and do not provide enough necessary information.

Koring (2016) suggests the role of a journalist has not changed. He asserts, "the reason journalists exist is because everybody else is too busy living their lives to spend all their time sifting through raw data. So journalists are paid directly or indirectly to turn data into information." When covering ISIS's terrorist agenda, the Internet is ripe with content. With the social media era, there is more information than ever before available at the touch of a button. As noted in the previous chapters, ISIS's success stems from its 
ability to strategically use social media to further its aims. ISIS is independent of the media, producing and publicizing its own propaganda on sites such as Twitter, Facebook, and YouTube. Further, technology has also allowed people on the ground, bearing witness to the atrocities unfolding before them in Syria and Iraq, to describe what they are experiencing via social media. Synthesis of this content, context, accuracy of information, and telling the story in a responsible way proves difficult. Ward (2016) says:

Your duty as a journalist is to record the events... but you don't want to give (ISIS) what has been called the oxygen of publicity. By writing about it you think you are showing the absolute horror of the subject and making the world pay attention but on the other hand, you are also alerting people who are disturbed enough to think that this is wonderful and to be more determined to get involved in the cause.

Ward is referring to the possibility of a "contagion effect," where the publicity of one terror attack can trigger other individuals to plan or to follow through with subsequent attacks (Phillips 1794: 352). Gabriel Weimann and Conrad Winn analyzed media coverage of terrorist acts and subsequent attacks that followed and determined that "considerable evidence of a contagion effect wrought by coverage" existed (Weimann and Winn 1994: 277). Paul Marsen and Sharon Attia analyzed suicide terrorism post-9/11 and its apparent surge in popularity in the coming years as a terrorism tool. They concluded that media publicity of suicide bombings could act as an influence for others.

Positive media coverage of suicide bombing in areas of recruitment may act as effective advertising campaigns for volunteers, whilst negative publicity may nevertheless encourage suicide bombing because it still gives bombers precisely what they want - media attention. This is not to say that the media can cause suicide bombing any more than sex (as opposed to HIV) can cause AIDS; it is at most a vector of transmission that can precipitate its spread (Marsen and Attia 2005: 153). 
When covering ISIS specifically, the dilemma that emerges for journalists is putting into perspective the heinous crimes that are being committed without letting their moral judgments interfere with how they tell the story. Stoffel (2016) admits:

In terms of balance, this is not a story where we can do that. I can't go and get a quote from ISIS to verify if what is being said about them is true. Fair is a word I would use over balance... In a story where you've got a terrorist organization that brutally murders people, how do you be fair? I think it is more about getting your facts right.

Jack Fuller tackles the concept of fairness in his article News Values: Ideas for an Information Age. Fuller acknowledges that journalists often attempt to describe their work as fair (Fuller 1996: 83). However, he states, "any deep consideration of the idea of fairness leads eventually to questions of distributive justice" (Ibid). For Fuller, the question is "whether fairness means letting everyone compete on the same terms, regardless of the advantages and disadvantages they bring to the competition" (Ibid).

Common (2016) says journalists should aim to provide an unbiased perspective while explaining what is happening, so that people can actually engage with the story. When reporting on ISIS, it is important to consider who your audience is and how your story will resonate with them. Common says, "There is no point in telling a story that gets it absolutely right (fact wise), that is either too boring or not presented properly, that nobody is going to get. If nobody understands it then all of your work is gone to waste." The conflict in Syria and Iraq and the atrocities perpetrated by ISIS receive extensive media coverage in the West, but the angle must be such that it engages and remains palatable to North American audiences. Ormiston (2016) suggests, "People are concerned about what affects them, and the constant struggle for journalists who are reporting on foreign affairs is to make it relevant to people who live in relatively safe and secure countries." 
As shown above, when covering ISIS, journalists remain committed to providing factual information and reporting responsibly. However, as a result of the deficit of verifiable information, the scale of the war crimes and abuse committed by or attributed to ISIS, and the physical challenges of reporting, these influences weigh on journalists and their reporting. It becomes difficult to remain neutral; it becomes difficult to not participate in the events and take sides, and not be used as tools for terrorist propaganda or recruitment. These challenges are met with diligence; journalists remain grounded in their training. If the story is newsworthy and important, they report using the investigative methods used to report any story.

\section{Routines}

Routines play a significant role in how stories are told. As noted in the previous chapter, routines "are those patterned, routinized, repeated practices and forms that media workers use to do their jobs" (Reese and Shoemaker 1996: 105). Journalists use routine to support their reporting tasks, triaging the types of stories (Tuchman 1973: 111). Journalists itemize and prioritize potential articles and news content by conducting background research, interviewing sources, organizing and synthesizing content, and finally developing the story (McKercher et al. 2011: 40). Based on the interviews for this thesis, time constraints, heavy workloads, and access are the biggest challenges for journalists reporting.

\section{Access}

For the majority of the journalists interviewed, the biggest challenge of covering ISIS is access. The use of terror to control the area, and the ongoing conflict, requires a level of commitment to the job that makes journalists question the value of pursuit of a story that could be terminal to the story teller, as ISIS targets journalists and 
propagandizes their brutal murders. In an execution video released by ISIS in December 2015, a Syrian reporter is seen "handcuffed to metal railings, with a camera hanging around his neck before the device detonate(s)" (Daily Mail 2016). In this video, the "ISIS narrator says the group is facing a media war" (Ibid). ISIS's means of exerting control dissuades journalists from getting close to the conflict. This can introduce misinformation because of the reliance of information from other sources who may introduce bias.

Ormiston (2016) stresses that the "More time you spend in the area you are reporting on, the more you are influenced back home to able to get behind the spin and provide your own context about what's happening." She highlights just how important firsthand knowledge of a situation is in an anecdote about her experience reporting from Kandahar, Afghanistan. Ormiston (2016) was able to report from Sarposa prison, one of the most prominent prisons in Kandahar City. There, she discovered that Canada had a huge role in developing the correctional system that was implemented. This was previously unknown and unreported information because the Canadian federal government's participation and operation were confidential. In June 2008, militants broke into Sarposa prison (CBC News 2008). The breakout was heavily reported in the media, however the significance of the event as it pertained to Canadian military involvement in the area was lost because information was being withheld (Ormiston 2016). Ormiston (2016) says Canadian Forces were declaring the breakout was "no big deal." However, thousands of prisoners, most of them Taliban members, had broken out and Canada largely invested in the upkeep and day-to-day operations of the prison, spending more than $\$ 1$ million to improve the facility (CBC News 2008). Ormiston says if it were not for her 
being there a year before the breakout, she would have not known the significance of this event:

Had I not been to the prison, I would've had no way of evaluating the spin on the story from those in power who had much to lose when it was exposed that this was a huge blow their security perimeter. It is a very simple description but we seem to forget it. We seem to be doing so much sitting at our desks, trolling the Internet, rather than going out and getting texture and context and characters on the ground.

Nagler (2016) confirms the biggest challenge in covering ISIS is access. For him, the biggest consideration is to "Look out for the interests of (our) journalists so that they don't put themselves into material harm."

The targeting of Western journalists and the propagandizing of their deaths is a marketing strategy ISIS knows well. The kidnapping of Western journalists serves to discourage other journalists "from reporting on the Syrian civil war and ISIS activities, thus limiting the flow of information about the region. In such an information vacuum, ISIS has greater power to shape its own narrative" (Zakreski). Nagler (2016) says, "Obviously you want as much access as you can... but it is an extremely dangerous thing to do. We don't want to put (our journalists) in harm's way lightly and we want to make sure they are safe." Common (2016) agrees:

It's very difficult for news organizations to actually go to a place like Syria. You face extreme threats... Journalists have been killed covering ISIS, journalists have been kidnapped covering ISIS, journalists have been tortured covering ISIS. So there is no doubt that it is much more difficult.

For journalists who have spent decades covering the national security beat, this lack of access to ISIS presents a real challenge when reporting. Ward (2016) asserts:

There is absolutely no substitute for being somewhere... Once you get there, even if you have preconceived notions, if you are responsible journalists, you are completely open. You are like a human recording machine, you just kind of suck it all in and process it. 
Ormiston (2016) says that this lack of access is "quite distressing." She states, "going into that environment with ISIS and a number of other players is so risky that even the big broadcasters, the ones who have shone a light on Syria so consistently, have gone in less and less. I believe it's an uncovered war."

Stoffel (2016) agrees, access affects how journalists report on terrorism. "Most of the time, I'm covering a war without having any access to it. It's just too dangerous most of the time for us to go there. It's because of the nature of this particular fight," he says. In the past, Stoffel recollects, journalists weren't considered enemies. Now that ISIS targets journalists as means to control the message, "it restricts us obviously," Stoffel says. Covering the story from afar affects the way journalists cover stories but according to Stoffel, when it comes to ISIS, "there is no better way to do it." For example, in his piece Inside the fight to free Mosul, Stoffel notes that March marked the first time "a handful of international news organizations got this close to the fighting" since 2014. News organizations were able to get close because Iraqi forces liberated the city of Mosul, which was under ISIS rule until January 2017 (Stoffel 2017). Until then, ISIS's strong censorship and control of communications made Mosul a "blackhole" in terms of the information that was coming out of the city (Reporters Without Borders 2016).

The lack of firsthand access has resulted in journalists depending a lot on other sources of information such as Twitter for eyewitness reports, citizen-shot videos from on the ground, ISIS-released content, expert opinions, and observations. When reporting on the Nice Attacks where a truck ran over people gathered for Bastille Day celebrations, Oved (2016) used social media to provide context in his piece Fallout from attack 
unveils ugly side of Nice. Oved referenced "several videos posted to social media" to capture heroic acts by people after the attack (Oved 2016). As journalists are unable to go to the areas under ISIS control in Syria and Iraq, the focus of reporting is redirected to terror acts and home grown terrorism inspired by, or orchestrated by, ISIS in the West. As an attack by a terrorist group can provide many inches of text it does not adequately reflect the activities or climate of attacks occurring where the battle is being fought. A side result of domestic reporting is that ISIS gains attention in one arena, while a chasm develops regarding coverage for the war on the ground; as Ormiston argues, it becomes underreported and almost hidden.

While ISIS is defined globally by its terrorist activity abroad, for audiences to get a true understanding of the group, it must be informed about its activities within the region it is trying to occupy. The West is fighting ISIS in the region and it appears ISIS is retaliating by inciting terror within the borders of their opponent's nations. When terrorist attacks perpetuated by ISIS occur in the West, the media has a clear routine for documenting and reporting on these attacks. However, when reporting on the group itself, and its activities within Syria and Iraq, there is a higher reliance on official sources such as government documents and national security experts to explain the encounters. Stephen Kinzer, a senior fellow at the Watson Institute for International Studies at Brown University, argues that this reliance on official sources means accepting a narrative that has been constructed by government:

Reporters who cover Syria check with the Pentagon, the State Department, the White House, and think tank "experts." After a spin on that soiled carousel, they feel they have covered all sides of the story. This form of stenography produces the pabulum that passes for news about Syria... We have almost no real information about the combatants, their goals, or their tactics (Kinzer 2016). 
Other sources of information such as citizen-provided videos, content produced by ISIS, and information found on social media is difficult, if not impossible, to verify. This reliance reflects the psychological battles for control over the message journalists have when they are reporting on terrorism. It would appear that ISIS, because of its success in keeping journalists out of regions it controls, has garnered the power and authority to define its brand, and control the message. Using "journalists as ammo" for its own propaganda (Zakreski) has been a valuable tool to maintain a stranglehold on information about its activities; its direct targeting of journalists suggests how other terrorist groups in the future deal with the media (Ibid).

\section{Investigative Processes}

As shown in the previous section, access to ISIS strongholds is very difficult for journalists. Thus, journalists must find new ways to get information. Despite limited access to Syria and Iraq, Western journalists are at the frontlines when an act of terrorism occurs abroad. A flux of coverage ensues every time a terrorist attack occurs in the West. However, over-reporting domestic terrorist acts has negative ramifications for the overall telling of the terrorism story with respect to how terrorism is covered over the long term. As noted in the previous chapter, Galtung and Ruge concluded that journalists should focus less on short-term events and more on long-term developments (Galtung and Ruge 1965: 22). Focusing on events and spot-news without paying closer attention to the long-term developments and providing in-depth analysis means short-term news stories such as terrorist attacks can be "presented out of context" (Oeffner 2005: 6). 
Ormiston (2016) says a "disconcerting trend has developed with the rise of ISIS." She argues that when a terror attack first occurs, the first question media organizations ask is whether it is ISIS-related:

If the answer is yes, the story gets more import, more resources, and more time. And if the answer becomes no, it gets immediate attention and reporting but falls off the interest level faster in terms of how much resources the media devotes to it.

Ormiston (2016) argues the result is a narrower lens used to investigate terrorism incidents. Instead of looking at the issue from a more open lens, the investigation process for journalists has become very obvious. When ISIS perpetrates a terror attack, Ormiston (2016) suggests the investigation process consists of "finding the cells, finding the connections, and finding the influences." If it is not ISIS-related, the question becomes, "Was it guns, was it violence, was he crazy?" Ward (2016) agrees that when reporting a terrorist attack there are a number of important angles that journalists must cover. She asserts:

The first angle is of course the terrible damage done and eyewitness reports. Then there's the national security angle, which asks what happened and why it happened. Then there's the story, which fascinates me, of the people who perpetrated the act itself.

Following the Paris Attacks, for example, Oved (2016) focused his piece, Attack on Paris cafe shatters family on eyewitness reports and the terrible damage that was done. His pieces also focused on the national security angle and the perpetrator angle as well. Oved (2016) discusses how journalists are barraged with information after a terror attack. If the terror attack occurs in a Western country, most news organization will send a reporter to the scene. "When it's a plane ride away, it's not like you're showing up and there's no information. Typically (journalists) know the basic outline of what's happened 
before (they) get on a plane," Oved says. Oved wrote the first story in the newspaper's coverage of the Paris attacks from his desk in Toronto, before heading over to France.

Ormiston (2016) sees an inherent difference when covering a specific act of terror versus a broader story on ISIS itself. She states, "When you're covering a specific act of terror it's so immediate, unfortunately you fall back on the voices you know and have heard from before, which necessarily aren't the most well informed. They're just the ones who are expedient at the moment which is again a weakness." She goes on to discuss how sources can influence journalists' pursuit of a developing story on active terrorism. She says:

When in active terror, you are just simply going for the national security advisors who can tell you something about what they know about the cell that's operating. And so that is very institutional; you're listening to talking points. It's people who know their stuff but they're coming at it from a perspective of revealing what they want the public to know, not what's out there. So they are shaping your story as you talk to them.

Present-day terrorism as perpetrated by ISIS is being fought in two ways: abroad

and at home. For journalists, one story is out of reach because of the dangers associated with reporting from the frontlines. The other is much more accessible. Furthermore, the approach taken to investigate domestic acts of terror in the West is routinized. As Ormiston and Ward explain, journalists have developed a formula for covering terrorist attacks in the West. This is expected because there are more stories that come about as a result of domestic terrorism, as domestic terror attacks are often "culturally proximate," relating to a number of people who can "find meaning in the story" (Galtung and Ruge 1965: 66-84). Ultimately, it is these events that shape the terrorism narrative because they impact lives as they happen. 
Journalists are adapting to the changing environment of interconnected news. When covering domestic terrorism or terror attacks occurring in the West, journalists follow regular newsgathering processes. The Internet has given journalists another avenue for newsgathering as Oved notes, however journalists still rely on sources to shape their stories. When covering terrorist attacks, sources include eyewitness reports, police sources, expert opinion from national security experts, and firsthand observations. However, when reporting on ISIS terror in Syria and Iraq, journalists have to depend on "government, political, and military sources" (Cheung and Wong 2016: 1095). As noted in the previous chapter, journalists "tend to prioritize known, 'safe' sources"' (Phillips 2010: 100). Thus, more often than not, the terrorism narrative is being shaped through the same voices. Journalists have adapted by thinking outside the box when it comes to reporting on stories occurring inside Syria and Iraq. For example, using citizen videos and eyewitness accounts, going on Twitter and Facebook to learn of new developments from within the country, and so on. However, the difficulty here is ensuring the accuracy of the information being presented. Journalists continue to find new ways to get information, however it comes with the caveat that this information may not always be verifiable.

\section{Organizational}

When it comes to terrorism, a national security issue, the most important consideration is the resources that media organizations are investing in foreign affairs coverage. An important question to ask is how the professional policies and guidelines that the news media use to create a cohesive working environment in the newsroom affect the overall narrative of terrorism coverage as it relates to ISIS. Moreover, it is important to understand how power hierarchies within the newsroom affect the way stories get told. 


\section{Resources Spent on Foreign Affairs:}

It is not surprising that most news organizations are cutting back on their foreign coverage (George and Rishikof 2011: 305). These cutbacks have affected coverage. "The reality is that a single foreign correspondent, even one who happens to be close to the scene of the crisis, often has to rely heavily on local or regional media coverage to put together a complete story" (Ibid). Ward (2016) states that at times the best sources are reporters from the area where the terrorist attack occurred that have cultivated police sources. In large part, the cutbacks on foreign coverage have to do with resources and the transitional period that the media is in. Koring (2016) says:

My organization, like every other big newspaper in the Western world, has cut back on its foreign coverage. Individually, and I think more broadly, if you look at Western media organizations; foreign coverage is down in terms of having people on the ground.

However, Koring (2016) asserts technological innovation has allowed for "more information to come out of far more difficult places than it ever used to be." He argues:

The caveat is it used to be if you weren't physically on the ground... you wouldn't know (anything). Today, people in the middle of Aleppo, Syria are engaging in two-way communication with the outside world. I think broadly we know more about the war in Syria even though there are fewer outside journalists on the ground.

Because of cuts to foreign coverage, most Western journalists have been covering the conflict inside Syria and Iraq from afar. When it comes to acts of terror occurring in the West, news organizations send reporters to cover the events on the ground. Oved (2016) states:

The sort of structure of daily news is such that we spend a lot of resources in the immediate aftermath of the attacks to go these places... and talk to victims or relatives of victims or people who were simply bystanders at these attack points. 
For Oved (2016) coverage of the immediate aftermath of an attack is very focused.

"I don't think (the media) spends anywhere near the amount of time and resources in trying to understand the people who are perpetrating these attacks," he says. Furthermore, the lack of resources also affects how stories on terrorism and ISIS are covered in the Middle East. Ormiston (2016) affirms the decision to undercover the Middle East is not just about access, but also about resources available. She says:

We have so fewer resources in the Middle East. I think we under-cover that part of the world. I think CBC under covers it, I don't think it's any surprise for me to say that. I constantly pitch to go for periods of time to be there. We have a Middle East bureau based in Jerusalem, it's one person... it's not enough. We have some freelance help in Beirut, Lebanon, but not enough... It's not conscious; it's a resource decision.

\section{Organizational Policies and Guiding Principles}

As observed in Chapter One, terrorism is a fraught term. It is difficult to define and difficult to understand. This has led media organizations such as The Toronto Star, CBC News, The Globe and Mail and so on, to create policies and guiding principles for journalists when covering terrorism to ensure that there is continuity and cohesiveness in reporting throughout the organization. From determining what name to use to refer to ISIS, to when it is acceptable to use the term terrorism, media organizations have been grappling with these decisions and attempting to highlight their stances in policies to help guide its journalists. Stoffel (2016) asserts, "You will never hear me use the word terrorism or terrorist unless I'm quoting someone." He says people complain that the $\mathrm{CBC}$ does not use the terms beyond direct quotes.

The CBC ombudsman responded to a complain in 2013 about the organization's refusal to refer to the attack at the Westgate Mall in Nairobi, Kenya as an act of terrorism and the perpetrators as terrorists. In CBC's response, managing editor Jennifer Harwood 
explained, "It is a long standing practice to use the words terrorist or terrorism when they are attributed by others. To describe the act or individual as 'bomber,' 'militant,' 'extremist,' or 'gunman,' for instance, let the viewer, reader, or listener make his own judgment about the nature of the event" (Enkin 2013).

Furthermore, the $\mathrm{CBC}$ noted that this practice has been in play for more than 30 years because "the use of the word can be highly politicized" (Ibid). Referencing the $\mathrm{BBC}$ editorial guideline to further explain why $\mathrm{CBC}$ journalists do not use the words terrorism or terrorists without attribution, the ombudsman cited the organization's journalistic standards and practices policy (2016), which "emphasizes that our journalistic independence and credibility is paramount." The BBC editorial guideline states the following about the definitional uncertainty of the word terrorist:

Unfortunately, there is no agreed or universal consensus on what constitutes a terrorist, or a terrorist attack. Dictionaries may offer definitions but the United Nations has again just failed to reach agreement. The obvious reason is that terrorism is regarded through a political prism (BBC editorial guideline as cited in Enkin 2013).

Following this line of thinking, the $\mathrm{CBC}$, through its language guide, provides guidance for its journalists when using the terms terrorist and terrorism. The language guide encourages $C B C$ journalists to "exercise extreme caution before using the words terrorist and terrorism" and "avoid labeling any specific bombing or other assault as a terrorist act unless this term is attributed" (Language Guide CBC as cited in Enkin 2013).

By restricting ourselves to neutral language, we aren't faced with the problem of calling one incident a "terrorist act" (e.g., the destruction of the World Trade Centre) while classifying another as, say, a mere "bombing" (e.g., the destruction of a crowded shopping mall in the Middle East" (Language Guide as cited in Enkin 2013). 
The Canadian Press Style handbook serves as a guide for many news organizations even when crafting their own policies (which many do - case in point, the CBC). This handbook says the following:

For journalists, the best advice is to be specific in the choice of terms used, and to guard against automatically labeling one side the terrorists, which makes the other side automatically the good guys. We do not shy away from the word terrorist, but we do use it with caution. There are always more neutral words available. Terms such as bombers, gunmen and killers also offer the advantage of being more specific.

Furthermore, editorial boards and corporate policies make the final decision about ethical calls, such as which images to publish, how much of a particular video to show, and how to cover especially horrendous acts. Nagler (2016) says that deciding whether an image released by ISIS makes it onto the news is "always an ethical dilemma." Nagler (2016) discusses the contentiousness of the issue, stating:

You recognize that you're trying to confront two competing needs. On the one hand, you're a journalist and you have an imperative to try to convey as much information to your audience about what's really happening and sometimes what's happening is not pleasant so you don't want to sugar coat things. On the other hand, you need to recognize that you want to minimize harm... That means showing respect for the dignity of the victims, of their families.

Ward (2016) says as a reporter, she does not make the decisions about which graphic images and videos to print. Oved (2016) reinforces this point, stating that decisions about using graphic images and videos "go above the decision-making level of an individual reporter." However, Ward asserts, "in spite of the fact that these (images and videos) are on the Internet and searchable," the editors and photo editors who make these decisions at The Toronto Star and a lot of mainstream media "do not want to publish the most gruesome images." Ormiston (2016) agrees. She says the most important consideration when deciding whether a horrific image or video makes the 
news is asking what part of this is newsworthy. The fact that (ISIS) is putting it out is not news, not always, and increasingly less so," she says.

This can be related back to the "copy cat effect" or "contagion effect." Gruesome terrorist attacks are often publicized in the media and garner a lot of attention and can influence others to act in a similar manner to garner the same widespread publicity. "Indirect observations of successful terrorist methods and strategies rely on traditional news reports and, more recently, new media outlets - especially Internet sites" (Sedgwick 2007: 102).

\section{Newsroom Hierarchies}

Another important consideration is newsroom roles. There is a clear hierarchical structure in a newsroom that affords more power to certain senior reporters who are responsible for making important decisions about how stories are covered. As demonstrated in the previous section, guidelines about language, and policies about which photos and videos to use are made at the editorial level. Individual reporters do not make these decisions, although their opinions may be asked. However, journalists interviewed for this thesis all asserted a level of independence and autonomy when deciding what stories are told.

Reporters that have seniority and have been working for an established news organization for a number of years assert they have quite a bit of autonomy in deciding what stories to cover and how to cover them. Common (2016) says:

I'm not a freelancer, I'm a senior member of the newsroom. So I have perhaps greater sway than some other people about what actually needs to go on a newscast... And I think I am able to get many of the things on that I want. 
Similarly, Ormiston (2016) asserts, "I have quite a bit of latitude in what I choose to pitch as a story and the majority of that gets accepted." However, Ormiston acknowledges, "anything that is not breaking or investigative is a tougher haul to get it accepted. We have a very hummingbird attention span, so things are hot one day and cold the next." Oved (2016) says when news organizations spend resources on a journalist to fly across the country to report on developing stories about acts of terrorism happening in the West, "The stories get front-page coverage guaranteed because the paper wants to give prominence to the fact that it has a reporter on the ground."

This is important to note as newsrooms generally make it a point to send journalists anywhere in the West where a terrorist attack has occurred and spend resources to do so. However, news organizations have one or two or no journalists stationed in the Middle East where the actual conflict is playing out. As Oved states, if a news organizations spends resources to get you to report on the ground in a different country, those stories get published. Thus, resources are spent covering short-term events rather than on the long-term developing terrorism narrative.

It is clear that newsroom hierarchy structures are maintained and the editorial staff makes the important decisions regarding coverage. However, in inclusive newsroom environments, reporters that have proven themselves throughout the years and gained a level of seniority in their field also hold sway when deciding which stories should receive resources and optimal coverage.

\section{Extramedia}

Individuals and organizations can influence how stories get covered in the news. Journalists rely on various sources for information. The terrorism narrative is 
shaped by the viewpoints of these sources. Thus, understanding the extramedia influences that impact the terrorism narrative helps determine how journalism is being affected by the various voices attempting to define the story.

\section{Government}

The Canadian government is involved in the U.S.-led coalition to "dismantle and ultimately defeat (ISIS)" (CAF 2017). The Canadian Armed Forces, Operation Impact was established in October 2014 to fight against the ISIS threat. Operation IMPACT "conducts air operations, provides training and assistance to the Iraqi security forces, provides capacity building capabilities to regional forces, provides medical services to Coalition forces, and supports the Coalition with highly skilled personnel" (Ibid). Canada has approximately $830 \mathrm{CAF}$ members deployed in Iraq (Ibid). The Canadian government extended its training mission against ISIS in Iraq for another three months, until June 2017 (Remiorz 2017). Defence Minister Harjit Sajjan also noted that "further adjustments" may be made depending on the situation (Ibid).

Ward (2016) asserts government sources are not useful when covering ISIS. "Frankly, there is very little information that can be gained from (government) sources," she says. "When it comes to foreign terrorism, Canadian government sources are not, in my experience, going to say anything that is of great value in advancing the story." Nagler (2016) says, "There's no question that we get a lot of information from government and from agencies about what's going on but (we) treat them like (we) treat any single source information." For Nagler (2016), the most important step when receiving information from government sources about ISIS is verification:

You have all the regular rules of journalism in place. You attribute information that you haven't been able to verify yourself and you try to 
make responsible decisions and try to resist being manipulated by anyone in the process whether it's ISIS themselves, or their surrogates, or when it's your own national government or another government institution.

Journalists interviewed agreed that traditional investigative methods should not be lost despite the stakes involved in gathering a story about ISIS. Most journalists interviewed stated that verifying the facts and ensuring they fully understand the subject they are reporting on is crucial to minimizing how much spin seeps in. Nagler (2016) admits that sometimes "You get information from governments or organizations who you know have a particular agenda in play." However, he asserts, "This is something that journalists deal with on many more stories than just ISIS.” Nagler adds:

As in any conflict situation, governments tell you information they feel is in their interest to share. Is that enough for us? Sometimes yes, other times no. Is it information we feel is always reliable? Sometimes yes, sometimes no.

Ormiston (2016) agrees that when using government sources, journalists always have to stay aware of the possible spin. However, she asserts, journalists have to rely on information about ISIS made available by the government because it is a source that has access to lines of information that are unreachable otherwise. Ormiston (2016) says:

I consider it and add it as a source with a big caveat. You need to be truly on guard for the political narrative. I'm sure people understand this. I hope they do. What the national security from the U.S. and the Department of Foreign Affairs and Defence staff in Canada make public is what they want to let out, it's not what they know. What they know is much greater than what they're willing to say and, I think in some cases, they keep back information that does not fit in with the narrative that the government or the leadership wants to put out.

For example, the shooting at Pulse Gay Night Club in Orlando, Florida by Omar Matteen, who killed 49 people, was first reported as a terrorist attack. Ormiston (2016) says there was a lot of pressure from some government sources to refer to this event as a terrorist attack. However, Ormiston (2016) says the motive was not clear. In her piece, 
Omar Mateen: What we know about the gunman in the Florida mass shooting, Ormiston includes details about the perpetrator and calls the event a mass shooting instead of a terrorist attack. Furthermore, Ormiston outlines details about Mateen such as his frequent visits to the night club for fun, his abusive traits, as well as his potential ties to a radical group. The piece ends with the conclusion that Mateen's motives are murky at best.

On the other hand, Koring (2016), in his piece Orlando gunman Omar Mateen vows allegiance to Islamic State in 911 call, focuses his article on Mateen's potential ties to ISIS, detailing only the aspects and motivations that came about as a result of Mateen's 911 call. There is no mention of Mateen's frequent visits to Pulse Night Club, his interactions with regulars there, and potential other motives.

The majority of journalists interviewed agree that unlike the war in Afghanistan and Iraq, where hundreds of journalists were cycled through the embed program and had on-the-ground access, the war against ISIS in Iraq and Syria has remained under wraps with little to no information being provided about ground movements. Common (2016) says, "The challenge with covering ISIS is that it is so difficult to be on the inside in a place like Syria or Iraq." When looking to Canadian government information on ISIS, he says:

You have limited ways of challenging it which is our instinct as journalists to challenge the information that is given to us particularly by powerful groups to ensure that it is credible and accurate.

Further to this point, unlike in other wars, Common (2016) says the Canadian military provides "no information on the ground movements" of Canadian troops. He says journalists are not allowed to speak to Canadian troops and are often "shown the door" when attempts are made. Even if journalists were embedded with Canadian troops, 
Common stresses it would be challenging because "your information flow is largely coming from one source and that is the military you are embedded with." Ward (2016) provided an example of when National Defence took some reporters along to Iraq, including one of her colleagues in April 2015. She stated the experience "was good and instructive, but of course one has to realize that you're only shown what they want you to see and that's the problem with being embedded." However, she argues, being embedded is better than having no access: "If you are embedded for some time, you keep a low profile, and you gain the trust of people particularly in the ranks, you can find out some very interesting stuff about what is really going on."

Stoffel, the $C B C$ 's Middle East correspondent, reaffirms the point that Canadian army bases in Iraq do not open their doors to journalists and the Canadian Department of National Defence has not allowed CBC access to Canadian forces in Iraq. Stoffel says this is the biggest difference between the war in Afghanistan and the one against ISIS. "I've asked them to go, and they say no," he says. "I don't see them as main sources of information."

ISIS makes it extremely difficult for journalists to get an inside scoop because it directly targets them. Thus, information on the ground is difficult to obtain. As suggested above, the Canadian government is not forthcoming with a lot of information about the operations in Iraq and Syria. The journalists only receive information that is in the government's best interest and it is limited. This leaves them in a precarious position where they have to rely on one source without an ability to really challenge information. As illustrated by the quotes above, journalists are aware of this caveat, and consider it when reporting on these stories. At times they have to use government information and at 
times they ignore it. Overall, the implications of having no physical access to the on-theground battles and limited access to information about on-the-ground activities by the Canadian Forces impacts journalist's ability to fully contextualize the conflict in Iraq and Syria as it pertains to ISIS.

\section{Social Media}

The disruptive period that journalists are facing is largely due to social media and technological advancements that have made information sharing easier than ever and have blurred both geographic borders and boundaries (Weaver and Willnat 2016: 844). Just how much has social media changed journalism? Oved (2016) provides an anecdote about how social media helped him report on the Paris Attacks on November 2015.

When first hearing of the attacks, Oved sat at his desk in The Toronto Star newsroom and wrote his first story in a series of stories on the incident. Afterward, he took a plane to Paris and began his on-the-ground reporting. For Oved (2016), Twitter and social media "were a fabulous source for information" while still in Canada. Using social media, Oved was able to communicate with people who were taking refuge in different areas of Paris and ask them directly if they heard gunfire. Oved says he was able to determine the exact location of a number of attacks using this method and provide consistent and accurate details about the shootings despite not being physically present:

Obviously, Twitter is filled with rumours and innuendos, but I found if you ignored all the pseudo-news sources and the echo effect of Twitter and simply went to individuals... you (can) with a fair degree of certainty know what you can trust and what you can't trust in terms of what's going on in the moment.

Koring (2016) agrees technological advancements have altered the journalistic landscape. He says, "Coverage patterns have changed, coverage methodologies have 
changed... but people have more access to more information than ever before in human history. The world is a better place for it."

How do social media and the Internet affect news coverage of terrorism? For one, they provide terrorist groups and other parties involved in the conflict with a direct pathway to audiences. However, ISIS produces content on its own that is directed at the news media. Thus, the group has a say in how its brand is represented through its attempt to control the message. Moreover, ISIS can speak directly to potential recruits by marketing their brand to them via social media. Common (2016) acknowledges one of the successes of ISIS is its ability to direct information to various groups it is targeting. Common (2016) uses the hostage scenario as an example of how ISIS attempts to exert or manipulate the media to promote the group. He asserts:

We are not a propaganda arm for ISIS. We might show a screen grab from a video but we are not going to show the entire forced statement from a hostage, we're not going to show someone being killed. We are not going to show someone getting tortured or beaten up because that serves (ISIS's) interest. And we don't like being a propaganda arm regardless of who it is for.

Stoffel (2016) says ISIS's real success is its ability to recruit people from around the world to fight alongside them in Iraq and Syria. He asserts, "Their strength is not only their brutality, but their ability to get their message across - they are masters of it." Stoffel argues there is a lot of information out there and ISIS is "a big purveyor of information" as well. Journalists interviewed all agreed that a lot of the information about ISIS comes from the group itself. In effect, ISIS is constantly working to progress its brand and be the primary definer of its organization. Nagler (2016) agrees, stating, "ISIS seems more than any other (terrorist) group to find a positive being as graphic as possible and having professional style production value around their acts of cruelty." 
Nagler says this presents a challenge for journalists. He acknowledges social media has made the spread of ISIS material "so much more universal and so much more rapid." Nagler (2016) asserts this shift has placed journalists in a different position than they were 10 or 15 years ago.

We used to make a choice as kind of the arbiters of public taste in a sense when we were making choices about whether it would be good or bad for the audience to see things. Now, people can find these videos on the web all by themselves. They don't need the media to decide whether to put them up or not.

This is an interesting quote as it shows how the Internet affects news decisions. The wide dissemination of information means news organizations know that people will have access to the content whatever their decision (to publish or not) is.

Ward (2016) says ISIS has "a great deal of control" over the discussions in Western news media regarding the atrocious human rights violations that the group commits in the Middle East. She says a reason for this is that ISIS is not a group "that wants to commit horrible acts and pretend that they are not responsible... The whole idea is to take responsibility for heinous crimes." For example, in Oved's (2016) piece, Fallout from attack unveils ugly side of Nice, Oved states that ISIS has claimed responsibility for the attack but also notes that this does not mean that ISIS directed the attack. Ormiston (2016) stresses that ISIS is "a very strategic and well-oiled media machine and they have been very successful at controlling the narrative and releasing videos and warnings that have turned the world on its head." The success ISIS has had with its social media marketing, Ormiston asserts, has put journalists in a precarious position:

We are very careful about (the information) we use that comes from them. We are very careful about how much we use. Always in our minds is the question: is this PR for ISIS that is useful for a news story or is it PR for 
ISIS that may be harmful or persuasive to people that are recruiting? Our job is not to make that stuff public; it's on the Internet. If somebody is interested, they can go and find it. Our job is to offer perspective and to explain what the context around it is.

Koring (2016) does not see the advent of social media as a negative thing in the fight against ISIS. He says while technological advancements have allowed ISIS a degree of control over its messaging, they have also meant "the mainstream media has access to (ISIS) in a way that it simply couldn't 15 or 20 years ago." He asserts ISIS's ability to transmit information "and for journalists to interact with them has been vastly greater" because of technological advancements and social media. Koring (2016) stresses that information about ISIS is everywhere, and people can ascertain more information about the group than any other terrorist organization from the past. He asserts that this information is useable and reliable. However, he worries that the proliferation of information sources could drown interest. Koring (2016) says:

I think there are plenty of people who are thinking about ISIS every day because they pay attention to sources that talk about ISIS every day. And I think there are people who never pay attention to ISIS. I think that we are in a bit of dis-equilibrium in the information space where it's really confusing what is important and what is not.

To conclude, ISIS's use of social media has allowed the group further control of its message. According to Ormiston (2016), ISIS has "100 per cent control" over its brand. This shifts the power away from official sources when it comes to defining the group. ISIS produces content targeting new recruits, the media, Western governments, and the general public. The challenge for news media is deciding what information to use and what to ignore. All journalists interviewed agreed that their goal is not to be a "propaganda arm" for ISIS, or any other group with political interests in the war. The constant stream of information that is produced and disseminated by ISIS and other 
parties involved in the conflict in Syria and Iraq presents a real dilemma for journalists. They do not have much access to Iraq or Syria, which leads to dependency on other information sources. Deciding which sources to use and which to disregard while taking into consideration the impact that decision will have on coverage is an ongoing discussion in the newsrooms of all journalists interviewed.

For example, when reporting on terrorism attacks occurring in the West, the sources that were used included eyewitness statements, statements from politicians, national security experts, and other official reports. As Oved (2016) mentioned in his interview, social media such as Twitter was useful in determining coordinates and understanding which areas were affected. However, when reporting on ISIS activity in Iraq and Syria, the journalists interviewed included official sources such as government releases. When possible, eyewitness statements were also used however these statements came from individuals who had fled conflict zones. Eyewitness statements from individuals who have fled conflict zones are legitimate sources of information. Although information is not necessarily verifiable, several people giving a similar account of an event has journalistic merit.

\section{Ideological}

An important consideration when looking at how the rise of ISIS has challenged reporting on terrorism is focusing on the conflation between the group and the entire religion of Islam. The journalists interviewed understood that reality for their audiences and discussed how media coverage of the group affects perceptions. Stoffel (2016) asserts the fight against ISIS should not be viewed as a fight between the East and the West. "This is not Islam versus the West... this is one group. A group that is losing territory, that is losing fighters," he says. "The biggest thing to remember on touchy 
stories like this is to stick to facts and to treat your audience with respect." Despite Stoffel's assertion, it is clear that audiences are making a connection between Islam, ISIS, and other radical Islamist movements. Nagler (2016) argues the whole world is struggling to try to understand the relationship between radical Islamists and the religion of Islam:

It's one of the great conflicts for people and it creates huge issues for Muslims around the world that have nothing to do with these groups, and are trying to live their life in peace.

The conflation of ISIS, a radical group, with the entire religion of Islam has some journalists worried. Oved (2016) worries that "a large portion of humanity" is being blamed for the actions of ISIS. He says readers should remember "as it has been pointed out in many non-mainstream media sources, that far more Muslims die as victims of terrorism than non-Muslims." Oved says just because time is not given to stories "talking about all the car bombs in Kabul or all the attacks in Baghdad" does not mean that these attacks are any less important than ones being committed against the West. "It's the classic Western bias," he says. "I think that there is a distinct lack of Muslim reporters in the West and I think that, not out of malice but out of ignorance, some people make mistakes." Newsroom diversity has been a challenge in Western newsrooms

Ward (2016) agrees, claiming the issue is so fraught because "so many people do not understand Islam" and unfortunately ISIS has allowed, "the conversation to focus on violence in Islam." Due to this lack of clarity on what the religion is about, "When (people) see 'Muslim," 'Islam,' 'Daesh (ISIS),' they right away identify that." To exemplify this point, Ward discusses her experience working on a story about the Council on American-Islamic Relations, a civil liberties group for Muslims in the U.S.. She visited the group after a terrorist attack in St. Bernardino, California where a mass shooting was carried out that resulted in the deaths of 14 people (CNN). Ward says: 
I was sitting with them all day and the phone was ringing off the hook. They had all of these people screaming at them. Of course the attack was followed by attacks on perfectly innocent Muslims. And that's really (ISIS's) bottom line. They want to terrify people who are non-believers in their utterly distorted view of Islam. The only way they can do that is by creating as much hatred as possible towards Muslims.

Ward urges that "the West not fall into that trap" where it isolates a huge group of people and blames them for the actions of a group of particularly violent radicals. Ormiston (2016) agrees, stating the way journalists cover events influences a great deal of what people understand about Islam. "There's no question that for some people ISIS is equal to Muslim. I think it's worrisome and we all need to be on guard against equating the two and falling into a pattern," she says. She argues that not seeing how this inadvertent connection affects perception is "the same kind of lazy and inattentive reporting that can equate things that shouldn't be connected." Common (2016) agrees, stating that the conflation of ISIS and Islam without broader explanations of the conflict and contextualization of the religion is "primarily the result of sloppy journalism or fictional television masquerading as journalism."

It is difficult to avoid conflating Islam with terrorism when it comes to ISIS because ISIS has branded itself as being Islamic. Thus, when reporting on ISIS, the issue of religion is brought forward in the articles written about the group. Most of the journalists interviewed included sources in their coverage of terror attacks that represented Muslim communities such as an Imam. However, the conflation between the Islam and Terrorism is not easy to subvert. The limited knowledge about Islam and the association to ISIS as purported by the media and by the terrorist group itself make it challenging. 


\section{Conclusion}

As demonstrated in this chapter, the journalists interviewed for this project were very well aware of the various levels of influences that attempt to spin how they cover terrorism, and ISIS in particular. For the majority of the journalists interviewed, the biggest challenge of covering ISIS is access: the inability to get on-the-ground coverage. They assert this leaves them vulnerable and more dependent on using official sources with political agendas to push forward. Furthermore, technological advancements and the rise of social media have made it particularly easy for rebel groups and state actors involved in the conflict to reach out directly to audiences they are targeting without the help of the media. This has resulted in multiple voices competing to become the primary definer of the conflict. Journalists cannot report from ISIS strongholds because they are targets and would face extreme dangers. The Canadian government is staying quiet about on the ground operations, making it difficult for journalists to get any valuable information. The only ISIS-related stories that can be well documented by the media are terrorist attacks occurring in the West. However, without a clear understanding of what is happening on the ground in Syria and Iraq, it becomes difficult to truly contextualize the fight against ISIS. There are multiple voices attempting to define the conflict, which presents a real challenge. Journalists' inability to see for themselves makes them more dependent on these other voices. As Ormiston (2016) warns, journalists have to be very careful of the "political bent" that sources have and aware of the bias they want to inject into journalists' work.

ISIS's use and mastery of social media has presented the biggest challenge for journalists. The group's violent nature and the direct targeting of journalists has limited the ability for on-the-ground reporting. The overall reliance on official sources has made 
it difficult to decide whose interests are being pushed forward. However, as the journalists noted throughout the interviews, ISIS, a radical group that incites terror, is nothing new. Koring (2016) emphasizes the point:

I think journalists have a habit of regarding everything as new. And that's understandable because that's what we do: we report on news, which is by definition new. To define an event as something that has been seen before in a different guise in a different name, or in a different circumstance kind of undermines the newness of something. I don't actually think that (ISIS) is uniquely different in any substantive way than other relatively small, relatively violent, ideologically driven organizations that people have been covering for as long as people have been covering them.

Ormiston (2016) agrees that the terror ISIS is inciting is nothing new. She asserts, "terror with any acronym is terror," and adds that acts by the Taliban and Al-Qaeda were also horrific. However, she notes that it is ISIS's reach that has been most alarming:

It is not 'new' terror. As the world moves on and everybody becomes more sophisticated and as the media treat these threats differently, it appears different. But terror is terror, and we are living through a particular time of repeated terror under the guise of ISIS.

What makes ISIS new is that the group has a strong social media presence. The group's power lies in its ability to market its ideology directly to those it is attempting to recruit. The group's ability to produce and create targeted content that has made it especially interesting and newsworthy. The style of terror incited by ISIS is not new, but the group's ability to publicize it is. ISIS's ability to define itself and control its brand makes the group unique. Journalists face challenges when covering ISIS because information, at this point, can only be obtained from other sources with their own political agendas. It is important to note that journalists are aware that the various parties involved in the conflict attempt to influence reporting. In effect, the nature of journalism itself leaves room for these influences to seep into coverage. 


\section{Conclusion}

With the rise of ISIS, the public is experiencing a different kind of war, a war of words and pictures delivered directly to the consuming public audience. As established in the literature review, Al-Qaeda and ISIS are different in many ways. While Al-Qaeda leaders were meticulously organized, structuring the terrorist group into a corporate enterprise and only accepting responsibility for attacks that furthered its aims, ISIS is decentralized, encouraging participation across the globe and waging war both in Iraq and Syria as well as abroad. ISIS has no issue with using extensive violence to incite fear through shock value tactics. While violence, fear and shock-tactics are not new - AlQaeda uses extensive violence as well - violence and public conveyance of violence, has become a major publicity crutch for ISIS.

Susan Ormiston (2016), foreign affairs reporter for the CBC, noted that the question that always comes to mind when reporting on ISIS is whether the story is "PR for ISIS." She admitted that seeing "the success of the ISIS marketing machine" is frustrating. For the journalists interviewed, terrorism has not changed, but the way terrorists interact with the media and the wider audience has. ISIS's use of social media and ability to control its message makes it difficult for journalists to sift through what is newsworthy content and what will only help spread ISIS propaganda. All journalists interviewed agreed that ISIS's use of social media to control its message, recruit, and inspire attacks is what truly makes the group different than other terrorist organizations in the past.

Normal journalistic routines and methods of reporting have changed in the last decade as a result of technological advancements. The Hierarchy of Influences model 
was used to sift through information about the various influences that affect terrorism coverage as it relates to ISIS. Using this model helped highlight common challenges journalists faced when covering the ISIS story. Chapter four highlighted that ISIS's marketing campaign has impacted the way journalists tell the terrorism story. Journalists are more reliant on third-party information that at times could be difficult to verify. Based on the sources that journalists use in their stories, there is always a potential for bias creep; shaping stories based on various point of views and sympathies. The direct targeting of journalists also raises questions about journalist's own safety when covering these conflicts and could warp their interpretation.

Individual role perception routinized work, and organizational structure impact media coverage of ISIS. The Internet and other social media have provided the ability for groups to directly target audiences. For the journalists interviewed, the overload of information that cannot be easily verified combined with limited access to the group is the most disconcerting. Similarly, the lack of direct access has resulted in a higher reliance on official sources for information about the on-the-ground battle against ISIS (Kinzer 2016). This combined with ISIS-produced content that is infiltrating the Internet creates barriers for journalists, specifically in determining what information to use, and the verifiability and accuracy of this information. Journalists interviewed agreed the traditional investigative methods that they use to synthesize and contextualize content have not changed, but over-reliance on official sources, lack of access, and an abundance of information online have influenced how they report on terrorism as it relates to ISIS.

Restricted access means relying on government sources for details on what is happening on the ground in Syria and Iraq. Domestic terrorism coverage focuses only on 
one angle of the battle against ISIS and does not provide in-depth coverage of the longterm developments correlated with terrorism. ISIS's targeting of journalists and its ability to control its own message also affects journalist's ability to inform. It becomes difficult to filter through this information in order to ensure what is being reported is accurate, verifiable, and responsibly written.

Moreover, it comes as no surprise that journalists are facing heavy workloads. Ormiston (2016) asserts journalism is "in a disruptive period" and the biggest change for working journalists are the multiple platforms to which they are now expected to file:

For the majority of my career I was primarily a television broadcaster with some radio responsibilities. Now I have television, radio, text-writing, video presentation that is packaged for social and online digital media, and live reporting, which is a different skill altogether. No matter what media you work in, you are now required to work in everybody else's media too.

The journalists interviewed all agreed that their workload is heavy and this impacts their storytelling. Writing is a thinking process. Common (2016) reflects on how little time he has to really think about the decisions on what stories to cover. "You don't have a lot of 'think time' anymore," he says. "You don't have time to spend days and days and days on formulating what you've ought to be covering." Koring (2016) agrees that journalists face long days and demanding work:

You have good days and bad days. Some days you don't earn the pay they give you and other days, particularly in tough places, you're working 28 hours a day. When it comes to resources, there's never enough time, and never enough money, and never enough resources to cover anything properly.

Ward (2016) asserts that on many days, she feels overwhelmed. "I often feel there is not enough of me to cover the stories. There were stories I felt I couldn't ignore and 
they were timely and I really wanted to write them but I simply couldn't," she says. Ormiston (2016) agrees:

I find it extremely challenging to perform at the level I set for myself because it's my belief that every medium requires a different story telling. And I try to hold true to that but sometimes it becomes almost insurmountable. It's very difficult in the timeframe on a daily news story to write three or four different treatments on a story.

As the profession of journalism evolves, there seems to remain a constant, that journalists chasing a story continue to face extreme pressures, tight deadlines, long hours and a potentially evolving story, thereby exasperating their ability to think deeply about their topic. As terrorism is a topic that requires in-depth knowledge and attention, especially when focusing on ISIS, heavy workloads and tight deadlines mean journalists have less time to engage with the story and provide that in-depth analysis. As noted in the previous chapter, focusing on the long-term development of terrorism events instead of short-term coverage of individual attacks is preferable, however the lack of resources, time, and the pace of story development means journalists cannot provide depth of coverage that a story may warrant.

More research is needed to determine how media coverage of terrorism has been affected by the rise of ISIS. This thesis project focused on journalist's perception of the challenges ISIS has brought forward. The main difference between ISIS and other terrorist groups, as noted through the interviews, is ISIS's ability to self-brand. An interesting question emerges: just how much control does ISIS have over its message? Another interesting area for future research is analyzing the sources used when reporting on ISIS to determine just how much news media relies on official sources. A lot of the interviews also stated that there exists an "echo-chamber" when reporting on ISIS- 
related stories. It would be interesting to research this assertion by analyzing the similarities in reporting about ISIS in the media.

Defining and contextualizing the ISIS story is difficult because the terrorist group controls its message and brand through the use of social media. It is this high visibility that has made ISIS seem more brutal and ruthless than any other terrorist group before it. Due to the nature of this conflict, the lack of access, and the excess of information available, it is not always possible to avoid the spin. However, journalists are constantly working to inform the public with the resources that they have available to them. As can be seen in chapter four, the challenges presented by ISIS has forced journalists to become more aware of the pitfalls when reporting on the group specifically relating to political agendas and ISIS propaganda that aim to shape their coverage. Journalists are adapting to their changing environments and attempting to find stability in contextualizing complex events in information era where the truth can be murky. Overall, journalism role as "definer" of issues has been weakened because a direct-line to audiences has been made possible because of social media and the Internet. However, journalism's strength lies in its ability to provide analysis and clarity. 


\section{APPENDIX A}

\section{$\underline{\text { CBC News }}$}

\section{Journalists Interviewed}

Jack Nagler has been working as a professional journalist for 27 years. Currently he is the Director of Journalistic Public Accountability. He has been working in this managerial role for three years. Nagler ensures that the $\mathrm{CBC}$ remains accountable for actions and decisions to the public.

David Common has been working as a professional journalist for 17 years and has covered conflicts and national security on-and-off for 14 years, including the wars in Afghanistan and Iraq. Currently he hosts World Report on CBC Radio One, and The National, News Network, The Current and Metro Morning.

Derek Stoffel has been working as a journalist for 21 years and has been working as the Middle East correspondent for CBC News since August 2011. Stoffel has reported from conflict zones, including Syria.

Susan Ormiston has been working as a professional journalist for 35 years and has been covering national security steadily for 10 years. She has reported from Afghanistan, Egypt, Libya, Haiti, Lebanon, South Africa, and Syria.

\section{Toronto Star}

Marco Chown Oved has been working as a professional journalist for 10 years. He has spent one-year covering terrorism. Oved was sent to Paris to cover the Paris Attacks in 2016.

Olivia Ward has been covering national security steadily for 17 years. Ward worked as the Star's UN correspondent and reported from conflict zones in the Middle East, Chechnya, Kosovo, Iraq, Palestine and more.

\section{The Globe and Mail}

Paul Koring has been working as a professional journalist for more than 30 years and has covered national security for 17 years. Koring has covered conflicts in Afghanistan, Europe, the Middle East, South Asia and Africa. 


\section{APPENDIX B}

\section{Interview Questions ${ }^{1}$}

Questions for managerial roles (people who have to look at the bigger picture of the news cycle)

1. How long have you been working as a professional journalist? How long have you been working in this managerial role?

2. How many people are you responsible for overseeing? How many of those people are working in foreign bureaus (and where are those foreign bureaus)?

3. On any given day, how much of your coverage would you estimate is on foreign affairs?

4. Has the way you cover foreign news changed since you started in your job? If so, how? (Budgetary, technology, staffing etc.)

5. What term is your organization using to define the group? Why did you choose that term?

6. What are the challenges of covering Daesh?

7. What resources do you use to cover Daesh?

8. How much do you rely on information about Daesh made available by government (DND, Foreign Affairs, the UN, etc.)?

9. How much information does DND/government provide about the fighting or ground moves of Canadian military in Syria and Iraq? Do you request information from DND about Canada's role in this war frequently? Is this information accessible?

10. Do updates from DND/IGOs often make it to press/air in the daily news cycle? How do you determine whether an update about Daesh is newsworthy or not?

11. What steps do you take to have balance in your reporting when dealing with official news releases or announcements from Canadian/Western governments about the group? Civilians on the ground? Social media account by civilians? By Daesh?

12. How does your organization respond when Daesh posts graphic images and videos? Do these images/videos pose an ethical dilemma for you?

13. From an organizational standpoint, has your approach to covering terrorism changed with the rise of Daesh? If so, how? (How did you cover terrorism before Daesh?)

14. How do you approach stories about domestic terrorism (related to Daesh)? How do you approach stories about terrorism (related to Daesh) happening abroad? Is there a difference in your reporting?

15. How much control do you think Daesh has over its message and brand through its own communications strategy?

16. How do you think media coverage of Daesh shapes the way people think about, or understand, Islam?

\footnotetext{
1 These questions are for a semi-structured interview, which means there may be additional follow up questions.
} 
Questions for reporters (journalists that are responsible for covering individual stories)

1. How long have you been working as a professional journalist?

2. How long have you been covering national security?

3. How do you feel about your workload on any given day? Do you feel as if you are able to cover the stories you need (and that they are getting picked up)? Are you able to cover stories you feel are important? Is your organization picking them up?

4. What are the challenges of covering Daesh?

5. Where are you usually when you are reporting on foreign threats? Where are you usually when you are reporting on Daesh?

6. Where do you get your information for covering Daesh? How difficult is it to obtain?

7. What are your sources for covering Daesh? Are they different when covering a specific act of terror versus a broader story on the group itself?

8. How do you approach stories about domestic terrorism (related to Daesh)? How do you approach stories about terrorism (related to Daesh) happening abroad? Is there a difference in your reporting?

9. How much do you rely on information about Daesh made available by government (DND, Foreign Affairs, the UN, etc.)?

10. How much information does $\mathrm{DND} /$ government provide about the fighting or ground moves of Canadian military in Syria and Iraq? Do you request information from DND about Canada's role in this war frequently? Is this information accessible?

11. Do updates from DND/IGOs often make it to press/air in the daily news cycle? How do you determine whether an update about Daesh is newsworthy or not?

12. What steps do you take to have balance in your reporting when dealing with official news releases or announcements from Canadian/Western governments about the group? Civilians on the ground? Social media account by civilians? By Daesh?

13. How much control do you think Daesh has over its message and brand through its own communications strategy?

14. How do you respond when Daesh posts graphic images and videos? Do these images/videos pose an ethical dilemma for you?

15. Has your approach to covering terrorism changed with the rise of Daesh? If so, how?

16. How do you think media coverage of Daesh shapes the way people think about, or understand, Islam? 


\section{Works Cited}

Accountable Journalism (1971) "Declaration of the Rights and Duties of Journalists," Donald W. Reynolds Journalism Institute. Web.

$<$ https://accountablejournalism.org/ethics-codes/International-Declaration $>$

Al Jazeera English (2004), "Full transcript of bin Ladin's speech," Al Jazeera English. Web. <http://www.aljazeera.com/archive/2004/11/200849163336457223.html>

Alexander, Harriet (2014). "American TV networks criticised for sensational coverage of the Ottawa shooting," The Telegraph. Web.

$<$ http://www.telegraph.co.uk/news/worldnews/northamerica/canada/11182189/AmericanTV-networks-criticised-for-sensational-coverage-of-the-Ottawa-shooting.html $>$

Altheide, David L. (2006). "Terrorism and the Politics of Fear," Cultural Studies/ Critical Methodologies, 6:4. 415-439. Print.

Altheide, David L. (1997). "The News Media, the Problem Frame, and the Production of Fear,” The Sociological Quarterly, 38:4. 647-668. Print.

Al-Zo'by, Mazhar (2015). "Representing Islam in the age of neo-orientalism: Media, politics and identity," Journal of Arab \& Muslim Media Research, 8:3. 217-238. Print.

Arnett, Peter (05 December 2001). "Osama bin Laden and returning to Afghanistan," CNN. Web.

<http://www.cnn.com/2001/COMMUNITY/12/05/gen.arnett.cnna/index.html >

Barber, Marsha and Ann Rauhala (2008). "The Canadian News Directors Study: Role Conceptions of Television Newsroom Decision Makers." Electronic News 2(1). Print. 46-50.

Bargu, Bargu, (2011). "Forging Life into a Weapon," Social Text.

Baluja, Tamara (2014). "Around the World: Canadian coverage of Ottawa shooting praised by international media," J-source. Web.

$<\underline{\mathrm{http}}$ ://jpress.journalism.ryerson.ca/jsource/around-the-world-canadian-coveragepraised-by-international-media/>

BBC News (2016). "Brussels explosions: What we know about airport and metro attacks," BBC News. Web < http://www.bbc.com/news/world-europe-35869985>

Beam, Randal A. (2006). "Organizational Goals and Priorities and the Job Satisfaction of U.S. Journalists," Journalism and Mass Communication Quarterly, 83:1. 169-185. Print. 
Becker, Olivia (2014). "ISIS has a Really Slick and Sophisticated Media Department." Vice News. Web. <https://news.vice.com/article/isis-has-a-really-slick-and-sophisticatedmedia-department $>$

Bell, Roberta (2016). "A Difficult Conversation: The News Media and the Story of the First Peoples of Canada," Thesis Dissertation: Carleton University. 1-180.

Bennett, Daniel (2013). "Exploring the impact of an evolving war and terror blogosphere on traditional media coverage of conflict," Media, War \& Conflict, 6:1. 37-53. Print. Bergen, Peter (2012). "Revisiting the Early Al-Qaeda: An Updated Account of its Formative Years," Studies in conflict and terrorism. 35:1. 1-36. Print.

Berglez, Peter (2008). “What is global journalism?” Journalism Studies, 9:6. 845-858. Print.

Blaker, Lisa (2015). “The Islamic State's Use of Online Social Media,” Military Cyber Affairs, 1:1. 1-9. Print.

Bro, Peter and Filip Wallberg (2014). "Digital Gatekeeping," Digital Journalism, 2:3. 446-454. Print.

Bush, George W., (2001). "Congress Address.” Carter, Chelsea J (2014). "Video shows ISIS beheading U.S. journalism James Foley," $C N N$. Web $<$ http://www.cnn.com/2014/08/19/world/meast/isis-james-foley/>

Carey, James W. (2007). “A Short History of Journalism for Journalists,” Press/Politics 12(1). 3-16. Print.

Carey, James W. (2000). "Journalism and Democracy Are Names for the Same Thing," Nieman Reports. Web. <http://niemanreports.org/articles/journalism-anddemocracy-are-names-for-the-same-thing/>

Call, Carlotta (2008). "Taliban Free 1,200 Inmates in Attack on Afghan Prison," The New York Times. Web.

$<$ http://www.nytimes.com/2008/06/14/world/asia/14kandahar.html? r=1\&partner=r

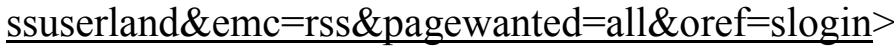

CBC News (2008). "Insurgent attack frees hundreds from Kandahar prison," $C B C$ News. Web. $<$ http://www.cbc.ca/news/world/insurgent-attack-frees-hundreds-fromkandahar-prison-1.725191>

CBC News (2014). "Ottawa shooting: A day of chaos leaves soldier, gunman dead," CBC News. Web. <http://www.cbc.ca/news/politics/ottawa-shooting-a-dayof-chaos-leaves-soldier-gunman-dead-1.2808710> 
CBC News (2016). "Omar Mateen: What we know about the gunman in the Florida mass shooting," CBC News. Web. <http://www.cbc.ca/news/world/omar-mateen-what-weknow-1.3631708>

CBC News (2017). "Canada extends mission against ISIS in northern Iraq to June 30," CBC News. Web. < http://www.cbc.ca/beta/news/politics/sajjan-isis-daeshextension-1.4049418>

CBC News (2017). "Journalistic Standards and Practices: War, Terror and Natural Disasters," CBC News. Web. <http://www.cbc.radio-canada.ca/en/reporting-tocanadians/acts-and-policies/programming/journalism/war-disasters/>

CBS News (2016). "ISIS attacks: A timeline of terror," CBS News. Web. $<$ http://www.cbsnews.com/pictures/isis-attacks-a-timeline-of-terror/>

Cheung, Meily M.F., and Tin Chi Wong (2016). "News Information Censorship and Changing Gatekeeping Roles: Non-Routine News Coverage and News Routines in the Context of Police Digital Communications in Hong Kong." Journalism \& Mass Communications Quarterly, 93:4. 1091-1114. Print.

CNN Library (2016). “2015 Paris Terror Attacks Fast Facts,” CNN Library. Web. < http://www.cnn.com/2015/12/08/europe/2015-paris-terror-attacks-fast-facts/> Coady, C.A.J (2004), “Terrorism, morality and supreme emergency," Ethics 113:4. 772. Print.

CNN World (2017). "ISIS goes global: 143 attacks in 29 countries have killed 2,043). CNN World. Web. <http://www.cnn.com/2015/12/17/world/mapping-isis-attacks-aroundthe-world/>

Cohen-Almagor, Raphael (2005). "Media Coverage of Acts of Terrorism: Troubling Episodes and Suggested Guidelines," Canadian Journal of Communication. Web.

$<\underline{\text { http://www.cjconline.ca/index.php/journal/article/view/1579/1734> }}$

Common, David (2016, September 8). Phone interview.

Cook, Timothy E. (1954). "Governing the News: The News Media as a Political Institution," Chicago: The University of Chicago Press. 1-164. Print.

Cottee, Simon (2015). "Why it's so Hard to Stop ISIS Propaganda," The Atlantic. Web. $\leq \mathrm{http}$ :/www.theatlantic.com/international/archive/2015/03/why-its-so-hard-to-stop-isispropaganda/386216/>

Deuze, Mark (2005). "What is journalism? Professional identity and ideology of journalists reconsidered," Journalism, 6:4. 442-464. Print. 
Diego Gambetta, (2005) ed., "Making Sense of Suicide Missions" New York: Oxford University Press. Print.

Doward, Jamie (2015). "Media coverage of terrorism 'leads to further violence'," The Guardian. Web. <https://www.theguardian.com/media/2015/aug/01/mediacoverage-terrorism-further-violence $>$

Elliott, Deni (2004). "Terrorism, global journalism, and the myth of the nation state," Journal of Mass Media Ethics, 19:1. 29-45. Print.

Engel, Matthew (2002). "War on Afghanistan: American media cowed by patriotic fever, says network news veteran." The Guardian. Print.

Enkin, Esther (2013). "Talking about Terrorists and Terrorism." Ombudsman CBC. Web. $<$ http://www.ombudsman.cbc.radio-canada.ca/en/complaint-reviews/2013/talking-aboutterrorists-and-terrorism/>

Epstein, Edward C. (1977). "The Uses of "Terrorism": A Study in Media Bias," Stanford Journal of International Studies. 67-78. Print.

Fanon, F. (1967) “The Wretched of the Earth.” London: Penguin. Print. 2748.

Farwell, James P. (2014). “The Media Strategy of ISIS,” Survival, 56:6. 49-55. Print.

Fine, Jonathan (2010), "Political and Philological Origins of the Term 'Terrorism' from the Ancient Near East to Our Times," Middle Eastern Studies, 46:2, 271-288. Print.

Fisk, Robert (1993). "Anti-Soviet warrior puts his army on the road to peace," The Independent: London. Web. $<$ http://www.independent.co.uk/news/world/anti-sovietwarrior-puts-his-army-on-the-road-to-peace-the-saudi-businessman-who-recruitedmujahedin-1465715.html>

Fisk, Robert (2001). "Osama bin Laden: The godfather of terror?" The Independent: London. Print.

Frampton, Ben (2015). "Clickbait: The Changing Face of Online Journalism," $B B C$ News. Web. $<$ http://www.bbc.com/news/uk-wales-34213693>

Friis, S.M. (2015). “'Beyond anything we have ever seen': beheading videos and the visibility of violence in the war against ISIS," International Affairs 91(4). 725-746. Print.

Fuller, Jack (1996). "News Values: Ideas for an Information Age." The University of Chicago Press. Print. 266.

G. Stuart Adam (1993). "Toward a Definition of Journalism: Understanding an old craft as an art form," The Poynter Institute. 55. Print. 
Galtung, Johan, and Mari Holmboe Ruge (1965). "The Structure of Foreign News: The Presentation of the Congo, Cuba, and Cyprus Crises in Four Norwegian Newspapers," Journal of International Peace Research 1. 84. Print.

Gans, Herbert (2005). "Deciding What's News: A Study of CBS Evening News, NBC Nightly News, Newsweek, and Time, 25th Anniversary Edition," Evanston, IL:

Northwestern University Press. 1-393. Print.

Gravengaard, Gitte. (2012). "The metaphors journalists live by: Journalists'

conceptualization of newswork," Journalism (London, England). (13)8.1064 - 1082.

Print.

Greene, Kyle J. (2015). "ISIS: Trends in Terrorist Media and Propaganda," International Studies Capstone Research Papers. Paper 3.

$<\underline{\text { http://digitalcommons.cedarville.edu/international_studies_capstones/3 }>}$

Hall, Stuart, Chas Critcher, Tony Jefferson, John Clarke, and Brian Roberts, "The Social Production of News," in Policing the Crisis: Mugging, the State, and Law and Order, London: Macmillan Press Ltd., 57.

Handley, Robert L and Lou Rutigliano (2012). "Journalistic field wars: defending and attacking the national narrative in a diversifying journalistic field." Media, Culture \& Society 34(6). 744-760.

Hansen, Kathleen A, Jean Ward, Joan L. Conners, and Mark Neuzil (1994). "Local Breaking News: Sources, Technology, and News Routines," Journalism Quarterly, 71:3. 561-572. Print.

Happer, Catherine, and Philo, Greg (2013). "The role of the media in the construction of public belief and social change," Journal of Social and Political Psychology, 1 (1).

Harcup, Tony and Deirdre O’Neill (2001). "What Is News? Galtung and Ruge revisited," Journalism Studies vol. 2, no. 2. 278-279

Hashim, Ahmed (2014). "The Islamic State: From Al-Qaeda Affiliate to Caliphate," Middle East Policy. XXI: 4. 69 - 83. Print.

Hattem, Julian (2015). "Poll: Fears of Islamic extremism on the rise," The Hill. Web.

$<\underline{\text { http://thehill.com/policy/national-security/248315-poll-extremism-fears-on-the- }}$ $\underline{\text { rise }>}$

Haynes, Jeffrey (2005). "Al-Qaeda: Ideology and action," Critical Review of International Social and Political Philosophy. 8:2. 177-191. Print. 
Held, Virgina (2008). "How Terrorism is Wrong: Morality and Political Violence.” Oup USA. Print.

Hellmueller, Lee, Sadia Ehsan Cheema \& Xu Zhang (2016). “The Networks of Global Journalism," Journalism Studies. 1-20. Print.

Herman, Edward and Noam Chomsky (2002). "Manufacturing Consent: The Political Economy of the Mass Media," Pantheon. 1-480. Print.

Holbrook, Donald (2015). "Al-Qaeda and the Rise of ISIS," Survival. 57:2. 93-104. Print.

Hossal, Robert (2012). "The Evolution of al-Qaeda's Strategy after Afghanistan," Smart War. Web. <http://www.smartwar.org/2012/02/the-evolution-of-al-qaedasstrategy-after-afghanistan/>

Huey, Laura (2015). “This is Not Your Mother's Terrorism: Social Media, Online Radicalization and the Practice of Political Jamming," Journal of Terrorism Research, 6:2. 1-16. Print.

Huntington, Samuel P (1993). "The Clash of Civilizations," Foreign Affairs. 22-49. Print.

Independent (2010). "Embedded journalism: A distorted view of war," Independent. Web. $<$ http://www.independent.co.uk/news/media/opinion/embeddedjournalism-a-distorted-view-of-war-2141072.html>

Jackson, Sir Geoffrey (1990). "Terrorism and the news media," Terrorism and Political Violence, 2:4. 521-528. Print.

Jallow, Alagi Yorro (2015). "Emerging Global Journalism and Social Media" SSRN. Web. $<$ https: $/ /$ papers.ssrn.com/sol3/papers.cfm?abstract id=2628915 $>$

James, Malcolm (2016). "The Colonial Representation of Jihadi John: Matters of Life and Death in the "War on Terror." Soundings 62. Web.

$<$ https://www.questia.com/magazine/1G1-452159404/the-colonial-representation-ofjihadi-john-matters $>$

Johnson-Cartee, Karen (2005). "News Narratives and News Framing: Constructing Political Reality." Rowman \& Littlefield Publishers. Print. 376.

Kellner, Douglas (2004). "9/11, spectacles of terror, and media manipulation," Critical Discourse Studies, 1:1. 41-64. Print.

Khan, Ali (1987). "A Theory of International Terrorism," Connecticut Law Review, Vol. 19. 945-972. Print. 
Khan, AL. (2006). "A Theory of International Terrorism: Understanding Islamic Militancy,” Koninklijke Brill NV. 1-367. Print.

Kinzer, Stephen (2016). "The media are misleading the public on Syria," The Boston Globe. Web.

$<$ https://www.bostonglobe.com/opinion/2016/02/18/the-media-are-misleadingpublic-syria/8YB75otYirPzUCnlwaVtcK/story.html>

Koerner, Brendan (2016). "Why ISIS is Winning the Social Media War," Wired. Web. $<\underline{\text { https://www.wired.com/2016/03/isis-winning-social-media-war-heres-beat/> }}$

Koring, Paul (2016). "Orlando gunman Omar Mateen vows allegiance to Islamic State in 911 call," The Globe and Mail. Web.

$<$ http://www.theglobeandmail.com/news/world/orlando-gunman-omar-mateen-vowsallegiance-to-islamic-state-in-911-call/article30413005/>

Koring, Paul (2016, September 8). Phone interview.

Kovach, Bill and Tom Rosenstiel (2007). "The Elements of Journalism: What Newspeople Should Know and the Public Should Expect," Three Rivers Press: New York. 259. Print.

Ladd, Jonathan (2010). "Why Americans Hate the Media and How It Matters," Princeton, NJ: Princeton University Press. Print.

Lancaster, John (1997). "Gunmen Kill 60 in Massacre At Egyptian Tourist Facility," The Washington Post. Web.

$<\underline{\text { http://tech.mit.edu/V117/N59/egypt.59w.html }>}$

Laqueur, Walter (1999). "The New Terrorism: Fanaticism and the Arms of Mass Destruction," Oxford University Press: 691. Print.

Laqueur, Walter (2007). "Terrorism: A Brief History. Historical context for the phenomenon of modern-day terrorism," IIP Digital: United States of America Embassy. $1-6$.

Law, Randall (2016), “Terrorism: A History, 2nd Edition,” Polity Press. 1- 363. Print. Lecheler, Sophie and Sanne Kruikemeier (2015). "Re-evaluating journalistic routines in a digital age: A review of research on the use of online sources," New media and Society, 18:1. 156-171. Print.

Lee, Kangil (2015). “Does Al-Qaeda Central Still Matter?” UNISCI Discussion Papers. 37. 15-48. Print. 
Lieberman, Ariel Victoria (2017). "Terrorism, the Internet, and Propaganda: A Deadly Combination," Journal of National Security Law \& Policy. Sacramento 9.1. 1-44. Print.

Listen, Tim, Ray Sanchez, Mark Bixler, Sean O'key, Michael Hogenmiller and Mohammed Tawfeeq (2017). "ISIS goes global: 143 attacks in 29 countries have killed 2,043," CNN News. Web. < http://www.cnn.com/2015/12/17/world/mapping-isis-attacksaround-the-world/>

Livingston, Steven (1997). "Clarifying the CNN Effect: An Examination of Media Effects According to Type of Military Intervention," President and Fellows of Harvard College. 1-21. Print.

Malo, Janelle, and Valérie Ouellette (2014). "Simplifying Terrorism: An Analysis of Three Canadian Newspapers, 2006-2013," Canadian Political Science Review $8(2), 59-73$.

March, Andrew (2014). "Is Vice's Documentary on ISIS Illegal," The Atlantic. Web. $<$ https://www.theatlantic.com/international/archive/2014/10/is-vicedocumentary-on-ISIS-illegal/380991/>

Marcuse, Herbert (1965). "Repressive tolerance," in R. P. Wolff, B. Moore, and H. Marcuse, A critique of pure tolerance. Boston: Beacon Press. 81-123. Print.

Matthews, Jamie (2013). "News narratives of terrorism: Assessing source diversity and source use in UK news coverage of alleged Islamist plots," Media, War \& Conflict, 6:3. 295-310. Print.

McArdle, Thomas (2016) "Americans Doubt Obama's Plan, Resolve To Fight ISIS: IBD/TIPP Poll," Investor's Business Daily. Web. http://www.investors.com/politics/ibdtipp-poll-distrust-on-what-obama-does-and-sayson-isis-terror/

McChesney, Robert W. (2003). "Corporate Media, Global Capitalism," Media Organization and Production. Simon Cottle, ed. London: Sage. 27-39. Print.

McChesney, Robert W. (2004). "The problem of the media: U.S. communication politics in the Twenty-First century," New York: Monthly Review Press. 1-43.

McCombs, Maxwell (2014). "Setting the Agenda: The Mass Media and Public Opinion, 2nd ed,". Cambridge, United Kingdom: Polity Press. 1-208. Print.

McKercher, Catherine, Allan Thompson and Carman McKercher (2011). "The Canadian Reporter: News Writing and Reporting." Nelson Education Ltd. Print. 
McKernan, Bethan (2016). "John Cantlie: Kidnapped Briton shown alive in Mosul in latest ISIS video," The Independent. Web.

$<$ http://www.independent.co.uk/news/world/middle-east/john-cantlie-kidnappedbriton-shown-alive-in-mosul-in-latest-isis-video-a7463111.html>

Meyers, Christopher (2010). "Practical and Professional Ethics: Journalism Ethics: A Philosophical Approach," Oxford University Press. 1-393. Print.

Miller, John (1998). "Interview with osama bin Laden," ABC: Frontline. Web. $<$ http://www.pbs.org/wgbh/pages/frontline/shows/binladen/who/interview.html $>$

Nacos, Brigitte L. (2007). "Al-Qaeda's Propaganda Advantage and How to Counter It," Perspectives on Terrorism, 1:4. 3-6. Print.

Nacos, Brigitte L. (2007). "Mass-mediated terrorism: The central role of the media in terrorism and counter- terrorism," New York, NY: Rowman and Littlefield Publishers. Print.

Nacos, Brigitte (2016). "Mass-Mediated Terrorism: Mainstream and Digital Media in Terrorism and Counterterrorism," Maryland: Rowman \& Littlefield Publishers. Print.

Nagler, Jack (2016, September 12). Phone interview.

Neofotisto, Vasiliki P. (2016). "On the ISIL attacks in Western Europe and Elsewhere," Anthropology Today, 32:3. 1-3. Print.

Nieman Reports (2000). "Election 2000 Politicians and the press," The Nieman Foundation for Journalists, 54(2). 1-99. Web.

$<$ http://1e9svy22oh333mryr8314s02.wpengine.netdna-cdn.com/wpcontent/uploads/2014/04/00summer.pdf>

Norrisa, Pippa, Montague Kern \& Marion Just, "Chapter 1:Framing Terrorism.” 3-23 in Norris, Pippa, Montague Kern \& Marion Just (2003), "Framing Terrorism: The News Media, the Government, and the Public," Routledge: New York. 3-323. Print.

Nossek, Hillel and Dan Berkowitz (2006). "Telling our story through news of terrorism," Journalism Studies, 7:5. 691-707. Print.

Novatt, Cole (2014). "Can American media learn a lesson from Canadian media coverage of the Parliament Hill shooting?" The Baltimore Zeitgeist. Web. $<$ https://baltimorezeitgeist.com/2014/11/03/can-american-media-learn-a-lessonfrom-canadian-media-coverage-of-the-parliament-hill-shooting/> 
Novenario, Celine Marie I. (2016). "Differentiating Al-Qaeda and the Islamic State Through Strategies Publicized in Jihadist Magazines," Studies in conflict and terrorism. (39)11. 953 - 967. Print.

O'Neill, Shane (2010). "Struggles against injustice: contemporary Critical Theory and Political Violence," Journal of Global Ethics 6, no.2. 127-139. Print.

Oeffner, Annalena (2005). "The role of the Inter Press Service in the international mediascape: The case of IPS reporting on the 2005 World Social Forum," Diplomarbeiten Agentur diplom.de.

Opgenhaffen Michael and Harald Scheerlinck (2014). "Social Media Guidelines for Journalists.” Journalism Practice 8(6). Print. 726-741.

Ormiston, Susan (2016, September 8). Phone interview.

Osborne, Stone (2015). "ISIS vs Daesh vs ISIL vs Islamic State: What do the different names mean and why are there so many?" The Independent. Web. $<$ http://www.independent.co.uk/news/world/middle-east/isis-vs-daesh-vs-isil-vsislamic-state-what-do-the-names-mean-and-why-are-there-so-many$\underline{\mathrm{a} 6759106 . \mathrm{html}>}$

Oved, Marco (2015). "Attack at Paris café shatters family," The Star. Web. $<$ https://www.thestar.com/news/world/2015/11/18/attack-at-paris-caf-shattersfamily.html $>$

Oved, Marco (2016). "Fallout from attack unveils ugly side of Nice," The Star. Web. $<$ https://www.thestar.com/news/world/2016/07/16/fallout-from-attack-unveils-ugly-sideof-nice.html>

Oved, Marco (2016, September 15). Phone interview.

Oxford English Dictionary (2016). Oxford: Oxford University Press. Web. $<$ http://www.oed.com.proxy.library.carleton.ca $>$

Palmerton, P. R. (1988). "The Rhetoric of Terrorism and Media Response to the "Crisis in Iran'." Western Journal of Speech Communication includes Communication Reports 52 (2). 105-121. Print.

Phillips, Angela (2010). "Old Sources: New Bottles," in New Media, Old New: Journalism and Democracy in the Digital Age, ed. Natalie Fenton, (London: Sage), 88101. Print.

Phillips, David P. (1974). "The Influence of Suggestion on Suicide: Substantive and Theoretical Implications of the Werther Effect," American Sociological Review, vol. 39, no. 3. 340-54. 
Picard, Robert G. (1993). "Media Portrayals of Terrorism," Ames: Iowa State University Press. 1-147. Print,

Picard, Robert G. (1989). “The Necessity of Publicity,” Public Relations Review, 15:4. 12-23. Print.

Powell, Kimberly A. (2011). "Framing Islam: An Analysis of U.S. Media Coverage of Terrorism Since 9/11," Communication Studies 62 (1). 90-112.

Ramsay, Gilbert (2015), "Why terrorism can, but should not be defined," Critical Studies on Terrorism, 8:2, 211-228.

Rapoport, David C. (2008). "Terrorism," Encyclopedia of Violence, Peace, and Conflict, Volumes 1-3, Set 2. 2087-2105. Print.

Reese, S. D., \& Lewis, S. C. (2009). "Framing the war on terror: The internalization of policy in the U.S. Press," Journalism, 10. 777-797. Print.

Reese, Stephen D (2016) “Theories of Journalism." Communication: Oxford English Encyclopedias. Web.

$<$ http://communication.oxfordre.com/view/10.1093/acrefore/9780190228613.001.0001/a crefore-9780190228613-e-83>

Reese, Stephen D. and Pamela J. Shoemaker (2016). "A Media Sociology for the Networked Public Sphere: The Hierarchy of Influences Model," Mass Communications and Society, 19:4.389-410.

Reinemann, Carsten, James Stanyer, Sebastian Scherr, and Guido Legnante (2011). "Hard and soft news: A review of concepts, operationalizations and key findings." Journalism, 13:2. 1-19.

Remiorz, Ryan (2017). "Canada extends mission against ISIS in northern Iraq to June 30.” CBC News. Web. $<$ http://www.cbc.ca/news/politics/sajjan-isis-daesh-extension$\underline{1.4049418>}$

Reporters without Borders (2014). "Round-up of Abuses Against Journalists," Reporters without Borders. Web. $<$ https://rsf.org/sites/default/files/2014-rsf-roundup-of-abuses-against-journlists-2014.pdf $>$

Reporters without Borders (2016). "Round-up 2016 of journalists killed worldwide," Reporters without Borders. Web.

$<\underline{\text { https://rsf.org/sites/default/files/rsf_2016-part_2-en.pdf }>}$

Reporters without Borders (2016). "Worldwide Round-up of journalists who are detained, held hostage or missing 2016," Reporters without Borders. Web. $<\underline{\text { https://rsf.org/sites/default/files/rsf_2016-en_0.pdf }>}$ 
Rose, Steve (2014). "The ISIS propaganda war: a hi-tech media jihad." The Guardian. Web. $<$ https://www.theguardian.com/world/2014/oct/07/isis-media-machine-propaganda$\underline{\text { war }>}$

Said, Edward (1977). “Orientalism.” London: Penguin Books. 1-345. Print.

Schmid, Alex P. and Albert J. Jongman (2005). “ Political Terrorism: A New Guide to Actors, Authors, Concepts, Data Bases, Theories, \& Literature" Transaction Books Amsterdam. 5-6.

Schmid, Alex P., "Frameworks for conceptualising terrorism," Terrorism and Political Violence, 16:2, 197-221.

Schmid, Alex P., "The response problem as a definition problem" Terrorism and Political Violence, 4:4, 7-13.

Schudson, Michael (2001). "The objectivity norm in American journalism," Journalism, 2:2. 149-170.

Schudson, Michael (2008). "Why Democracies Need an Unlovable Press," Polity Press. 147.

Sedgwick, Mark (2007). "Inspiration and the Origins of Global Waves of Terrorism." Studies in Conflict \& Terrorism. 30:2. 102.

Seib, Philip (2008). The al-Qaeda media machine. Military Review, 88(3), 74. http://www.au.af.mil/au/awc/awcgate/milreview/seib.pdf

Shoemaker, Pamela J. and Akiba A. Cohen (2006). "News around the World. Content, Practitioners, and the Public." New York: Routledge. [Codebook available from the authors]

Shoemaker, Pamela J. and Stephen D. Reese (1996). "Mediating the Message: Theories of Influences on Mass Media Content," New York: Longman Publishers USA. 1-261.

Shoemaker, Pamela and Timothy Vos (2009). "Gatekeeping Theory," Taylor \& Francis. 1-176. Print.

Shughart, William (2006), "An analytical history of terrorism, 1945-2000," Public Choice, 128, 7-39.

Skogerbo, Eli, et al. (2016) "Agenda-Setting Revisited: Social Media and Sourcing in Mainstream Journalism." in The Routledge Companion to Social Media and Politics. Routledge Taylor \& Francis Group. 104-120. Print. 
Skovsgaard, Morten, Erik Albaek, Peter Bro, Claes de Vreese (2013). "A reality check: How journalists' role perceptions impact their implementation of the objectivity norm," Journalism, 14:1. 22-41.

Smilansky, Saul (2004), "Terrorism, Justification, and Illusion,” Ethics, 114:4, 790 -805. Sprusansky, D. (2014). "Understanding ISIS: Frequently asked questions," The Washington Report on Middle East Affairs 33(7), 19-20.

Stamm, Keith and Doug Underwood (1993). "The Relationship of Job Satisfaction to Newsroom Policy Changes,” Journalism Quarterly, 70:3. 528-541.

Steed, Brian (2016). "ISIS: An Introduction and Guide to the Islamic State," ProQuest Library. 63- 66.

Stoffel, Derek (2017). "Inside the fight to free Mosul." CBC News. Web. $<\underline{\text { http://www.cbc.ca/news/multimedia/inside-the-fight-to-free-mosul-1.4026607> }}$

Stoffel, Derek (2017). "Life under ISIS: Mosul residents reflect on a brutal occupation." CBC News. Web. $<$ http://www.cbc.ca/news/world/life-under-isis-mosul-residents-reflecton-a-brutal-occupation-1.4034574>

Stoffel, Derek (2016, October 11). Phone interview.

Stone, Rose (2014). "The ISIS propaganda war: a hi-tech media jihad.” The Guardian. Web. $<$ https://www.theguardian.com/world/2014/oct/07/isis-media-machine-propaganda$\underline{\text { war }>}$

Tandoc Jr., Edson and Tim P. Vos (2016). "The Journalist is Marketing the News," Journalism Practice, 10:8. 950-966.

Taras, David (2015). "The ever-shrinking world of public broadcasting," in Digital Mosaic: Media, power, and identity in Canada. Toronto: University of Toronto Press. 227-242

Taras, David (2015). “The Ownership Juggernaut," in Digital Mosaic: Media, power, and identity in Canada. Toronto: University of Toronto Press. 79-113.

Tasko, P., \& Canadian Press. (2010). The Canadian Press stylebook: A guide for writers and editors. Toronto: Canadian Press.

The Guardian (2001). "Text of George Bush's speech," The Guardian. Web. $<\underline{\text { https://www.theguardian.com/world/2001/sep/21/september11.usa13 }>}$

Tomlinson, Lucas (2017). "It's Official: Pentagon now calling terror group 'ISIS'”. Fox News: Politics. Web. $<$ http://www.foxnews.com/politics/2017/02/24/its-officialpentagon-now-calling-terror-group-isis.html $>$ 
Tuchman, Gaye (1973). "Making News by Doing Work: Routinizing the Unexpected," American Journal of Sociology, 79:1. 110-131.

Turan, Aykut Hamit, Seleuk Colakoglu, and Bengu Emine Colakoglu (2009).

"Perceptional Differences of International News: Western Media Influence on NonWestern Media," China Media Research, 5:2. 55-63.

Underwood, Doug and Keith Stamm (1992). "Balancing Business with Journalism:

Newsroom Policies at 12 West Coast Newspapers," Journalism Quarterly, 69:2. 301-317.

United Nations News Centre (2015). "Security Council Calls for eradicating ISIL safe havens in Syria and Iraq," United Nations News Centre. Web. $\leq$ http://www.un.org/apps/news/story.asp?NewsID=52623\#.V0qjOTZOHFI>

Ureneck, Lou (1999). "Newspapers Arrive at Economic Crossroads: Which Way They Go Could Depend On What Journalists Know and How They React," Neiman Reports. 219.

Van Dijk, T.A. (1996) "Chapter 5: Discourse, power and access" in Texts and Practices: Readings in Critical Discourse Analysis. Caldas-Coulthard, C.R. and Coulthard M. (2003). eds. Routledge. $84-107$.

Wahl-Jorgensen, Karin (2016). "Rethinking balance and impartiality in journalism? How the BBC attempted and failed to change the paradigm." Journalism. Web. $<$ http://journals.sagepub.com/doi/full/10.1177/1464884916648094\#_i12>

Waisbord, Silvio (2011). “Journalism, Risk and Patriotism," in Journalism after

September 11. $2^{\text {nd }}$ edn. Barbie Zelizer and Stuart Allan, eds. London: Routledge. 273-91.

Waldron, Jeremy (2004). "Terrorism and the Uses of Terror." The Journal of Ethics 8(1). Print. 5-35.

Walzer, Michael (1973), "Political Action: The Problem of Dirty Hands," Philosophy and Public Affairs, 2: 160-80.

Ward, Olivia (2016). "Investigating Daesh on the Dark Web," The Star. Web. $<$ https://www.thestar.com/news/world/2016/06/19/investigating-daesh-on-the-darkweb.html $>$

Ward, Olivia (2016). "Vanishing peace, rising inequality and the lessons of history," The Star. Web. $<$ https://www.thestar.com/news/insight/2016/09/23/vanishing-peace-risinginequality-and-the-lessons-of-history.html>

Ward, Olivia (2016, September 29). Phone interview. 
Watson, B. R. (2014). “Assessing ideological, professional, and structural biases in journalists' coverage of the 2010 BP oil spill," Journalism and Mass Communication Quarterly, 91(4). 792-810.

Weimann, Gabriel (2014). "New Terriorism and New Media," Commons Lab of the Woodrow Wilson International Center for Scholars. 1-20.

West, James (2014). "Canada's Coverage of the Ottawa Shooting Put American Cable News to Shame," Mother Jones. Web. <http://www.motherjones.com/mixedmedia/2014/10/cbc-ottawa-shootings-cable-news $>$

Williams, Lauren (2016). "Islamic State propaganda and the mainstream media," Lowy Institute. 1-28.

Yusufzai, Rahimullah (11 January 1999). "Wrath of God," Time. Web. $<\underline{\text { http://content.time.com/time/world/article/0,8599,2054517,00.html }>}$

Zakreski, Alexandra. "Journalists as Hostages of ISIS: The lasting chill on free expression," Canadian Journalists for Free Expression. Web.

$<$ http://www.cjfe.org/journalists as hostages of isis the lasting_chill_on free ex pression>

Zalman, Amy \& Jonathan Clarke (2009). "The Global War on Terror: A Narrative in Need of a Rewrite," Ethics \& International Affairs. 101-113. 